\title{
Organic solvent exposure and neuropsychiatric disorders : results from an epidemiological study among Dutch painters and construction workers
}

Citation for published version (APA):

van Vliet, C. (1989). Organic solvent exposure and neuropsychiatric disorders : results from an epidemiological study among Dutch painters and construction workers. [Doctoral Thesis, Maastricht University]. Rijksuniversiteit Limburg. https://doi.org/10.26481/dis.19891109cv

Document status and date:

Published: 01/01/1989

DOI:

10.26481/dis.19891109cv

Document Version:

Publisher's PDF, also known as Version of record

Please check the document version of this publication:

- A submitted manuscript is the version of the article upon submission and before peer-review. There can be important differences between the submitted version and the official published version of record.

People interested in the research are advised to contact the author for the final version of the publication, or visit the DOI to the publisher's website.

- The final author version and the galley proof are versions of the publication after peer review.

- The final published version features the final layout of the paper including the volume, issue and page numbers.

Link to publication

\footnotetext{
General rights rights.

- You may freely distribute the URL identifying the publication in the public portal. please follow below link for the End User Agreement:

www.umlib.nl/taverne-license

Take down policy

If you believe that this document breaches copyright please contact us at:

repository@maastrichtuniversity.nl

providing details and we will investigate your claim.
}

Copyright and moral rights for the publications made accessible in the public portal are retained by the authors and/or other copyright owners and it is a condition of accessing publications that users recognise and abide by the legal requirements associated with these

- Users may download and print one copy of any publication from the public portal for the purpose of private study or research.

- You may not further distribute the material or use it for any profit-making activity or commercial gain

If the publication is distributed under the terms of Article $25 \mathrm{fa}$ of the Dutch Copyright Act, indicated by the "Taverne" license above, 
Organic solvent exposure and neuropsychiatric disorders 


\section{Organic solvent exposure and neuropsychiatric disorders}

Results from an epidemiological study among

Dutch painters and construction workers

\section{Proefschrift}

ter verkrijging van de graad van doctor

aan de Rijksuniversiteit Limburg te Maastricht, op gezag van de Rector Magnificus, Prof. Dr. F.I.M. Bonke, volgens het besluit van het College van Dekanen, in het openbaar te verdedigen

op donderdag, 9 november 1989 om 14.00 uur

door

Cornelis van Vliet

geboren te Noordwijkerhout in 1959 
CONTENTS

Chapter 1: Introduction

Chapter 2: The organic solvent syndrome among painters: fact or fiction

Chapter 3: Organic solvent exposure and meuropsychiatric disorders: design of an epidemiological study

Chapter 4: The organic solvent syndrome. A comparison of cases with neuropsychiatric disorders among painters and construction workers

Chapter 5: Neuropsychiatric disorders anong solvent exposed workers. First results from a Dutch case-control study

Chapter 6: Dose-response relationships between organic solvent exposure and neuropsychiatric disorders. Results from a Dutch case-control study

Chapter 7: Neurotic disorders due to organic solvent exposure: fact or pitfall

Chapter 8: Prenarcotic and neurasthenic symptoms among Dutch workers exposed to organic solvents

Chapter 9: Organic solvent exposure and premature disability due to neuropsychiatric disorders: state of the art in epidemiological research

Chapter 10: Summary and concluding remarks

Chapter 11: Psychische aandoeningen onder schilders; resultaten van een patient-kontrole onderzoek (Nederlandse samenvattingl 
Appendix 1 : List of Three-digit Categories of mental disorders $(I C D-9)$

Appendix 2 : Létter of introduction

Appendix 3 : Letter accompanying the questionnaire 
CHAPTER 1

INTRODUCTION 


\section{IMTOEUCHON}

The air of the study presented in this dissertation is to elucidate the role of exposure to organic solvents with respect to the occurrence of premature disability due to neuropsychiatric disorders among Dutch painters. Painters are occupationaly exposed to organic solvents as these chemicals are an essential part of most paints and lacquers. The question whether long-term exposure to organic solvents ewentually results in the development of neuropsychiatric disorders originates from the scandinavian countries. The wide spread use of organic solvents together with the alarming results from scandinavian countries have resulted in a world-wide interest into this matter.

A brief historical review may clarify the reasons why an epidemiological study, investigating the neuropsychiatric effects of organic solvent exposure as experienced by Dutch painters, has been carried out in the Netherlands.

In 1979 the Dutch painters branche joined the Dutch organization for the Improvement of working Conditions in the Construction Industry (Stichting Arbouw). Apart from organising occupational health service for the construction industry, this organization stimulates scientific research concerning health problems related to working conditions. Consequently several studies were started to evaluate the health risks of the painting profession. The most remarkable finding emerged from a study into absenteism of painters in the construction industry. Compared with other construction workers, painters had a 35 increased risk for being prematurely disabled due to neuropsychiatric disorders.

these results were rather alarming and, in view of the results from Scandinavian countries, the question was raised whether this increased occurrence of neuropsychiatric disorders among painters was caused by organic solvent exposure.

clearly, the absenteism study could not answer this question, because, apart from organization membership, no information was avallable about the organic solvent exposure of the compared groups.

Purthermore, information about other factors related to the etiology of neuropsychiatric disorders (such as alcohol consumption, headtrauma, other diseases) must be known in order to make a fair comparison between two groups with respect to the occurrence of neuropsychiatric disorders. Therefore a new study was initiated in order to evaluate the relationship between organic solvent exposure and neuropsychiatric disorders. This study started in 1985 at the Department of occupational and Environmental Health and Toxicology of the University of Limburg in Mastricht. 
Financial support was given by the stichting Arbouw. The Dutch Painters and construction workers Organizations co-operated in this study by providing the possibility to approach persons receiving disability benefits due to neuropsychiatric disorders.

The results of this study were edited into articles and subsequentiy submitted to relevant medical journals. Therefore, 9 chapters of this dissertation are based upon articles which have been submitted to or published in medical journals. A disadvantage of this approach is that some sections of the relevant articles/chapters will inevitably show some overlap and repetitions. An advantage is that these chapters can be read separately.

The second chapter of this dissertation provides a review of the lepidemiological) literature with respect to neurotoxic effects of organic solvent exposure. The study design used in the presented epidemiological study is described and discussed in Chapter 3.

Chapter 4 shows the results of a study into medical files of persons prematurely disabled due to neuropsychiatric disorders. The next chapters reveal the results of a case-control study conducted among Dutch painters and construction workers. The overall risk for painters to be prematurely disabled due to neuropsychiatric disorders is presented in Chapter 5, while Chapter 6 deals with the analysis concerning dose-response relationships. Special attention is given to the occurrence of neurotic disorders among Dutch painters (Chapter 7). The occurrence of prenarcotic and neurasthenic symptoms among solvent exposed workers is presented in Chapter 8. Chapter 9 reviews all epidemiological studies (including our own study results) investigating the relationship between organic solvent exposure and premature disability due to neuropsychiatric disorders. Next, a chapter called "summary and concluding remarks" reviews the results as described in the preceding chapters (Chapter 10).

A Dutch article about the results of this study, simultaneously meant as a Dutch summary, conludes this dissertation (Chapter 11). 


\section{CHAPTER 2}

THE ORGANIC SOLVENT SYNDROME AMONG PAINTERS: FACT OR FICTION*

C van Vliet ${ }^{1}$, GMH Swaen ${ }^{1}$, JMM Meijers ${ }^{1}, \mathrm{Tj}^{\mathrm{j}}$ de Boorder ${ }^{1}$, F Sturmans $^{2}$

1 Dept. of Occupational and Environmental Health and Toxicology, University of Limburg, PO Box 616, 6200 MD Maastricht, The Netherlands.

2 Dept. of Epidemiology, University of Limburg.

* Submitted for publication 
ABSTRACT

This review article deals with the question whether long-term exposure to organic solvents may lead to irreversible danage of the central nervous system, like the "organte solvent syndrome". The exposure of painters to organic solvents and the relevant epideniological ilterature are discussed. The discrepancy between the results of studies from scandinawian countries and other countries, such as Great Britain and West-Germany, attracts attention. The obscurity of the underlying pathofysiological mechanism, the lack of uniformity in the diagnosis of the organic solvent syndrome, methodological shortcommings and the absense of a clear dose-response relationship in many studies complicate the interpretation of the epidemiological data.

Based on currently available epidemiological data the central question of this review article can not be answered with a straightforward yes or no. This restriction applies in particular to occupational exposure to low concentrations of organic solvents (i.e. below the MAC-values).

\section{INTRODUCTION}

The Dutch painters population consists of approximately 35,000 persons ${ }^{1}$. Painters are an important group of workers within the construction industry who, due to the nature of their work, are exposed to all sorts of potentially harmful chemi$\mathrm{cals}^{2}$. Organic solvents, which are an important ingredient of many paints and lacquers, belong to these potentially harmful chemicals.

For some time concern exists among occupational physicians about the long-term health effects of exposure to organic solvents. This concern includes exposure to concentrations below the Dutch MAC-value (maximum allowed concentration of gas, vapour, spray or of a chemical in the airl. Particularly Scandinavian scientists suggest a relationship between long-term exposure to organic solvents and irreversible harmful effects on the central and peripheral nervous system ${ }^{3}$. In this review article first of all attention is paid to some general characteristics of organic solvents and the way in which painters are exposed to these chemicals. Next, the acute and chronic neurotoxic effects attributed to organic solvent exposure are described and the literature with respect to these effects is 
reviewed. Emphasis is given to epidemiological studies of humans in which attention is focussed on neurotoxic effects of long-term occupational exposure to organic solvents.

The article concludes with a discussion of some problems with regard to muman epidemiological research of chronic neurotoxic effects due to organic solvent exposure.

ORGANIC SOLVENTS

Organic solvents are defined as "at room temperature or moderatley increased temperature volatile liquids in which other liquids/gasses and/or chemicals are dissolved (molecularly divided). Furthermore, during or after dissolvation "no chemical reaction takes place between the solvent and the dissolved chemical"4. organic solvents are used at large scale"

- To dissolve and to dilute paint, lacquer, synthetic resin, rubber, glue and printing ink:

- To degrease and to clean metal objects (e.g. as pretreatment for welding) and textile ("dry cleaning");

- to extract fats and oils from vegetable materials;

- as basic chemical or additive in chemical synthesis:

- as coolant:

- as anti-vreeze;

- as pesticide:

- as narcotic;

- as fuel:

- as anti-knock;

- as basic chemical in pharmaceutic and cosmetic industry.

The use of organic solvents is not restricted to certain occupations. Furthermore, organic solvents are frequently used in hobbles and housekeeping. organic solvents as a group consist of compounds with a great diversity of chemical structures. Table 1 gives a frequently used classification of organic solvents. 
1. Hydrocarbons (mostly technical mixtures):

- Boiling point gasolines

- White spirits; mineral spirits

- Cyciodilphatic hydrocarbons

- Benzene, toluene, xylene

- Aromatic solvents with higher boiling points

- Terpenes.

2. Hallogenated hydrocarbons

3. Nitrogeneous hydrocarbons

4. Alcohols

5. Aldehydes

6. Ethers

7. Esters

8. Glycols and glycolethers

9. Ketones

In connection with the volatility of organic solvents, the airways are the most important absorption route in humans. However, uptake through the skin is also possible. The rate of admission and transfer to depots (various lipoid tissues) depends on the partition coefficient between blood and air of the concerning solvent. A high partition coefficient facilitates uptake and transfer to depots. The concentration of solvents in the brain shall rapidly increase because of the high blood flow in the brain compared to subcutaneous fat. The main excretion route of solvents is through the airways. A low participation coefficient between blood and air facilitates a rapid excretion ${ }^{5}$. Sometimes solvents are metabolised to more water soluble products, thus facilitating excretion by the kidneys or the liver.

painters are exposed to organic solvents, since these chemicals are an important part of many paint products. The Dutch paint industry consumed in 197926,300 tons terpentines, which brings these solvents on top of the list of much-used solvents. In the Netherlands hydrocarbons constitute $40 \%$ of the organic solvent use. Doorgeest et $\mathrm{l}^{4}$ do not expect a drastical change of this percentage within the next five to ten years. The mostly used hydrocarbons are mixtures, e.g. white 
spirit consists of more than a hundred different hydrocarbon compounds. Exposune of painters to organic solvents depends on warious factors, such as "

- Type of paint product;

- Composition of the paint product:

- Daily appliea amount of paint, lecquer etc.:

- Working conditions (e.g. ventilationy:

- The use of respirators:

- Personal hygiene.

The chemical department of the Dutch National Labour office and two have carried out measurements in the painting trade of organic solvent concentrations in the ambient air. Both personal air sampling and stationary measurements were used. These measurements showed that only incidentally individual measurements exceeded the MAC-value (= Dutch TLV-value). The exposure index, calculated by adding up the quotients of the detected concentrations and MAC-values of the various solvents to which one was exposed, turned out to be more of ten ellevated (= above 1). however the health implications of an increased exposure index are still uncertain $^{4}$. Measurements from the past are virtually not available. As apparent from the above information, determination of the nature and level of organic solvent exposure among painters is not a simple matter. Furthermore, important changes have occurred in the composition of paint products during the last decades ${ }^{4}$.

\section{HEALTH EFFECTS DUE TO ORGANIC SOLVENT EXPOSURE}

The health effects of exposure to organic solvents can be divided into acute and chronic effects. Effects on the central nervous system play an important role, but are certainly not the only potential health effects of organic solvent exposure.

Acute health effects of organic solvents are ${ }^{5}$ :

- Degreasing and dehydrating effects on the skin;

- Irritating effect on the mucosa of eyes and airways;

- Acute chemical pneumonia after uptake of liquid solvents in the lungs;

Chronic health effects are:

- Peripheral neuropathy (e.g. n-hexane); 
- Blood anomales, including levkaema benzenel;

- Effects on liver and kidney (e.g. chlorinated mydrocarbons).

The neurotoxicity of organic solvents depends on their lipoid solubility by which they can pass the blood-brain barrier. Furthermore, as mentioned before, the high blood flow through the brain facilitates the development of high concentrations in the central nervous syster. The first description of neurotoxic effects due to organic solvent exposure dates from 1856. In that year August Delpech described a psychotic syndrome among some workers from a rubber factory who were exposed to carbon disulfide $\left(\operatorname{cs}_{2}\right)^{6}$. Next, in the first decade of this century a neurasthenic syndrome was described among workers occupationally exposed to trichloroethylene, xylene and white spirits ${ }^{3}$.

The neurotoxic effects of organic solvent exposure can be divided into acute chronic effects. The acute neurotoxic effects are represented by the contact synarome ${ }^{5}$. The severity of the symptoms is determined by the momentaneous exposure to organic solvents. The narcotic effects ldiminution of the level of consciousness) dominate this syndrome. The severity of this syndrome varies from a slight diminution of the level of consciousness to death. An important characteristic of this syndrome is the rapid reversibility once exposure has ceased. In view of this effect it is not surprising that a lot of organic solvents have been used as anaesthetics ${ }^{7}$. The narcotic effect is preceded by prenarcotic symptoms, such as drowsiness, nausea, dizziness, headache, drunken feeling, alcohol intolerance and incoordination ${ }^{8}$.

The (sub)chronical neurotoxic effects of long-term exposure to organic solvents are (from times) divided in two syndromes $5,9,10$ :

a) Subchronical syndrome.

Beside prenarcotic symptoms the following complaints occur in this syndrome: fatigue, sleeplessness, nightmares, stomach and precordial pains, ear tingling and paraesthesia. The severity of this syndrome is also dependent on the exposure duration and the complaints cease after a few days or weeks.

b) organic psychosyndrome.

The organic psychosyndrome consists of chronic disturbances in psychological functioning. The main symptoms are fatigue, slow and inaccurate perception, memory and concentration disturbances, emotional lability, depressive complaints and personality changes. This syndrome was thought to occur after long-term exposure.

Apparently forty years ago ${ }^{9}$ scientists were aware of the possibility of the occurrence of chronic neuratoxic effects due to organic solvent exposure. How 
ever, the assumption was made that these chronic neurotoxic effects only occurred among workers with long-term exposure to wery high concentrations of strong neurotoxic solvents (e.g. $\left.\operatorname{cs}_{2}\right)$. The notion that moderate or low exposure to organic solvents, such as white spirits, as experienced by painters could induce serious damage to the central nervous system originates from Sweden ${ }^{3}$. In a Swedish hospital a striking number of house painters was seen, who complained of extreme fatigue, memory disturbances, loss of appetite and precordial pains. Subsecuentiy, several investigations were carried out among Scandinavian painters and other workers who were exposed to organic solvents. On the basis of the results of these studies (which will be discussed later) Scandinavian scientists cane to the conclusion that organic solvent exposed workers, particularly painters, are at increased risk for the development of an organic psychosyndrome, also designated as organic solvent syndrome. The organic solvent syndrome manifests itself by a great number of (aspecific) complaints, such as forgetfulness, diminished ability to concentrate, diminished comprehension, emotional lability, depression, fatigue, headache, diminished coordination 4 . The organic solvent syndrome is an officially recognized occupational disease in the scandinavian countries. Criteria have been formulated to diagnose this syndrome. In these criteria emphasis is put upon anamesis (history of exposure to organic solvents, presence of neurasthenic complaints) and the results of neuropsychological investigations (Table 2).

Table 2: Diagnostic criteria for organic solvent intoxication ${ }^{11}$.

1. Verified quantitative and qualitative exposure to solvent known to be neurotoxic.

2. Clinical picture of organic damage to the central and/or peripheral nervous sys tem:

- "Typicial" subjective symptoms:

- pathologic findings in some of the following:

* Clinical neurological status;

* Electroencephalography;

* Electroneuramyography;

* Psychological tests.

3. Other arganic diseases reasonably well excluded (by neuroradiological methods, special laboratory investigations or follow-up if necessary).

4. Primary psychiatric diseases reasonably well excluded. 
The organic solvent sydrone has been given several different names in the international it terature, such as organic brain syndrome, chronic encephalopathy, presenile dementia, painters syndrome, neurasthenic syndrome and Scandinavian syndrome. This lack of unifomity hampers the interpretation and comparison of the investigations as well as the international sollaboration in the field of chronic neurotoxic fifects due to organic solvent exposure ${ }^{11}$.

In order to solve these problens, the world Health Organization established a working group to study the neurotoxic effects of organic solvent exposure. The working group stated that the chronic effects could be divided into two different syndromes, an "organic affective syndrome" and a "chronic toxic encephalopathy". characteristics of these syndromes are presented in Table $3^{11}$.

Table 3: Classification schemes of chronic neurotoxic effects attributed to organic solvent exposure.

I Worla Health Organisation ${ }^{11}$ :

- An organic affective syndrome, predominated by disorders of mood.

- A chronic toxic encephalopathy that may be mild or severe. This symdrome is characterised by a change in personality, accompanied by "core symptoms" of fatiguability, bad memory, difficulties in concentration and loss of initiative.

II Working group North Carolina ${ }^{13}$

- Type 1 : Non-specific symptoms such as fatiguability, bad memory, difficulties in concentration and loss of initiative.

- Type 2A: Pronounced and sustained change in personality denoted by fatigue, emotional lability, alterations in general mood etc.

- Type 2B: Difficulties in concentration, impairment of memory and a decrease in learning capacity. These symptoms (unlike those in 2A) may be accompanied by objective evidence of impairment. There may also be minor neurological signs.

- Type 3 : Marked global deterioration in intellect and memory (dementia). often accompanied by neurological signs and/or neuroradiological findings.

A few months later, a working group in North Carolina evaluating the same neurotoxic effects, came up with a completely different classification of the syndromes thought to be attributed to organic solvent exposure. This classification 
was not primarly based on speciftc syndromes as shown in Table $3^{6,12,13}$. The above described course of affairs illustrates that the orgamic solvent syndrome is still not well defined and/or internationally accepted as an existing syndrome or occupational disease.

\section{EPIDEMIOLOGICAL INVESTIGATIONS INTO CHRONIC NEUROTOXIC EFFECTS}

Most studies into chronic neurotoxic effects of long-term exposure to organic solvents have been carried out in Scandinavian countries. Painters and workers from the paint industry were shown to have more neuras thenic complaints than workers from non-exposed control populations $8,14-16$. Furthermore, painters had a tendency to score worse on neuropsychological testbatteries than workers from non-exposed control populations $8,15,17-19$.

Some investigators detected anomalies in electroencephalograms of exposed workers $15,16,20$. A number of investigators found brain atrophy and/or decrease in the bloodflow of brain tissue among patients diagnosed with an organic solvent synarome $15,21,22$.

It is hardly surprising that, in particular in Scandinavian countries, the question was raised whether chronic neurotoxic effects due to organic solvent exposure could lead to premature disability. This issue is addressed in three Scandinavian case-control studies and one scandinavian cohort study ${ }^{23-26}$. It appeared from these studies that workers exposed to organic solvents are at increased risk for being prematurely disabled due to neuropsychiatric disorders.

study results showing no indications for the existence of an organic solvent syndrome mainly originate from countries outside Scandinavia. Cherry and waldron ${ }^{27}$ found no indications for a relationship between neuropsychiatric disorders and organic solvent exposure in Great Britain. Furthemore cherry et al ${ }^{28}$ detected no differences between neuropsychological testscores of painters and a control group of non-exposed workers. However, the painters did report nore neurasthenic complaints. Triebig et al ${ }^{29}$ concluded that the organic solvent syndrome does not occur among German construction painters. Maiszlish et al ${ }^{30}$ could not demonstrate neurological anomalies among a group of solvent exposed workers. The study of orbaek et $\mathrm{l}^{31}$ did not indicate the existence of brain atrophy among a group patients diagnosed as having an organic solvent syndrome. Some recently published case-control studies did not reveal a relationship between organic solvent expo- 
sure ard the development of dement $a^{32}$ or mortality due to presenile dementia ${ }^{33}$. From a 5 ws cohort study emerged no $\mathrm{signifucantly}$ increased risk for painters (compared to electricians) to become disabled due to neuropsychiatric disorders. Resides, alcoholism appeared to be an important factor in the development of neuropsychiatric disorders among painters ${ }^{34}$. In the Netherlands scheffers et al ${ }^{35}$ carrled out a study into absenteism of painters in the construction industry, by order of the Dutch organization for the Improvenent of working conditions in the Construction Industry (stichting Arbow! " They compared the absenteism statistics of the Dutch painters and Construction Wokers organizations. Attention was paid to the number of cases reaching the maximum payment period of the Dutch health law (- 52 weeks) during the period 01-01-1975 to 31-12-1977. Diagnoses were coded according to a national list of disease classification based on the 9 th revision of the International Classification of Disease. Neuropsychiatric disorders appeared to occur 35\% more often among painters than among construction workers.

\section{DISCUSSION AND CONCLUSIONS}

This review article deals with the question whether long-term occupational exposure to organic solvents may lead to irreversible damage of the central nervous system. To answer this question attention must be paid to the quality and the validity of the conducted studies. Several authors place critical comments at all evidence put forward in favor of the organic solvent syndrome.

Grasso et a $^{3}$ are particularly sceptical in their review article. They point out that many of the used neurological examinations (neuropsychological, tests, EEG" $s$ etc.) are not suited to be applied in epidemiological studies. Frequently, there is uncertainty about for example the reference values, reproducibility, interpretation of the results and the influence of other factors on the test results. In case of a causal relationship between exposure to organic solvents and chronic effects on the central nervous system, one may assume that the risk of developing these chronic neurotoxic effects increases with higher levels of organic solvent exposure. However, many studies do not reveal a positive dose-response relationship. As mentioned, measurements from the past are virtually not available and painters are generally exposed to mixtures of organic solvents. Furthermore the dose of organic solvent exposure is frequently expressed as "number of exposure years", which is of course a poor and inaccurate reflection of the exposure intensity. 
Remarkably follow-up studies show little improvement or deterioration in the condition of painters diagnosed with an organic solvent syndrome as the exposure to organic solvents has ceased ${ }^{36}$. According to Grasso et al this fact is inconsistent with the hyposthesis that long-term exposure to organic solwents 1 is responsible for the development of an organic solvent syndrome. After all, the condition of patients with an electromyographically proved neuropathy improves after disappearance of the exposure, while the condition of persons diagnosed with other neurodegenerative diseases, such as Morbus Alzheimer, deteriorates in due course of time.

waldron ${ }^{6}$ pointed to other abscurities with respect to the organic solvent syndrome. An oppressive question concerns the differences between e.g. Derniark. where hundreds of painters have been diagnosed as having an organic solvent syndrome and countries outside Scandinavia in which this syndrome is hardy recognized. Recently Errebo-Knudsen and $01 \operatorname{sen}^{37}$ and Gade et al ${ }^{38}$ stated that many Danish painters were wrongly diagnosed as suffering from an organic solvent syndrome. When reference values were determined of the used neuropsychological testmethods in well chosen control populations, the scores of many painters appeared to be within the normal population distribution of the test scores. Ekberg et a ${ }^{39}$ suggested that the neurasthenic complaints and abnormalities in neuropsychological investigations as detected among solvent exposed workers merely reflect acute neurotoxic effects. Many investigations have been carried out among exposed workers who actively participated in the labour process, thus being daily exposed. to organic solvents.

The complaints reflecting chronic neurotoxic effects attributed to organic solvent exposure are rather non-specific. The same complaints may be caused by other factors and disorders, such as alcohol abuse, stress, aging, heact trauma, lead intoxication etc. It is essential to take the influence of these potential confounders into account in the analys is of the data and interpretation of the $g$ tudy results ${ }^{13}$. Many studies fail to handle this issue adequately. Correction for e.g. differences in age and alcohol abuse between exposed and non-exposed groups has been carried out, but the influence of e.g. workstress as confounding factor has not yet been evaluated in this context.

However, the criticism stated above applies to both the positive and negative studies.

Diagnostic criteria, as formulated in the Scandinavian countries, show that the "organic solvent syndrome or intoxication" can only be diagnosed by exclusion ${ }^{40}$. However, it is very difficult to exclude all other possible causes of the complaints. Therefore it is not surprising that follow-up studies show that for some 
persong other causes of their complaints emerge in due course of time ${ }^{41}$. The underlying pathology of this androme remains unclear ${ }^{6} 12$. Is there actually a loss of neurones or do other (biochemical?) changes occur in the brain tissue of patients diagnosed with an organic solvent syndrome? There is an urgent need for an animal model for further research with respect to this syndrome.

The choice of the control population in the scandinavian disability pension studies can be criticised. The control population consisted of persons disabled due to non-neuropsychiatric disorders. If non-exposed workers are at increased risk for developing these disorder le.g. more disorders of the musculoskeletal system among brick layers because of carrying heavy cement bags) compared to organic solvent exposed workers, an overrepresentation of non-exposed persons will occur among the control population. Thus, the observed risk for exposed persons to be disabled due to neuropsychiatric disorders would be wrongly increased ${ }^{42}$. Probably another limitation of these disability studies is the lack of reliability of diagnoses awarded by social security physicians to people receiving disability benefits $^{43}$. This limitation (at random misclassification) tends to mask existing relationships ${ }^{44}$,

The investigation of scheffers et $a 1^{35}$ of absenteism of painters in the construction industry has some weak points. They mention in their publication a few shortcommings of their study design. The main objections are the lack of a longitudinal component and the absence of information concerning nature and duration of organic solvent exposure of the persons included in the absenteism statistics. Furthermore the results were not adjusted for confounding factors, such as education level and alcohol consumption.

All these critical remarks, together with some negative results from studies conducted outgide Scandinavia, indicate that at the moment no certainty exists with respect to the presence of a causal relationship between long-term occupational exposure to organic solvents and the development irreversible damage to the central nervous system. This lack of clarity concerns especially occupational exposure to organic solvents in concentrations below or hardly exceeding the MACvalues. The presence of a harmful effect due to long-term exposure to high concentrations of organic solvents is more plausible. Obvious ly individual differences may be present with respect to the susceptibility to the neurotoxic effects of organic solvent exposure. Undoubtedly a lot of research has to be done on the field of the health effects of organic solvents which were already designated by Delpech in 1856 as "a foul and pestile congregation of vapours". 
REFEREMCES

1. Economisch Instituut voor de Bouwnijverheid (EIB). Het werknemersbestand in het schildersbedrijf in 1985. Amsterdam, 1986.

2. Scheffers TML, Jongeneelen FJ. Arbeidshygienisch onderzoek naar de blootstelling van onderhoudsschilders aan oplosmiddelen. Stichting Bedrijfsgezondheidsdienst voor de Bouwnijverheid, Amsterdam, 1982.

3. Grasso $P$, sharrat $M$, Davies DM, Irvine D. Neurophysiological and psychologi cal disorders and occupational exposure to organic solvents (review section). Fd Chem Toxic 1984; 22: 819-852.

4. Doorgeest T, Meijer PB, Mik de G. Chronische effecten tengevolge van blootstelling aan organische oplosmiddelen: Literatuuronderzoek, s 29-1. Directoraat-Generaai van de Arbeid, Voorburg. 1986.

5. Verberk MM, Zielhuis RL. Giftige stoffen uit het beroep. De Nederlandse Bibilotheek der Geneeskunde, Stafleu's Wetenschappelijke Uitgewersmatschappij BV, Alphen aan den Rijn/Brussel, deel 130, 1980.

6. Waldron HA, Solvents and the brain (Editorial). Br J Ind Med 1986;43: 73-74.

7. Axelson 0 , Hane $M$, Hogstedt $c$. Current aspects of solvent-related disorders. In: Zenz C, ed. Developments in occupational medicine: Year Book Medical Publishers, Chicago 1980: 237-248.

B. Elofsson SA, Gamberale F, Hindmarsh T, Iregren A, Isaksson A, Johnsson I, Knave B, Lydah1 E, Mindus P, Persson HE, Philipson B, Steby M, Struwe G, Söderman E, Wennberg A, Widén L. Exposure to organic solvents: A cross-sectional epidemiological investigation on occupational exposed car and industrial spray painters with special reference to the nervous system. Scand $\mathrm{J}$ Work Environ Health 1980; 6: 239-273.

9. Borbely $F$. Erkennung und Behandlung der organischer Lösungsmittel - Vergiftungen. Huber, Bern, 1946.

10. Burger GCE. Arbeids- en bedrijfsgeneeskunde, HE Stenfert Kroese BV, Leiden, 1974 .

11. World Health Organisation, Enwironmental Health 5 . Chronic effects of organic solvents on the central nervous system and diagnostic criteria. Copenhagen, WHO, 1985.

12. Baker EL, Fine LJ. Solvent Neurotoxicity: The Current Evidence (editiorial). J Dccup Med $1986 ; 28: 126-129$. 
13. Cranter JM, Goldberg L. Human aspects of solvent neurobehavioral effects. Report of the Horkshop session on Clinical and Epidemiological Topics. Heurotoxicology 1987; $7: 43-56$.

14. Husman $K$. Symptons of car painters wh long-term exposure to a mixture of organic solvents. Scand J Work Environ Health $1980 ; 6: 19-32$.

15. Orbaek 2, Rliberg J, Rosén J, Haeger-Aronson B, Hagstadius S, Hjortsberg U, Regnel1 $G$. Rehnstrom $S$, Svensson $K$, Welinder $H$. Fffects of long-term exposure to solvents in the paint industry: A cross-sectional epidemiologic study with clinical and laboratory methods. Scand J Work Environ Health 1985; 11, suppl. $2 \ldots$

16. SeppäIäinen AM, Husman K, Martenson C. Neurophysiological effects of longterm exposure to a mixture of organic solvents. Scand $J$ Work Enwiron Health 1978: $4: 304-314$.

17. Anselm Olsen B. Effects of Organic Solvents on Behaviaral perfarmance of workers in the Paint Industry. Neurobehavioral Toxicology and Teratology 1982; 4: 703-708.

18. Hănninen $H$, Eskelinen $L$, Husman $K$, Nurminen $M$. Behavioral effects of longterm exposure to a mixture of arganic solvents. Scand $J$ work Environ Health 1976 ; $4: 240-2.55$.

19. Hane M, Axelson 0, Blume J, Hogstedt C, Sundell L, Ydreborg B. Psychological function chariges among house-painters. Scand $J$ Work Envilron Health 1977; 3: $91-99$.

20. Seppăläinen AM. Applications of neurophysiological methods in accupational medicine. Scand J Work Environ Health 1975; 1: 1-14.

21. Arlien-Soborg P, Hendriksen L, Gade A, Gyldensted C. Paulson OB. Cerebral blood flow in chronic encephalopathy in house painters exposed to organic solvents. Acta Neurol Scandinav 1982; 66: 34-41.

22. Maximilian VA, Risberg J, prohovnik I, Rehnstrồn S. Regional cerebral blood flow and verbal memory after chronic exposure to organic solvents. Brain Cognition 1982; 1: 196-205.

23. Axelson 0 , Hane $M$, Hogstedt $C$. A case-referent study on neuropsychiatric disorders among workers exposed to solvents. Scand J work Environ Health 1986 ; $2: 14-20$.

24. Mikkelsen S. A Cohort Study of Disability Pension and Death among Painters with special Regard to disabling presenile Dementia as an occupational Disease. Scand I Soc Med 1980; supp1. 16: 34-43. 
25. Olsen J, Sabroe S. A Case-Reference Study of Neuropsychiatric Disorders among workers Exposed to Solvents in the Danish Wood and Furniture Industry. Scand J Soc Med 1980; suppl. 16: $44-49$.

26. Lindström $K$, Ríhimăki $H$, Hänninen $K$. Occupational solwent exposure and neuropsychiatric disorders. Scand J Work Environ Health 1984; 10: 321-323.

27. Cherry N, Waldron HA. The Prevalence of PSychiatric Morbidity in Solvent Workers in Britain. Int J Epidem 1984; 13: 197-200.

28. Cherry N, Hutchins $H$, Pace $T$, Waldron HA. Neurobehavioral effects of repeated occupational exposure to toluene and paint solvents. Br J Ind Med 1985: 42: 291-300.

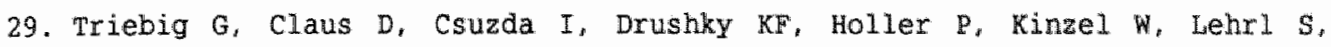
Reichwein $\mathrm{P}$, Weidenhammer $W$, Weitknecht wu, Weltle D. Erianger Malerstudie. Multidisziplinäre Querschnittsuntersuchung zur Neurotoxizität von Losemittein in Farben und Lacken. ASP - Sonderheft 1986; 9: 1-45.

30. Maizlish NA, Fine LJ. Albers JW, Whitehead $\mathrm{L}$, Langolf GD. A neurological evaluation of workers exposed to mixtures of organic solvents. $\mathrm{Br}$ J Ind Med 1987; $44: 14-25$.

31. Ørbaek $\mathrm{P}$, Lindgren $\mathrm{M}$, Olivecrona $\mathrm{H}$, Haeger-Aronson $\mathrm{B}$. Computed tomograplyy and psychometric test performances in patients with solvent induced chronic toxic encephalopathy and healthy controls. Br J Ind Med 1987; 44: 175-179.

32. Rasmussen $H$, Olsen J, Lauritsen J. Risk of Encephalopathia Among Retired Solvent-Exposed Workers: A Case-Control study Among Males Applying for Nursing Home Accomedation or Other Types of Social Support Facilities. J Occup Med 1985; 27: 561-566.

33. O'FlYnn RR, Monkman SM, Waldron HA, Organic solvents and presenil dementia: A case referent study using death certificates. Br J Ind Med 1987: 44: 259 262 .

34. Gubéran $\mathrm{E}$, Usel $M$, Raymond $L$, Tissot $R$, Sweetnam PM. Disability, mortality and incidence of cancer among Geneva painters and electriciens: a historical prospective study. Br J Ind Med 1989; 46:16-23.

35. Scheffers TML, Wit de JNF, Saris-Wijnands MJ. Ziekteverzuim van Schilders in de bouwnijwerheid. Stichting Bedrijfsgezondheidsdienst voor de Bouwnijverheid, Amsterdam, 1984.

36. Bruhn P, Arlien S $\phi b o r g$ P, Gyldensted C, Christensen BL. The prognosis in chronic toxic encephalopathy. A two years follow-up study in 26 housepainters with occupational encephalopathy. Acta Neurol Scand 1982; 64: 259-272. 
37. Erebo-knudsen EO, OLen F. SOlvents and the brain: Explanation of the discrepancy between the number of toxic encephalopethy reported land compensated in Dentark and other countries. Br J Ind wed 1987; 44:71-72.

38. Gade A, wortensen EL, Bruhn $P$. "Chronic painters syndrone". A reanalysis of psychological test data in a group of diagnosed cases, based on comparisons with matched controls. Hcta Neurol scand 1988; 77: 293-306.

39. Ekberg $K$, Barregára $L$, Hagberg $S$, sàlisten $G$. Chronic and acute effects of solvents on central nervous system functions in floorlayers. Br I Ind Med 1986; 43: 101-106.

40. Juntunen J, Hupli $V$, Hernberg $S$, Luisto $M$. Neurological Picture of Organic Solwent Poisening in Industry. Int Arch Occup Environ Health 1980; 46: $219-$ 231.

41. Antt Polka M. Overall prognosis of patients with diagnosed chronic solvent intoxication. Int Arch Occup Environ Health 1982; 51: 127-138.

42. Hogstedt $C$, Axelson 0 . Long-term health effects of industrial solvents - a critical review of the epidemiological research. Med Lav 1986; 77: 11-22.

43. Hooglendijk EMG. Chronische effecten tengevolge van blootstelling aan organische oplosmiddelen, literatururonderzoek, $\$ 29-2$. Directoraat-Generaal van de Arbeid, Voorburg, 1986.

44. Monson RR. Occupational Epidemiology. CRC Press, Inc. Boca Raton, Florida, 1980. 
CHAPTER 3

ORGANIC SOLVENT EXPOSURE AND NEUROPSYCHIATRIC DISORDERS; DESION OF AN ERIDEMIOLOGICAL STUDY.*

C van Vliet ${ }^{1}$, GMH swaen $^{1}$

1 Dept. of Occupational and Environmental Health and Toxicology, University of Limburg, PO Box 616, $6200 \mathrm{MD}$ Maastricht, The Netherlands.

* A Dutch abstract of this chapter has been published in Tijdschrift voor Sociale Gezondheidszorg 1986; 64: 154-155. 
MOTYVATON OF THE ETUDY DESIGN

The central issue of this study is whether organic solvent exposure, as experienced by Dutch painters leads to an increased risk for being prematurely disabled due to neuropsychiatric disorders. To test a hypothesis, the epidemiologist may use experinental and observational studies. In experimental studies persons must be exposed intentionally to the potential toxic agent, which from an ethical point of view yields prohibitive objections.

With regard to observational studies, a choice must be made between cross-sectional and longitudinal study designs. Considering the time factor enclosed in the central question, a cross-sectional study design is less suitable. Therefore a choice must be made from the observational study designs. Observational longitudinal epidemiological research has two approaches. The investigator may compile a group of exposed and a group of non-exposed workers. These groups then are followed for a certain period of time in order to determine the occurrence of morbidity or mortality in the relevant groups. This so-called cohort study design starts from the specific health-threatening exposure, e.g. exposure to organic solvents.

Case-control studies follow a reversed approach. The starting point of a casecontrol study is a group of persons with a certain disease ("cases") and a group of persons without the disease under study ("controls"). Next, the frequency of the occurrence of a (potential) causal factor among the cases is compared with the occurrence of the relevant factor among the controls ${ }^{1}$.

Both approaches have specific advantages and disadvantages. If the epidemiologist is interested in a wide range of health effects due to one specific exposure, a cohort study is the approach to be preferred. If the objective of the study is to investigate a wide range of causes and factors that may play a role in the development of a specific disease, a case-control study is the most obvious choice. The aim of this study is to investigate the relationship between a speciEic disease (neuropsychiatric disorders) and a specific exposure lorganic solvents). In this case the choice of study design can be based on other considerations. Oftenly efficiency considerations are of additional importance. Cohort studies are more extensive, more expensive and more labour intensive than casecontrol studies. In view of the above mentioned arguments we have chosen for a case-control study design ${ }^{2}$. 


\section{POPULATION BASE}

The first step at the start of a case-control study is to define the population base, that is the population from which cases and controls will be selected. This case-control study has been carried out among workers affiliated to the Dutch Painters Organization (SFS) and Construction Workers organization (SFB). The SFB was founded in 1952 by employers and employees in the construction industry. in broad outlines, the assignments of the SFB can be divided in three parts:

- Collection of contributions and insurance money;

- Management of funds;

- Granting of payments and benefits.

Dredging companies and painters companies are (just like construction workers) affiliated to the industrial insurance board of the construction industry. However, these companies have not delegated the above mentioned assignments to the SFB. Instead, both dredging companies and painters companies have a separate organization that manages these tasks. Thus, the painters organization (SFS) carries out the Dutch health law and disability law for painters, while these laws are carried out by the SFB for ather construction workers. However, for applications of unemployment benefits all workers lincluding workers of painters and dredging companies) ought to turn to the SFB.

Two kinds of considerations play an important part at the definition of the population base:

1) Efficiency (power) considerations;

2) Availability of the data.

\section{Ad 1. Efficiency (power) considerations}

It is of importance that within the population base some variability exists with respect to the exposure to the potential etiological factor i.e. organic solvent exposure). The power, that is the statistical chance to detect an in reality existing association in a case-control study, depends on the number of cases and controls included in the study, the percentage of controls exposed (at present or previously) to the potential etiological factor and the $\alpha$-level used for statistical tests. A satisfactory efficiency of a case-control study may be defined as a situation in which as few cases and controls as possible are needed to detect a certain association with a high power. The efficiency of a case-control study is optimal if about half of the controls have been exposed to the possible etiological 
Factor ${ }^{3}$. If the study was restricted to the sps-population, the greater part of the population would have been exposed to organic solvents. The population base was compiled in such a way that about 50 originated from the SFs (exposed) and about 50\% originated from the SFB (non-exposed). As for education and jobs a strong relationship excist with respect to certain occupations with SFs and SFB. Bricklayers, plasterers and carpenters are just like painters involved in maintenance and newbuilding activities. Moreovex, painters and construction workers are frequently present at the same workstation". Given the fact that the SFB is approximately seven times greater than the SFS, only one seventh of the SFB-population needed to be included in the study. This situation was approximated by including in the study workers affiliated to the $S F B$ whose sixth digit of the registration number is a six or seven (born on day 06, 07, 16, 17, 26, 27 of any month). In this way only one fifth of the $\$ F B$-population was included in the population base. In the above considerations SFB was considered as non-exposed and SFS was considered as exposed to organic solvents. However, this is a simplification of reality since higher trained and administrative personal affiliated to the SFS may not have been exposed to organic solvents. On the other hand the SFB-flle contains painters and other construction workers, e.g. road markers, who are also exposed to organic solvents. Thus, the construction workers and painter organizations are impure with respect to the exposure to organic solvents. During the case-control study information of the exposure to arganic solvents of all participants will be collected by questioninaires.

\section{Ad 2. Avallability of the data}

The preparation of the case-control study was complicated by the fact that SFS and $3 F B$ have separate and different registration systems. Data of both registration systems ought to be combined in order to compile one file of workers (painters and construction workers) from which cases and controls could be collected. With reference to the sampling of the control population it was desirable to have computer prints of all registration numbers of the included population base. After intensive consultation with SFS and SFB on this matter, it was decided to use the following files:

SFS: The population base from which cases and controls were selected consisted of male workers affiliated to the SFS who built up rights (holiday allowance and/or pension claims/ between 25 April 1984 and 25 April 1985. 
since April 1983 a so-called "painters coupon" is used by the sFs. This coupon includes a vacation bonus, a risk fund bonus and a pension bonus. wost workers of the painting trade receive with their payments a painters coupon in accordance to regulations from the collective labour agreement of the painting trade. The worker can cash the vacation bonus of these coupons by submitting the coupons, together with a payment request to the local representative of the SFS. Painters submitting a payment request are centrally registered at the SFS. The collective labour agreement does not apply to a small group of workers (mainly administrative) within the painters trade. The persons involved receive no painters coupons, but do pay pension contributions. These pension contributions are also centrally registered. The population base was compiled by combining the "payment request file" and the "pension claim file". "These files are drawn up at the end of each coupon year (from April to April) and include data from the entire preceding year.

This population includes:

- Persons who have left the painting trade by the end of the coupon year. but who worked in the painting trade for some period during the preceding coupon year;

- Persons receiving benefits according to the Dutch health law:

- Persons receiving partial benefits from the Dutch disability law.

A computer print of this population base was supplied by the SFS at 24 october 1984 . This print consisted of 35,811 registration numbers.

SFB: The population base from which cases and controls were selected, consisted of male workers included in the so-called RBS-system (Rechten Beheer Systeem) of the SFB between April 1984 and April 1985, whose sixth digit of the registration number is a 6 or 7 .

The RBS-system of the SFB started in 1983 and replaced the coupon system. In this system the employer transfers the rights of his workers isuch as holiday bonus, pension and risk fund contributions) every four weeks to the SFB. These rights are entered on the account of the workers. Once a month the workers receive a survey, indicating their balance. The data included in the RBS-system are related to the preceding year.

This population includes:

- Persons who have left the construction trade by the end of the RBS-year, but who worked in the painting trade for some period during the preceding RBS-year; 
- Dersons receiving benefits due to the Dutch health or unemployment law (including painters!):

- Reisons receiving partial benefits from the Dutch disability law. The SFB supplied a computer print of the RBS-population base on 28 August 1985. This print consisted of 38,079 registration numbers.

\section{POWER CALCULATION}

originally it was intended to include as many controls as cases in the study. Based on the assumption that 400 cases would participate in the study, $400 \mathrm{con}-$ trols ought to be selected. Based on these numbers (400 cases and 400 controls) the power of this study to detect a relative risk of 1.4 for exposed workers compared with non-exposed workers to develop neuropsychiatric disorders was calculated to be $80 \%$.

During the conduct of the study, it became clear that the number of cases participating in the study remained significantly below the expected number of 400 cases. Therefore it was decided to increase the number of controls included in the study to prevent a decrease of the study power. The size of the control population was increased to 1,000 persons to preserve a power of $80 \%$ based on the participation of 250 casies.

DEFINITION OF CASES AND CONTROLS

\section{Cases}

Cases were defined as male persons from the population base receiving disability benefits due to neuropsychiatric disorders as from a date between 01-07-1984 and 01-07-1986 (incident cases).

Iliness of a worker is reported by the employer to the Organization (SFS or SFB) to which he is affiliated. In case of recovery within 2 to 4 weeks the insured patient is generally visited once or more by a rapporteur $l=$ employee of the SFS or SFB, who is not a physician). If no recovery occurs within this period the 
patient must contact a social security physician (= medical adviser of SFS/SFB) or visit him during office hours " Social security physicians organised in regional medical departments are engaged in patient counseling of both painters and construction workers. The maximal duration of benefits under the Dutch health law is 52 weeks. After this period patients may be eligible for disability benefits. In The Netherlands the disability pension system has its legal basis in a specific disability act. Patients who are eligable for a disability pension (1.e. Who will probably exceed the period of 52 weeks) are examined by medical advisers of the GMD (= Gemeenschappelijke Medische Dienst). They determine the degree of disability which is important for the magnitude of the disability benefits granted after 52 weeks of illness. Granting of disability benefits is not related to the question whether working conditions have lead or contributed to the development of the disease. Social security physicians of the GMD will make a diagnosis for all examined patients. Diagnoses are converted to diagnostic codes by specially trained nosologists. Diagnoses are coded according to a list based on the International Classification of Diseases, 9 th revision (Appendix 1). Neuropsychiatric disorders are classified under group $v$. Since the end of the seventies the Federation of Dutch Industrial Insurance Boards use also a list of diagnostic codes based on the ICD-9.

Patients suffering from an organic solvent syndrome will, based on the nature of their complaints (see chapter 2), prabably be diagnosed under:

- ICD 300: neuratic disorders;

- ICD 309: adjustment reactions;

- ICD 311: depression, not elsewhere classified.

Since it is assumed that this syndrome reflects the presence of organic brain damage, the correct ICD-code for these patients would probably be ICD-31.0 Ispecific non-psychotic mental disordexs following organic brain damage). However, the organic solvent syndrome among painters is no officially recognized symdrome or accupational disease among Dutch physicians.

Preceding the case-control study, a cross-sectional study of medical files was carried out to get a clear insight in the neuropsychiatric disorders occurring among painters. Medical files, kept by social security physicians, of painters and construction workers receiving disability benefits due to neuropsychiatric disorders were compared with respect to the occurrence of diagnoses and neuropsychiatric complaints. Possibly the results of this file study would permit to res trict the case-control study to specific ICD-codes within the group of neuropsychiatric disorders. 
The results of this file study, as reported in Chapter "together with the above described considetations lead to the decision to include initially all neuropsychatxic ICD-Codes (group $v$ ) in the study. Next, during the analysis of the data a distinction could be wade between ICD-codes in all probability more 1300,309 , 311) or less frequently awarded to persons suffering from the organic solvent syarome.

Cases originated from the population base of SFS and SFB workers, as described earlier. Consistent with this description sFB-cases must fulfill an additional criterion, i.e. the sixth digit of their registration number must be a six or seven.

\section{Controls}

The control population consisted of a representative sample from the population base, taking into account differences in size and age distribution between SFS arid SFB.

Table 1: Age distribution of the population base and of the randomiy selected stratified control sample of 1,000 persons.

\begin{tabular}{|c|c|c|c|c|c|c|c|c|c|}
\hline \multirow{2}{*}{$\begin{array}{l}\text { Year of } \\
\text { birth }\end{array}$} & \multicolumn{3}{|c|}{ SFS } & \multicolumn{3}{|c|}{$\mathrm{SFB}$} & \multicolumn{3}{|c|}{ Total } \\
\hline & n & $(2)$ & $\begin{array}{l}\text { Number } \\
\text { of con- } \\
\text { trols }\end{array}$ & $\mathrm{n}$ & 101 & $\begin{array}{l}\text { Number } \\
\text { of con- } \\
\text { trols }\end{array}$ & $\mathrm{n}$ & 181 & $\begin{array}{l}\text { Number } \\
\text { of con- } \\
\text { trols }\end{array}$ \\
\hline $1915-1919$ & 0 & $(0.0)$ & 0 & 4 & $(0.0)$ & 0 & 4 & $(0.0)$ & 0 \\
\hline $1920-1924$ & 217 & $(0.6)$ & 3 & 334 & $(0.9)$ & 5 & 551 & $(0.7)$ & 8 \\
\hline $1925-1929$ & 693 & $(1.9)$ & 9 & $1,3.44$ & $(3.5)$ & 18 & 2,037 & $(2.6)$ & 27 \\
\hline $2930-1934$ & 1,734 & $(4.8)$ & 23 & 2.470 & $(6.5)$ & 33 & 4,204 & $(5.7)$ & 56 \\
\hline $1935-1939$ & 2,345 & $(6.5)$ & 32 & 3.467 & $|9.1\rangle$ & 47 & 5,812 & $(7.9)$ & 79 \\
\hline $1940-1944$ & 3,340 & $(9.3)$ & 45 & 4.475 & $(11.8)$ & 61 & 7,815 & $(10.6)$ & 106 \\
\hline $1945-1949$ & 5,521 & $(15.4)$ & 75 & 6.180 & $(16.2)$ & 83 & 11.701 & $|15.8|$ & 158 \\
\hline $1950-1954$ & $6,073 i$ & $(17.0)$ & 82 & 5.939 & $(15.6)$ & 80 & 12,012 & $|16.3\rangle$ & 162 \\
\hline $1955-1959$ & 6,115 & $(17.1)$ & 83 & 5,791 & $(15.2)$ & 78 & 11,906 & $(16.1)$ & 161 \\
\hline $1960-4964$ & 6,828 & $(19.1)$ & 93 & 5,511 & $(14.5)$ & 75 & 12.339 & $(16.7)$ & 168 \\
\hline $1965-1969$ & 2,945 & $(8.2)$ & 40 & 2,564 & $(6.7)$ & 35 & 5.509 & $(7.5)$ & 75 \\
\hline Tota 1 & 35,811 & $(100.0)$ & 485 & 38.079 & $(100.0)$ & 515 & 73.890 & $(100.0)$ & 1,000 \\
\hline
\end{tabular}


The computer prints with registration numbers as delivered by the SFS and SFE served as the starting point for the selection of controls. In total these prints contained 73,890 registration numbers. The first six digits of the registration number constitute of the date of birth (year/month/day). Thus the age distribution of the SFS and SFB-population could be calculated from these prints. Sampling was performed with lists of aselect numbers 5 . Table 1 shows the age distribution, converted into "years of birth"-categories of the population base and of the stratified sample of 1,000 persoms. For all control persons it was checked at the SFS and SFB whether they belonged to the group of persons included in the population base receiving partial disability benefits. None of the controls was found to receive these benefits, so the control population was build up exclusively of people receiving no disability benefits, thus being not long-term disabled.

Cases and controls were not matched with respect tot the occurrence of potential confounding factors such as age. This decision was taken in order to be able to investigate the effects of these variables on the development of neuropsychiatric disorders. Matching would eliminate the effects of the relevant variables.

Figure 1 depictures the case-control study design used in our study.

\section{THE QUESTIONDAIRE}

A questionnaire was used to collect information from the participating cases and controls. The questionnaire consisted of 44 questions (Appendix 4). The following topics were addressed in the questionnaire:

- Personal identification (1 and 2):

- Disability (3 to 6);

- Education $(7$ to 9);

- Occupations (10 and 11);

- working conditions and exposure to organic solvents among painters (12 to 24):

- Exposure to organic solvents in other occupations $(25$ and 26):

- Work-related complaints (prenarcotic symptoms) (27 and 28):

- State of health (29 to 33$)$ :

- Symptoms fitting the "organic solvent syndrome" (neurasthenic symptoms) (34); 
Figure 1: Schematical presentation of de case-control study design.

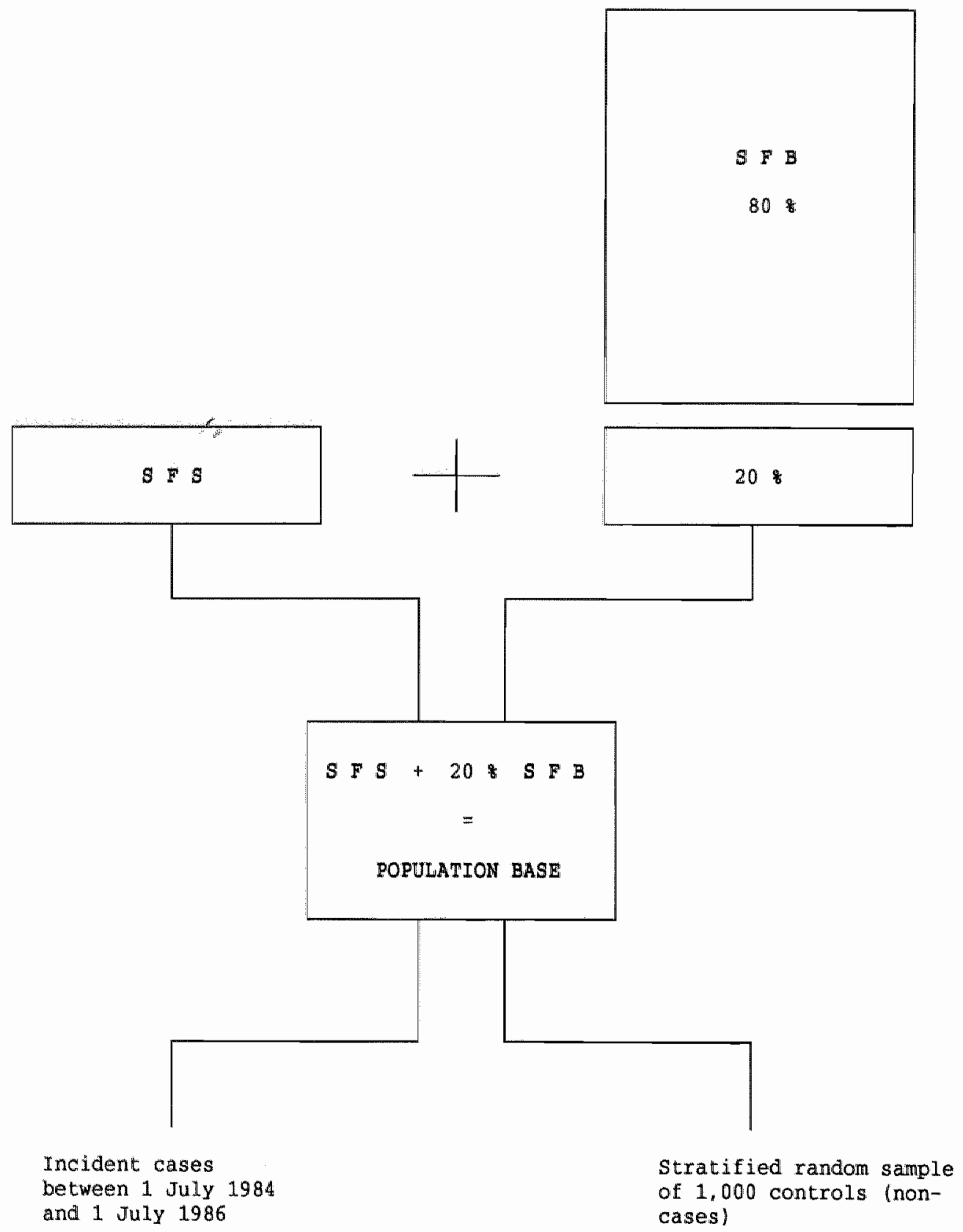


- Potential confounding variables: - Quetelet-index (35):

- Alcohol consumption (36):

- Smoking (37)

- Horkstress and private stress (38 to 43$)$.

A pilot study with this questionnaire was carried out among 36 painters and construction workers in July 1985. This pilot study showed that the questionnaire was easily completed by the participants and that the questions were clear and understandable.

Construction workers completed the questionnaire in an average of 15 minutes. Painters needed on the awerage 30 minutes to complete the questionnaire. This difference between painters and construction workers is explicable, since a number of questions are only intended for painters.

\section{APPROACE OF CASES AND CONTROLS}

Cases and controls were approached both by letter and telephone to ask them to participate in this study. The choice for a combined approach lby letter and by telephone) was made to achieve a high response (i.e. percentage of the approached persons participating in the study).

The response of an exclusively written approach was expected to be around 40\%, based on experiences in previous studies. A response rate of $60 \%$ was expected by adding a telephone call to the approach policy.

The approach of cases and controls took place according to the following plan:

1) Forwarding of a letter of introduction (Appendix 2). The object and nature of the investigation are elucidated in this letter. The study is introduced under the title: "Health and working conditions among construction workers and painters". This general title was chosen in order to reduce information bias. The letter announced a telephone call of the investigator to the (potential) participant to request co-operation in the study.

2) Minimally four days after mailing the letter of introduction, the invegtigators tried to telephone the approached cases and controls. The following rules were kept while phoning: 
- Questions about the investigation were answered as clear as passible whout mentioning the relationship between organic solvent exposure and neuropsychitatic disorders;

- In the absence of the participant, the investigator consulted, if possible, his partner or wife about participation in the study of the approached persons:

- In case of a refusal to participate, the investigators asked for the reason.

3) Persons wilingly to participate in this study, as agreed by telephone, were sent a questionnaire. The questionnaire was accompanied by a letter supplying some additional information about the completion of the questionnare (Appendix 31 .

4) If the questionnaire was not returned within four weeks the investigators made a reminder by telephone. This reminder was, if necessary, repeated after another 4 weeks.

5) Respondents who did not return the questionnaire after two reminders were considered as non-respondents.

\section{RESPONSE}

During the period from 01-07-1984 to 01-07-1986, 505 male persons of the study population were granted disabiiity benefits due to neuropsychiatric disorders. Consequently 505 cases and 1,000 controls were eligible to participate in this study. The approach of potential respondents was restricted to persons who had a telephone. This decision was made after it became clear that the response rate in the group without telephone would be very low (about 208). Since of all cases and controls information was available about their affiliation (to sFS or SFB). a conparison could be made regarding accesibility by telephone of different subgroups (Table 2 ).

part of the approached persons with a telephone refused to participate in the study. This is the total number of refusers. Refusing to participate was sometimes indicated in the first telephone call (refusers I). In other cases the refusal was expressed at the telephonic reminder, or the questionnaire was not 
returned in spite of telephonic promises (refusers II). Table 3 shows the distribution of non-respondents (refusers) among the different subgroups.

Table 2: Accesibility by telephone of cases and controls.

\begin{tabular}{|c|c|c|c|c|c|c|c|c|c|c|c|c|}
\hline & \multicolumn{2}{|c|}{$\begin{array}{c}\text { SFB } \\
\text { controls }\end{array}$} & \multicolumn{2}{|c|}{$\begin{array}{l}\text { SFB } \\
\text { cases }\end{array}$} & \multicolumn{3}{|c|}{$\begin{array}{c}\text { SFS } \\
\text { controls }\end{array}$} & \multicolumn{3}{|c|}{$\begin{array}{l}\text { SFS } \\
\text { cases }\end{array}$} & \multicolumn{2}{|c|}{ Total } \\
\hline & $\mathrm{n}$ & 101 & $\mathrm{n}$ & $(1)$ & $\mathrm{n}$ & 1 & 61 & $\mathrm{n}$ & 1 & 1 & $n$ & $(1)$ \\
\hline $\begin{array}{l}\text { Approachable } \\
\text { by telephone }\end{array}$ & 437 & $(84.9)$ & 222 & $(85.4)$ & 385 & 1 & 79.41 & 187 & & 76.31 & 1,231 & $(81.8)$ \\
\hline $\begin{array}{l}\text { Not approa- } \\
\text { chable by } \\
\text { telephone }\end{array}$ & 78 & $(15.1)$ & 38 & $(14.6)$ & 100 & 1 & 20.61 & 58 & & 23.71 & 274 & $(18.2)$ \\
\hline Total & 515 & $(100.0)$ & 260 & $(10,0.0)$ & 485 & & .00 .01 & 245 & & 00.01 & 1,505 & $(100.0)$ \\
\hline
\end{tabular}

Table 3: Co-operation of the approached persons.

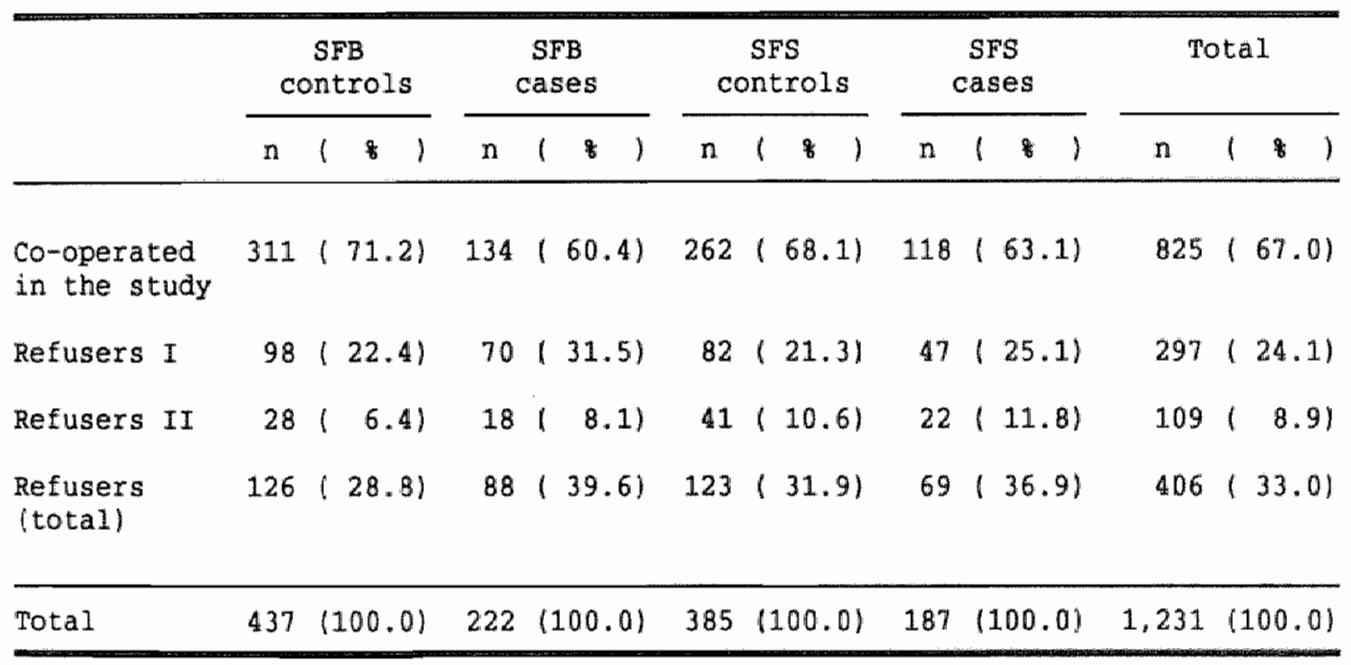

Controls not willingly to participate in this study were replaced by new controls, selected from the same organization (SFS or SFB) and birth-cohort. There-- 
fore the control population included in the study consisted of 822 persons. Since the total rumber of cases occuring during the study period was limited to 505 . the same procedure could not be applied to the cases. Thus, the number of cases included in the study was restricted to 252 .

\section{REFEREES}

1. Sturmans F. Epidemiologie. Theorie, methoden en toepassing Dekker \& van de Vegt, Nijmeger, 1984.

2. Sturmans $F$, Valkenburg HA. Vormen van observationeel onderzoek voor analytische epidemiologie. T. Soc. Gez. 1977; 55: 885-895.

3. Schlesselman JJ, Case-control studies. Design, Conduct, Analysis. Oxford University Press, New York, 1982.

4. Scheffers TML, Wit de JNF, Saris-Wijnands MJ. Ziekteverzuim van schilders in de bouwnijverheid. Stichting Bedrijf sgezondheidsdienst voor de Bouwnijverheid, Ams terdam, 1984 .

5. Snedecor GW, Cochran WG. Statistical Methods, 7 th ed. The Iowa State University Press, Ames. Iowa, USA, 1980. 
CHAPTER 4

THE ORGANIC SOLVENT SYNDROME. A COMPARISON OF CASES WITH NEUROPSYCHIATRIC DISORDERS AMONG PAINTERS AND CONSTRUCTION WORKERS."

C van Vliet ${ }^{1}$, GMH Swaen ${ }^{1}$, JJM Slangen ${ }^{1}, T j$ de Boorder ${ }^{1}$, F Sturmans $^{2}$

1 Dept. of Occupational and Environmental Health and Toxicology, University of Limburg, PO BOx 616, 6200 MD Maastricht, The Netherlands.

2 Dept. of Epidemiology, University of Limburg.

* Published in International Archives of Occupational and Environmental Health 1987; $59: 493-501$. 
ABSTRACT

A gtudy wa conducted to investigate the existence of a "specific" neurotoxic effect due to long-tern exposure to organic solvents. A comparison was made regarding diagnoses, symptoms and other relevant medical data between persons receiving a disability pension on the basis of a neuropsychiatric disorder selected fror an expoged (painters) and non-exposed (construction workers) trade organization. Information was collected from their medical files at the medical department. Concerning diagnoses and symptoms, no significant differences were found between exposed and non-exposed patients. No indications were found for the existence of a "typical" complex of symptoms associated with exposure to organic solvents among painters in The Netherlands. The number of reported symptoms was not related to the duration of exposure, thus lending no support for a doseeffect relationship. If a neurotoxic effect does exist among Dutch painters, it is of a non-specific type and not clearly distinguishable from other mental disorders.

\section{INTRODUCTION}

Recently substantial attention has been given to the potential neurotoxic effects of prolonged exposure to organic solvents ${ }^{1}$. Publications, particularly from scandinavian countries, have reported adverse neurological, neurophysiological and psychological disorders in solvent exposed workers ${ }^{2}$.

Neurasthenic symptoms have been reported to be more frequent in exposed workers than in non-exposed controls ${ }^{3-7}$. The relative risk of disability pension due to piresenile dementia appeared to be higher among solvent exposed workers in several epidemiological studies ${ }^{8-10}$. Some studies conducted outside scandinavia did not support these findings. Cherry et al ${ }^{11}$ found no evidence of an association between psychiatric morbidity and solvent-exposure in British workers. Triebig et $a^{12}$ conducted a retrospective casuistic study among patients examined in their clinic, who were suspected of suffering from an accupational disease. During the period 1963 to 1984 they had not seen a painter with disorders of the peripheral and/or central nervous system as an occupational disease.

This study was not designed to detect a possible increased risk of solvent expo- 
sed workers for developing neuropsychiatric disorders. Instead, it focusses on the rature of the organic solwent syndrome. The symdrome thought to be caused by organic solvent exposure has been given a number of different names, such as psycho-organic syndrome, chronic encephalopathy, presenile dementia, painters syndrome, neurasthenic syndrome. Recently two attempts have been made to describe the disorders of the central nervous system that may be caused by long-term exposure to organic solvents. A who working group ${ }^{13}$ distinguished between an organic affective symirome and a chronic toxic encephalopathy that may be mild or severe. However, four months later at a meeting held in North Carolina, another classification was suggested, implying that the condition is still not as well defined or understood as one would like $1,13,14$.

orbaek et al $^{7}$ carried out a cross-sectional epidemiological study among workers in the paint industry. They stated that a clinical important neurasthenic syndrome in a patient who was exposed to solvents for at least one decade should be recognized as work-related when other important diseases have been excluded reasonably well. Juntunen ${ }^{15,16}$ formulated diagnostic criteria for the diagnosis of organic solvent intoxication, one of these being the existence of typical subjective symptoms. The most common symptoms observed among patients with organic solvent intoxication are: headache, memory disturbances, tiredness, dizziness, nervousness, paresthesia and concentration difficulties $3-5,15$.

painters are exposed to the vapours of various solvents. Riala et al ${ }^{17}$ determined the exposure to organic solvents among Finnish maintenance painters. The mean 8-h concentration of white spirit (= a mixture of organic solvents) in the breathing zone averaged 40 ppm over the painters' total worklife. A study concerning the exposure of Dutch maintenance painters to organic solvents ${ }^{18}$ revealed exposure to $c 8$ - C11 alkenes and $C 7$ - C10 aromates among all painters, while incidentally alcohols, ketones, esters and chlorated hydrocarbons were detected in the breathing zone.

Although some construction workers are occasionally exposed to organic solvents we assume this exposure to be of little significance compared with painters.

The study population of the present study consists of patients diagnosed with neuropsychiatric disorders. They (all) receive a disability pension from the Dutch Painters Organization (SFS) or Construction workers organization (SFB). In this study a comparison has been made regarding diagnoses, symptoms and some other relevant medical data of patients from the painters and construction workers Organization. The aim of this comparison was to investigate the existence of specific symptoms or syndromes among neuropsychiatric patients previously exposed to organic solvents. This study preceeds the performance of a case-con- 
trol study among painters and construction workers which will be carried out in order to determine whether exposure to organic solvents is associated with the risk for receiving disability beneits due to neuropsychiatric disorders.

\section{MATERIAL AND METHODS}

Dutch painters and construction workers are organised in a similar way for the execution of social laws, such as health, unemployment and disability insurances. In The Netherlands the disability pension system has its legal basis in a specific disability law. According to this law payment of disability benefits is considered after 52 weeks of iliness. The disability pension is not related to whethex or not the dísease/injury was a result of working conditions. Local departments of social security physicians engaged in granting of disability benefits. cover the members of both organizations. Diagnoses of persons receiving disability benefits for neuropsychiatric disorders were awarded by these social security physicians. These diagnoses were coded by expert nosologists according to a list based on the International Classification of Diseases - 9 th revision (ICD-9). These codes (see Table 2) were used to sellect male persons receiving a disability pension due to neuropsychiatric disorders. Participation in the study implied agreement to exploration of their medical files. In this case the medical file refers to the information collected by the physicians of the above mentioned medical department. From the files of the participating workers information was collected concerning age, diagnosis, occupational history, symptoms, medication and further medical history.

Informed consent was given by 239 patients receiving a disability pension due to a neuropsychiatric disorder. The number of refusals was equally divided among the painters and the construction workers organizations.

In the statistical analysis of the collected data we calculated means, standard deviations and Odds Ratio's. The Odds Ratio (OR) approximates the relative risk. in case few diagnoses/symptoms appear in both the exposed and non-exposed group. Besides, the odds Ratio as such is a commonly used measurement of association between exposure and illness $\langle 1=$ a negative relation; $1=$ no relation; $\rangle 1=$ a positive relation) ${ }^{19}$. The confidence limits $(\alpha=0.05)$ of the odds Ratio's were calculated according to Schlesselman ${ }^{20}$. Student"s t-test was used to define the significance of the difference between two means (Table 4 ). 
A division was made between exposed and non-exposed patients, based on the occupational history of all 239 persons. Subjects, previously working as painters were classified as being exposed to organic solvents, while those who had worked as construction workers were classified as non-exposed, if it was not stated that they had been involved in painting work. The number of years worked as a painter was also known in this study. A subdivision of painters (e.g. construction painters, maintenance painters) could not be made, since this classification was missing in most files.

Table 1: Age distribution and magnitude of exposed and non-exposed persons.

\begin{tabular}{|c|c|c|c|c|}
\hline \multirow[t]{2}{*}{ Age (years) } & \multicolumn{2}{|c|}{ Exposed } & \multicolumn{2}{|c|}{ Non-exposed } \\
\hline & $\mathrm{n}$ & 8 & $\mathrm{n}$ & 8 \\
\hline $19-29$ & 9 & 9.2 & 9 & 6.4 \\
\hline $30-39$ & 24 & 24.5 & 33 & 23.4 \\
\hline $40-49$ & 31 & 31.6 & 41 & 29.1 \\
\hline $50-59$ & 22 & 22.4 & 45 & 31.9 \\
\hline$>60$ & 12 & 12.2 & 13 & 9.2 \\
\hline Total & 98 & 100.0 & 141 & 100.0 \\
\hline
\end{tabular}

Table 1 shows the age distribution and number of exposed/non-exposed subjects. Mean age at first disability payment data of the exposed workers was 44.5 (SD 10.8) years compared to 45.8 years (SD 10.3 ) for the non-exposed workers." The mean exposure time of the painters was 24 years (SD 10.7). The mean working time of the non-exposed construction workers was 25.3 years (SD 10.2).

Physicians of the medical department of the painters and construction workers organizations coded their diagnosis according to a list based on the ICD-9 classification. Diagnoses (and codes!) can change during an illness. Therefore we agreed upon using the diagnosis/code stated in the medical file at the time of application for a disability pension.

Table 2 shows a review of the diagnoses as coded by the physicians mentioned above. 
Table 2: Occurrence of diagnostic codes among the exposed and non-exposed groupas coded by the social security physicians.

\begin{tabular}{|c|c|c|c|c|c|c|c|c|}
\hline \multirow{2}{*}{$\begin{array}{l}\text { ICD- } \\
\text { code }\end{array}$} & \multirow[t]{2}{*}{ Description } & \multicolumn{2}{|c|}{ Exposed } & \multicolumn{2}{|c|}{ Mon-exposed } & \multirow{2}{*}{$\begin{array}{l}\text { Odds } \\
\text { Ratio } \\
\text { (OR) }\end{array}$} & \multirow{2}{*}{\multicolumn{2}{|c|}{$\begin{array}{l}\text { Confidence } \\
\text { limits of } O R \\
(\alpha=0.05)\end{array}$}} \\
\hline & & $\mathrm{n}$ & 8 & $\mathrm{n}$ & 8 & & & \\
\hline 290 & Dementia & - & - & 1 & 0.7 & - & & - \\
\hline 295 & Schizophrenic psychosis & 1 & 1.0 & 1. & 0.7 & 1.44 & 0.09 & -23.30 \\
\hline 296 & Affective psychosis & 4 & 4.1 & 5 & 3.5 & 1.16 & 0.30 & -4.43 \\
\hline 298 & $\begin{array}{l}\text { Other non-organic psy- } \\
\text { chosis }\end{array}$ & 2 & 2.0 & 2 & 1.4 & 1.45 & 0.20 & -10.47 \\
\hline 300 & Neurotic disorders & 29 & 29.6 & 33 & 23.4 & 1.38 & 0.77 & -2.47 \\
\hline 301 & Personality disorders & 2 & 2.0 & 4 & 2.8 & 0.71 & 0.13 & $-\quad 3.95$ \\
\hline 303 & $\begin{array}{l}\text { Alcohol dependence } \\
\text { syndrome }\end{array}$ & 1 & 1.0 & 4 & 2.8 & 0.35 & 0.03 & -3.81 \\
\hline 304 & Drug dependence & - & - & 2 & 1.4 & - & & - \\
\hline 306 & $\begin{array}{l}\text { Physiological malfunction } \\
\text { arising from mental fac- } \\
\text { tors }\end{array}$ & 3 & 3.1 & 13 & 9.2 & 0.31 & 0.09 & -1.12 \\
\hline 307 & $\begin{array}{l}\text { Special symptoms or syn- } \\
\text { dromes not elsewhere } \\
\text { classified }\end{array}$ & 1 & 1.0 & - & - & - & & - \\
\hline 309 & Adjustment reaction & 50 & 51.0 & 73 & 51.8 & 0.97 & 0.58 & -1.62 \\
\hline 310 & $\begin{array}{l}\text { Specific non-psychotic } \\
\text { mental disorders follo- } \\
\text { wing organic brain damage }\end{array}$ & - & - & 2 & 1.4 & - & & - \\
\hline 311 & $\begin{array}{l}\text { Depressive disorder, not } \\
\text { elsewhere classified }\end{array}$ & 3 & 3.1 & 1 & 0.7 & 5.47 & 0.56 & -53.38 \\
\hline 317 & Mild mental retardation & 2 & 2.0 & - & - & - & & - \\
\hline
\end{tabular}

Schizophrenic psychosis (295), affective psychosis (296), other non-organic psychosis (298), neurotic disorders (300) and depressive disorders not elsewhere classified (311) occurred more often anong the exposed group (Odds Ratio > 1). However, the differences between the exposed and the non-exposed group are relatively small and of no statistical significance. 
Table 3: Frequency distribution of symptoms among exposed and non-exposed subjects.

\begin{tabular}{|c|c|c|c|c|c|c|c|}
\hline \multirow{3}{*}{$\begin{array}{l}\text { Description } \\
\text { Nervousness }\end{array}$} & \multicolumn{2}{|c|}{ Exposed } & \multicolumn{2}{|c|}{ Non-exposed } & \multirow{3}{*}{$\begin{array}{l}\text { Odds } \\
\text { Ratio } \\
\text { (OR) }\end{array}$} & \multirow{2}{*}{\multicolumn{2}{|c|}{$\begin{array}{l}\text { Confidence } \\
\text { limits of or } \\
(\alpha=0.05)\end{array}$}} \\
\hline & $\mathrm{n}$ & * & $\mathrm{n}$ & 8 & & & \\
\hline & 74 & 75.5 & 95 & 67.4 & & 0.83 & -2.67 \\
\hline Depressive feeling & 61 & 62.2 & 80 & 56.6 & 1.26 & $0.75-$ & -2.13 \\
\hline Somatic symptoms & 34 & 34.7 & 70 & 49.6 & 0.54 & 0.32 & -0.92 \\
\hline Vegetative disorders & 33 & 33.7 & 44 & 31.2 & 1.12 & 0.64 & -1.97 \\
\hline Anxiety & 31 & 31.6 & 44 & $3: 1.2$ & 1.02 & $0.63-$ & -1.66 \\
\hline sleeping disturbances & 29 & 29.6 & 35 & 24.8 & 1.27 & 0.71 & $-\quad 2.26$ \\
\hline Dizziness & 22 & 22.5 & 20 & 14.2 & 1.75 & 0.90 & -3.42 \\
\hline Psychosomatic symptoms & 22 & 22.5 & 38 & 27 & 0.78 & $0.43-$ & -1.43 \\
\hline Headache & 21 & 21.5 & 30 & 21.3 & 1.01 & 0.54 & -1.89 \\
\hline Fatigue & 20 & 20.4 & 26 & 18.4 & 1.13 & $0.59-$ & -2.16 \\
\hline Agressive behaviour & 19 & 19.4 & 30 & 21.3 & 0.89 & $0.47-$ & -1.69 \\
\hline Concentration disturbances & 16 & 16.3 & 20 & 14.2 & 1.18 & 0.58 & -2.41 \\
\hline Hyperventilation & 15 & 15.3 & 14 & 10 & 1.64 & 0.75 & $-\quad 3.57$ \\
\hline Major psychic symptoms & 14 & 14.3 & 19 & 13.5 & 1.07 & $0.51-$ & -2.25 \\
\hline Suicidal thoughts/behaviour & 12 & 12.2 & 19 & 13.5 & 0.90 & $0.42-$ & -1.95 \\
\hline $\begin{array}{l}\text { Numbness or parasthesia of } \\
\text { extremities (neuropathy) }\end{array}$ & 6 & 6.1 & 3 & 2.1 & 3.00 & 0.73 & -12.30 \\
\hline Memory disturbances & 5 & 5.1 & 14 & 9.9 & 0.49 & 0.07 & -1.87 \\
\hline
\end{tabular}

There is no evidence in the literature that the organic solvent syndrome includes disorders like psychosis, alcohollism, anorexia nervosa ete. It is mostly characterized as a neurasthenic syndrome and hence probably coded as 300 (neurotic disorders), 309 (adjustment reaction), or 311 (depressive disorders not elsewhere classified). Taking these three codes together the odds Ratio is 1.6210 .84 3.16). We could not demonstrate a dose-effect relationship in terms of an increased frequency of ICD codes fitting the organic salvent syndrome among the group 
Wth longest (\$20 years) exposure to organic solvents.

In order to rule out coding errors by the social security physicians, the 239 cases were coded according to the ICD classification, independent of the ICDcodes given by the social security physicians. This also revealed only minor differences between the exposed and the non-exposed group.

A list was compiled of the symptoms noted in the medical files. All symptoms were grouped in 17 categories. Table 3 gives a review of the results.

Nearly all these symptoms occurred more often among the exposed patients, but here again the differences are of no statistical significance. The mean number of symptoms occurring among the exposed group was 7.0 compared to 6.3 for the Inon-exposed group.

In search of a possible dose-effect relationship in terms of the number of reported symptoms and duration of exposure, the two groups were divided in subgroups according to their number of working years. For each group the mean number of symptoms was calculated. As shown in Table 4 the highest prevalence occurred among the youngest painter group.

Table 4: Mean number of reported symptoms among exposed and non-exposed persons related to their number of working years.

Mean number of reported symptoms

Exposed

Non-exposed

\begin{tabular}{rll}
\hline $1-10$ & 8.2 & $5.2^{*}$ \\
$11-20$ & 6.6 & 7.1 \\
$21-30$ & 7.5 & 6.8 \\
& 6.3 & 5.6 \\
\hline
\end{tabular}

* $p<0.05$ (Student's t-test)

Three items collected from the medical files were regarded to be indicative for the severity of the mental disorder:

- medication (use of psychopharmaca).

- admission to a psychiatric ward/hospital during the examined 52-week period prior to disability pension.

- psychiatric history (previously treated for a mental disorder). 
All three items were observed more often among the exposed patients, but here again the differences between the two groups are not statistically significant (see Table 5 ).

Table 5: Severity indicators among exposed and non-exposed persons.

\begin{tabular}{|c|c|c|c|c|c|c|}
\hline & \multicolumn{2}{|c|}{ Exposed } & \multicolumn{2}{|c|}{ Non-exposed } & \multirow{2}{*}{$\begin{array}{l}\text { Odds } \\
\text { Ratio } \\
\text { (OR) }\end{array}$} & \multirow{2}{*}{$\begin{array}{l}\text { Confidence } \\
\text { limits of or } \\
(\alpha=0.05)\end{array}$} \\
\hline & $\mathrm{n}$ & 8 & $\mathrm{n}$ & * & & \\
\hline Psychopharmaca & 56 & 57.2 & 72 & 51.1 & 1.28 & $0.76-2.14$ \\
\hline Hospital admission & 16 & 16.3 & 14 & 9.9 & 1.77 & $0.82-3.82$ \\
\hline Psychiatric history & 39 & 39.8 & 43 & 30.5 & 1.51 & $0.88-2.60$ \\
\hline
\end{tabular}

DISCUSSION

occupational exposure to organic solvent is encountered in a range of occupations, but certainly among painters, since organic solvents are an essential part of most paints. In the present study we investigated the existence of specific neurotoxic effects of the occupational exposure to organic solvents. The medical files of patients with neuropsychiatric disorders who had previously worked as painters and construction workers were compared.

A problem in this study is the quality of the basic material. There was a potential lack of uniformity in the recording of data in the medical files. Recording of data sometimes was obviously imcomplete. Furthermore random misclassification can not be excluded. However, these potential sources of bias should have affected both the exposed cases and the non-exposed cases similarly, because at the time that most cases were diagnosed no particular interest had yet been given to the organic solvent syndrome in The Netherlands. Thus, it is unlikely that report bias, over-reporting of symptoms among exposed cases or under-reporting of symptoms among non-exposed cases has af fected the results of this study. Subsequently it is clear that both exposed and non-exposed cases were medically examined by the same physicians. Besides the above mentioned problems, the small number of patients and the resulting small statistical power should be remembered while interpreting the results. 
In this study no significant differences were found in diagnoses ldiagnostic codes) between the expoed and non-exposed patients. Mikxelsen ${ }^{9}$ suggested that painters are more likely to develop presenile denentia. In our study only one (non-exposed!) person recelved a disability pension due to dententia (ICD-code: 2901. However the use of the diagnostic term "presenile dementia" differs in Dermark and rhe vetherlands.

Furthermore, stated in the introduction the neuropsychiatric disorders of the central nervous system caused by long-term exposure to organic solvents are still not well defined. possibly these two factors are responsible for the lack of differences in diagnoses between the two groups.

One of the criteria formulated by Juntunen et $\mathrm{I}^{15}$ for diagnosing organic solvent intoxication is the existence of typical subjective symptoms. The symptoms appear gradually and persist for some time following cessation of the exposure ${ }^{21,22}$. A number of these symptoms (e.g. nervousness, dizziness and paresthesial did accur more often among the exposed group. However, the differences were of no statistical significance and, surprisingly, another important symptom, memory disturbances, was more common among construction workers (the non-exposed group). Besides, one must realise that the "typical subjective symptoms" associated with the organic solvent syndrome are of a non-specific nature, and are more or less present in a number of neuropsychiatric disorders.

In case of the existence of a dose (i.e. the number of years worked as a painter) - effect relationship we would expect to find the highest prevalence of neurasthenic symptoms and ICD-codes fitting the organic solvent syndrome, among the patients who worked the longest as painters. Instead, with respect to the ICDcodes no dose-effect relationship was detected and the highest prevalence of symptoms was found among the lowest exposed painter group. The reason for this last observation remains unclear, but certainly does not support the existence of dogemefect relationship.

The items we chose for indicating the severity of the mental disorder were rather crude. It is noteworthy that they all occurred more often among the exposed group, but as a result of the lack of substantial significance no far reaching conclusion may be drawn from this observation.

Al1 in all the results of our study are not in favour of the existence of any specific neurotoxic syndrome among neuropsychiatric patients with previous exposure to organic solvents. Probably exposure to organic solvents has a more general neurotoxic effect not distinguishable from other mental disorders by means of specific symptoms or syndromes. These results indicate that a broad variation of neuropsychiatric disorders should be included in studies designed to detect 
any risks of solvent exposed workers to be prematurely disabled due to neuropsychiatric disorders.

\section{REFERENCES}

1. Waldron HA. Solvents and the brain. Br J of Ind Med 1986; 43:73-74.

2. Grasso $\mathrm{p}$ et al. Neurophysiological and psychological disorders and occupational exposure to organic solvents. Fd Chem Toxic 1984; 22: 819-852.

3. Knave et al. Long-term exposure to jet fuel II. A cross-sectional epidemiological investigation on occupational exposed industrial workers with special reference to the nervous system. Scand J work Environ Health 1978; 4: 19-45.

4. Husman K. Symptoms of car painters with long-term exposure to a mixture of organic solvents. Scand J Work Environ Health 1980; 6: 19-32.

5. Struwe $G$, Wennberg A. Psychiatric and neurological symptoms in workers occupationally exposed to organic solvents - results of a differential epidemiological study. Acta Psychiat Scand 1983; Suppl 67:68-80.

6. Cherry $N$ et al. Neurobehavioural effects of repeated occupational exposure to toluene and paint-solvents. Br J of Ind Med 1985;42: 291-300.

7. Orbaek $\mathrm{P}$ et al. Effects of long-term exposure to solvents in the paint industry. A cross sectional epidemiologic study with clinical and laboratory methods. Scand J work Environ Health 1985; 11, Suppl 2.

8. Axelson 0 et a1. A case-referent study on neuropsychiatric disorders among workers exposed to solwents. Scand J work Environ Health 1976; 2: 14-20.

9. Mikkelsen S. A cohort study of disability pension and death among painters with special regard to disabling presenile dementia as an occupational disease. Scand I Soc Med Suppl 1980; 16: 34-43.

10. Olsen J, Sabroe S. A case-referent study of neuropsychiatric disorders among workers exposed to solvents in the Danish wood and furniture industry. Scand J Soc Med Supp1. 1980: 16: 44-49.

11. Cherry $N$, Waldron $H A$. The prevelance of psychiatric morbidity in solvent workers in britain. Int J Epid 1984; 13: 197-200.

12. Triebig $G$, Gröner $P$, Valentin $H$. Berufskrankheiten bei Malern, Anstreichern und Lackierern. Retrospektive empirisch - kasuistigche Analyse von Erkrankungsfällen der Jahre 1964 - 1984. Arbeitsmed Sozialmed Präventivmed 1986; 21: $81-86$. 
13. World Health Organisation Environmental Health 5 . Chronic effects of organic solvents on. the central nervous system. Copenhagen, WHO, 1985.

14. Baker $\mathrm{dL}$, Fine LJ. Solvent neurotoxicity: The current evidence. J Occup Med 1986:28:126-129.

15. Juntunen $J$ et 1 . Neurological Picture of Organic Solvent poisening in Industry. Int Arch Occup Environ Health 1980; 46: 219-231.

16. Juntunen J. Organic solvent intoxication in occupational neurology. Acta Heurol scand 1984; 69, supp1. 98: 105-119.

17. Riala $\mathrm{R}$ et al. Solvent exposure in construction and maintenance painting. Scand J Work Environ Health 1984; 10: 263-266.

18. Scheffers TML. Jongeneelen FJ. Arbeidshygiënjsch onderzoek naar de blootstelling wan onderhoudschilders aan oplosmiddelen. BGBouw-publikatie, 1982.

19. Lilienfeld AM, Lilienfeld DE. Foundations of Epidemiology, 2th edn. New York, Oxford. Oxford University Press, 1980.

20. Schlesselman Jít. Case-control studies. Design, Conduct, Analysis. New York, Oxford University Press, 1982.

21. Arlien Sфborg et al. Chronic Painter"s syndrome: Chronic toxic encephalopathy in house painters. Acta Neurol Scand 1979; 60: 149-156.

22. Elofsson SA et al. Exposure to organic solvents: A cross sectional epidemiological investigation on occupational exposed car and industrial spray painters with special reference to the nervous system. Scand $J$ work Environ Health $1980 ; 6: 239-273$. 


\section{CHAPTER 5}

NEUROPSYCHIATRIC DISORDERS AMONG SOLVEMT EXPOSED WORKERS. FIRST RESULTS FROM A DUTCH CASE-COMTROL STUDY.*

C van vliet ${ }^{1}$, GMH Swaen $^{1}$, A volovics ${ }^{2}$, M Tweehuysen $^{1}$, JMM Meijers ${ }^{1}$, TH de Boorder ${ }^{1}$, F sturmans ${ }^{3}$

1 Dept. of Occupational and Environmental Health and Toxicology, University of Limburg, Po Box 616, $6200 \mathrm{MD}$ Maastricht, The Netherlands.

2 Dept. of Biostatistics, University of Limburg.

3 Dept. of Epidemiology, University of Limburg.

* Submitted for publication 


\section{ABETRACI}

This case-control study was undertaken to determine whether exposure to organic solvents, as experienced by Dutch painters, causes an increased risk for disability due to neuropgychiatric disorders. Cases and controls were selected from the Dutch Painters and construction workers organizations.

Cases were defined as male persons receiving disability benefits due to neuropsychiatric disorders. The controls consisted of a random sample of 1,000 male persons from the total study population. 252 cases and 822 controls participated in our study by returning the completed questionnaires. The questionnaire was used to collect information about their accupational history and the presence of potential confounding factorm. The adjusted odds Ratio for the total group of neuropsychiatric disorders did not reach a statistical significant level $\quad$ OR $=1.17$ $\mathbb{p}<0.30)$. Although a stronger association was suggested between "neuroses" (ICD $300)$ and exposure to organic solvents $(O R=2.30 ; p<0.05)$, there are indications that this relationship is merely the result of classification bias. The results of this study do not confirm, but do also not completely exclude, that Dutch painters are at increased risk for being prematurely disabled due to neuropsychiatric disorders.

\section{INTRODUCTION}

During the past fifteen years the question whether long-term exposure to organic solvents can induce chronic neurotoxic effects, has received quite some attention in the bio-medical literature ${ }^{1}$. Epidemiological studies, particularly from scandinavian countries, reported increases of disturbed psychological functions ${ }^{2-6}$, electroencephalographic abnormalities ${ }^{6-8}$ and an increased prevalence of neurasthenic symptoms ${ }^{3,6,8-10}$ among workers with long-term exposure to organic solwents.

The question was raised whether these chronic neurotoxic effects might lead to premature disability among solvent exposed workers. Four Scandinavian studies have investigated this issue. A Swedish and a Danish case-control study among construction workers who had been granted disability pensions showed an increased morbidity due to neuropsychiatric disorders among solvent exposed construction 
workers 11,12 . The results of a Finnish case-control study indicated that exposure to organic solvents was associated with an increased risk of being prematurely pensioned due to neuroses, while early pensioning due to other neuropsychiatric disorders was not increased among solvent exposed workers 13 . In a Danish cohort study painters had an increased risk to be pensioned due to presenlie dementia ${ }^{14}$. Some studies conducted outside Scandinavia did not confirm these results. Cherry and waldron ${ }^{15}$ found no evidence of an association between psychiatric morbidity and organic solvent exposure in British workers. Triebig et al ${ }^{16}$ concluded that German construction painters are not at increased risk for developing mental disorders.

painters are usually exposed to a mixture of organic solvents. A study concerning the exposure of Dutch maintenance painters to organic solvents ${ }^{17}$ revealed exposure to $\mathrm{c8-C11}$ alkenes and $\mathrm{C7-C10}$ aromates among all painters while incidentally alcohols, ketones, esters and chlorated hydrocarbons were detected in the breathing zone. The hygienic standards of these solvents were rarely exceeded. However, the above mentioned measurements are not representative for the individual exposure to organic solvents of all painters. Furthermore, in the past thirty years considerable changes have accurred with regard to the nature and level of organic solvent exposure among butch painters ${ }^{18}$.

The present case-control study was undertaken to clarify some of the contradicting results obtained in Scandinavian studies compared to studies conducted outside Scandinavia and to determine whether exposure to organic solvents, as experienced by Dutch painters, is associated with the risk for receiving disability benefits due to neuropsychiatric disorders.

MATERIAL AND METHODS

In the study presented in this article a population based case-control design was applied. The first step at the start of a population based case-control study is to define the population from which cases and controls will be selected. The population base was taken from the Dutch Painters and Construction Workers organizations. These organizations have been founded by employers and employees in order to execute a number of social laws, such as health care, unemployment and disability insurances for painters and construction workers. In the Netherlands the disability pension system has its legal basis in a specific disability act. 
According to this act payment of disalility benefits starts after 52 weeks of illness. Local departments of social security physicians engaged in granting of disability benefits cover the members of both organizations. Merbers of the above mentioned organizations, receiving disability benefits are centrally registered. If only the members of the painters organization were included in the study. nearly all cases and controls would have been more or less exposed to organic solvents. In order to include non-exposed persons in the study population, one fifth of the construction workers organization was incorporated into the study. A selection was made by including only those members of the construction workers organization in our study population, who were born on day no. 06, 07, 16, 17, 26. 27 of any month in any year. From this combined population of about 74,000 persons, as registered in July 1985, cases and controls were selected.

Cases were defined as male persons receiving disability benefits for mental disorders as from a date between 1 July 1984 and 1 July 1986. Diagnoses of persons receiving disability benefits for neuropsychiatric disorders were awarded by social security physicians. These diagnoses were coded by expert nosologists according to a classification based on the 9 th revision of the International classification of Diseases. Mental disorders are grouped in categories (Table 5) which have all been included in the study.

The controls consisted of a stratified random sample of 1,000 male persons (noncases) from the total study population, taking into account the differences in population size and age distribution between the painters and construction workers organizations. The structure of the population base and the control population is presented in Table 1.

Cases and controls were approached by telephone in order to ask them to participate in this study. The study was restricted to persons who could be approached. by telephone. In an early phase of the data collection it became clear that the response rate whin the group without telephone turned out to be very low labout 20:3). Furthermore, as shown in Table 2, there are no important differences between cases and controls with respect to telephone connections. Therefore the above mentioned restriction of the study population seems justifiable.

After cases and controls were approached by telephone and having consented to participate in the study, participants received a mailed questionnaire to collect information about their occupational history and the presence of potential confounding factors (e.g. alcohol intake, education level, stress factors). The willingness to participate in this study was somewhat higher among the controls. 
Table 1: Age distribution of the population base and of the randomly selected stratified control sample of 1.000 persons.

\begin{tabular}{|c|c|c|c|c|c|c|c|c|c|c|}
\hline \multirow{2}{*}{$\begin{array}{l}\text { Year of } \\
\text { birth }\end{array}$} & \multicolumn{4}{|c|}{ SFS } & \multicolumn{3}{|c|}{$\mathrm{SFB}$} & \multicolumn{3}{|c|}{ Total } \\
\hline & $\mathrm{n}$ & 1 & * 1 & $\begin{array}{l}\text { Number } \\
\text { of con- } \\
\text { trols }\end{array}$ & $\mathrm{n}$ & $1 * 1$ & $\begin{array}{l}\text { Number } \\
\text { of con- } \\
\text { trols }\end{array}$ & $n$ & $1 * 1$ & $\begin{array}{l}\text { Number } \\
\text { of con- } \\
\text { trols }\end{array}$ \\
\hline $1915-1919$ & 0 & 1 & 0.01 & 0 & 4 & $(0.0)$ & 0 & 4 & $(0.0)$ & 0 \\
\hline $1920-1924$ & 217 & 1 & $0.6)$ & 3 & 334 & $(0.9)$ & 5 & 551 & $(0.7)$ & 8 \\
\hline $1925-1929$ & 693 & 1 & 1.9) & 9 & 1,344 & 13.51 & 18 & 2.037 & $(2.6)$ & 27 \\
\hline $1930-1934$ & 1.734 & 1 & 4.81 & 23 & 2,470 & $(6.5\rangle$ & 33 & 4,204 & $(5.7)$ & 56 \\
\hline $1935-1939$ & 2,345 & 1 & 6.51 & 32 & 3.467 & $(9.1)$ & 47 & 5,812 & $(7.9)$ & 79 \\
\hline $1940-1944$ & 3.340 & 1 & 9.31 & 45 & 4.475 & $(11.8)$ & 61 & 7,815 & $(10.6)$ & 106 \\
\hline $1945-1949$ & 5,521 & 1 & 15.4 & 75 & 6,180 & $(16.2)$ & 83 & 11,701 & $(15.8)$ & 158 \\
\hline $1950-1954$ & 6.073 & & 17.08 & 82 & 5,939 & $(15.6)$ & 80 & 12,012 & $(16.3)$ & 162 \\
\hline $1955-1959$ & 6.115 & 1 & 17.11 & 83 & 5,791 & $(15.2)$ & 78 & 11,906 & $(15.1)$ & 161 \\
\hline $1960-1964$ & 6.828 & & $19.1)$ & 93 & 5,511 & $(14.5)$ & 75 & 12,339 & $(15.7)$ & 168 \\
\hline $1965-1969$ & 2.945 & 1 & $8.2)$ & 40 & 2.564 & $(6.7)$ & 35 & 5.509 & $(7.5)$ & 75 \\
\hline Tatal & 35,811 & & 00.01 & 485 & 38.079 & $(100.0)$ & 515 & 73,890 & $(100.0)$ & 1,000 \\
\hline
\end{tabular}

Table 2: Response among cases and controls.

\begin{tabular}{|c|c|c|c|c|c|c|}
\hline & \multicolumn{3}{|c|}{ Painters Organization } & \multicolumn{3}{|c|}{$\begin{array}{c}\text { Construction workers } \\
\text { Organization }\end{array}$} \\
\hline & \multicolumn{2}{|c|}{ Cases } & Controls & \multicolumn{2}{|c|}{ Cases } & Controls \\
\hline & $\mathrm{N}$ & 181 & $\mathbf{N}(1)$ & $\mathrm{N}$ & $1 \div 1$ & $\mathrm{~N}(1)$ \\
\hline No telephone connection & 58 & $(23.7)$ & $100(20.6)$ & 38 & $(14.6)$ & $78(15.1)$ \\
\hline Refusers & 69 & $(28.2)$ & $123(25.4)$ & 88 & $(33.8)$ & $126(24.5)$ \\
\hline Participants & 118 & $(48.2)$ & $262(54.0)$ & 134 & $(51.5)$ & $311(60,4)$ \\
\hline Total & 245 & $(100.0)$ & $485(100.0)$ & 260 & $(100.0)$ & $515(100.0)$ \\
\hline
\end{tabular}

In the analysis of the collected data Odds Ratios $\mid O R)$ and confidence limits (two sided, $\alpha=0.05$ ) were calculated according to schlesselman ${ }^{19}$. The odds Ratio 
approximate: the relative risk under the condition that the prevalence of the disease is low in both the exposed and the non-exposed group. Furthermore, the on as such is a comonly used measure of the strength of the relationship between exposure and i.luness 20 .

1ogistic regression model was applied to adjust the cdds Ratios for potential confounding factors. Chi square test and student's t-test were used to analyse the significance of the differences between cases and controls with respect to some population characteristics.

\section{RESULTS}

The questionnaire was returned by 252 cases and 822 controls. The number of controls differs from the figure in Table 2, as new controls were selected to compensate for the non-response group within this population. The refusal rate within this additional control group remained more or less the same. The number of cases was limited to 505 during the study period, therefore the same procedure could not be applied to the cases population. Table 3 shows some characteristics of the study population, based on information collected by the questionnaires.

As can be seen from this table, cases and controls differ significantly with respect to several factors. For all cases and controls lincluding refusers and non-approachable personsl it was known from which organization they originated. probably inost persons occupationally exposed to organic solvents were members of the palnters organization, while most non-exposed persons originated from the construction workers organization. Table 4 shows a $2 \times 2$ Table, based on the assumptions that only members of the painters organization are exposed to organic solvents and al1 cases and controls lincluding refusers and non-approachable persons) participated in the study.

Furthermore, for all cases ICD-codes were available, whether or not they had participated in our study. This created the possibility to make a subdivision by type of neuropsychiatric disorder. Consequently unadjusted odds Ratios could be calculated for all cases and controls whether or not eventualy participating in the study. Using this approach the results as shown in Table 5 were calculated. 
Table 3: Characteristics of the study population.

\begin{tabular}{|c|c|c|c|c|}
\hline & \multicolumn{2}{|c|}{ Cases } & \multicolumn{2}{|c|}{ Controls } \\
\hline & $\mathbf{N}$ & 181 & $\mathrm{~N}$ & \筆】 \\
\hline Mean age (years) & \multicolumn{2}{|c|}{42.9} & \multicolumn{2}{|c|}{$35.5 *$} \\
\hline Divorced/widower & 26 & $(10.3)$ & 12 & $(1.5) *$ \\
\hline $\begin{aligned} \text { Education level: } & 1 \text { (low) } \\
2 \text { (medium) } & 3 \text { (high) }\end{aligned}$ & $\begin{array}{r}214 \\
32 \\
6\end{array}$ & $\begin{array}{l}(84.9) \\
(12.7) \\
(2.4)\end{array}$ & $\begin{array}{r}706 \\
103 \\
13\end{array}$ & $\begin{array}{l}(85.9) \\
(12.5) \\
(1.6)\end{array}$ \\
\hline $\begin{aligned} \text { Alcohol-intake: none } & \\
& <25 \text { consumptions/week } \\
& \geq 25 \text { consumptions/week }\end{aligned}$ & $\begin{array}{r}57 \\
175 \\
20\end{array}$ & $\begin{array}{l}(22.6) \\
(69.4) \\
(7.9)\end{array}$ & $\begin{array}{r}77 \\
661 \\
84\end{array}$ & $\begin{array}{l}(9.4) \\
(80.4) \\
(10.2)\end{array}$ \\
\hline Smoking & 211 & $(83.7)$ & 626 & $(76.2) *$ \\
\hline Positive family history of dementia & 17 & $(6.7)$ & 26 & $(3.2)$ \\
\hline Previous head trauma & 43 & $(17.0)$ & 88 & $(10.7) *$ \\
\hline $\begin{array}{l}\text { Other illnesses (diabetes, hypertension, } \\
\text { cardiovascul. dis., epilepsy, thyreoid } \\
\text { gland.) }\end{array}$ & 82 & $(32.5)$ & 97 & $(11.8) *$ \\
\hline Private stress & 117 & $(46.4)$ & 100 & $(12.2) *$ \\
\hline Work stress & 56 & $(22.2)$ & 27 & $(3.3)$ \\
\hline
\end{tabular}

$* p<0.05\left(x^{2}\right.$-test; student's t-test)

Table 4: Relationship between neuropsychiatric disorders and organization membership, assuming that only members of the palinters organization are exposed to organic solvents and all cases and controls participated in the study.

\begin{tabular}{llcc} 
& \multicolumn{3}{c}{ Neuropsychiatxic disorder } \\
\cline { 2 - 4 } & Yes & No & Total \\
\hline Painters Organization (exposed) & 245 & 485 & 730 \\
$\begin{array}{l}\text { Construction Workers Organization } \\
\text { (non-exposed) }\end{array}$ & 260 & 515 & 775 \\
Total & & & 1505 \\
\hline
\end{tabular}

$O_{R}=1.00(0.81-1.24)$ 
Table 5: Odas satios of ICD-codes of all cases, including non-response and nonapproachable group.

\begin{tabular}{|c|c|c|c|c|c|c|c|c|}
\hline \multicolumn{2}{|c|}{$\begin{array}{l}\text { Iov-codes of mental } \\
\text { disorders }\end{array}$} & \multicolumn{2}{|c|}{$\begin{array}{l}\text { Painters } \\
\text { Organization } \\
\text { (exposed) }\end{array}$} & \multicolumn{3}{|c|}{$\begin{array}{l}\text { Construction } \\
\text { workers Orga- } \\
\text { zation (non- } \\
\text { exposed) }\end{array}$} & \multirow[t]{2}{*}{ OR } & \multirow[t]{2}{*}{$\begin{array}{l}\text { Confidence } \\
\text { limits } \\
(\alpha=0.05)\end{array}$} \\
\hline & & $\mathrm{N}$ & (2) & $\mathbb{N}$ & & (8) & & \\
\hline 290 & Dementia & - & - & 2 & $i$ & 0.81 & - & - \\
\hline 296 & Affective psychosis & 5 & $(2.0)$ & 8 & 1 & $3.0)$ & 0.66 & $0.21-2.03$ \\
\hline 298 & $\begin{array}{l}\text { other non-organic } \\
\text { psychosis }\end{array}$ & 3 & $(1.2)$ & - & & - & - & - \\
\hline 300 & Neurotic digorders & 76 & $(3.1 .0)$ & 48 & 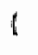 & 18.51 & 1.68 & $1.14-2.47$ \\
\hline 301 & Personality disorders & 8 & $(3.3)$ & 6 & 1 & 2.31 & 1.42 & $0.49-4.12$ \\
\hline 303 & $\begin{array}{l}\text { Alcohol dependence } \\
\text { syndrome }\end{array}$ & 9 & $(3.7)$ & 10 & 1 & 3.84 & 0.96 & $0.39-2.38$ \\
\hline 304 & Drug dependence & 4 & $(1.6)$ & 2 & 1 & 0.81 & 2.12 & $0.39-11.60$ \\
\hline 306 & $\begin{array}{l}\text { Physiological mall func- } \\
\text { tion arising from men- } \\
\text { tal disorders }\end{array}$ & 12 & $(5.0)$ & 14 & 1 & $5.4 j$ & 0.91 & $0.42-1.98$ \\
\hline 307 & Anorexia nervosa & 1 & $(0.4)$ & - & & - & - & - \\
\hline 309 & Adjustment reaction & 122 & $(49.8)$ & 157 & 1 & 60.41 & 0.83 & $0.63-1.09$ \\
\hline $3: 10$ & $\begin{array}{l}\text { Specific non-psychotic } \\
\text { mental disorders fol- } \\
\text { lowing arganic brain } \\
\text { damage }\end{array}$ & - & - & 1 & 1 & 0.41 & - & - \\
\hline 311 & $\begin{array}{l}\text { Depressive disorder, } \\
\text { not elsewhere classi- } \\
\text { fied }\end{array}$ & 5 & $(2.0)$ & 12 & 1 & $4.6)$ & 0.44 & $0.15-1.26$ \\
\hline $\begin{array}{l}\text { ICD } \\
\text { toris } \\
\text { inve } \\
\text { to } 1 \\
\text { vent } \\
311 \text { ) }\end{array}$ & $\begin{array}{l}\text { codes fitting the symp- } \\
\text { reported by other } \\
\text { stigators to be related } \\
\text { ong-term organic sol- } \\
\text { exposure }(300+309+\end{array}$ & 203 & $(82.9)$ & 217 & 1 & $83.5 !$ & 0.93 & $0.74-1.17$ \\
\hline Tota & 1 number of cases & 245 & $(100.0)$ & 260 & & 100.01 & 1.00 & $0.81-1.24$ \\
\hline Tota & 1 number of & 485 & & 515 & & & & \\
\hline
\end{tabular}


It appears that members of the painters organization are more often diagnosed with neurotic disorders (ICD 300). On the other hand some diagnoses (e.g. ICD 309: adjustment reactions) are more frequent among the construction workers population. Reviewing the relevant literature, persons suffering from syndromes reported by other investigators to be related to long-term organic solvent exposure will most likely be diagnosed as 300 (neurotic disorders), 309 (adjustment reactions) or 311 (depressive disorder, not elsewhere classified). A combination of these codes did not indicate an increased risk for possibly exposed persons to be disabled because of neuropsychiatric disorders.

Not all members of the painters organization are exposed to organic solvent le.g. administrative personnell. On the other hand exposure to organic solvents is encountered in quite some occupations within the construction industry. A high degree of exposure will certainly be present among painters, carpet layers, paint sprayers and road markers. Although persons from other occupations may also be exposed to organic solvents, their exposure was considered to be of little significance compared to the occupations mentioned above. Consequently all persons who worked or had worked as painter, car sprayer, carpet layer or road marker las stated in the questionnaire) were classified as exposed to organic solvents, while all other persons were classified as non-exposed.

Table 6 shows a $2 \times 2$ Table based on this classification.

Table 6: Relationship between neuropsychiatric disorders and exposure to organic solvents in our study population.

\begin{tabular}{lllcc}
\hline & \multicolumn{3}{c}{ Neuropsychiatric disorder } \\
\cline { 2 - 4 } & Yes & No & Tota d. \\
\hline \multirow{2}{*}{ Exposure to organic solvents: Yes } & 117 & 379 & 496 \\
& No & 135 & 443 & 578 \\
\cline { 2 - 5 } & & & 822 & 1074 \\
\hline
\end{tabular}

$\mathrm{OR}=1.01(0.76-1.34 \mathrm{~J}$

Here again Odds Ratios could be calculated for different types of neuropsychiatric disorders (Table 7). 
mable 7: Oads Ratios of dianostic codes of the participants.

\begin{tabular}{|c|c|c|c|c|c|c|c|}
\hline \multirow{2}{*}{\multicolumn{2}{|c|}{$\begin{array}{l}\text { ICD-codes of mental } \\
\text { disorders }\end{array}$}} & \multicolumn{2}{|c|}{ Exposed } & \multicolumn{2}{|c|}{ Non-exposed } & \multirow{3}{*}{$\frac{\text { OR }}{2.92}$} & \multirow{3}{*}{$\begin{array}{l}\text { Confidence } \\
\text { limits } \\
(\alpha=0.05) \\
0.56-5.13\end{array}$} \\
\hline & & \multirow{2}{*}{$\frac{1}{5}$} & \multirow{2}{*}{$\frac{(8)}{(4.3)}$} & \multirow{2}{*}{$\frac{W}{2}$} & \multirow{2}{*}{$\frac{(1)}{(1.5)}$} & & \\
\hline 296 & Affective psychosis & & & & & & \\
\hline 298 & $\begin{array}{l}\text { other non-organic } \\
\text { psychos is }\end{array}$ & 1 & $(0.8)$ & - & - & - & - \\
\hline 300 & Neuratic disorders & 38 & $(32.5)$ & 23 & $(17.0)$ & 1.93 & $1.13-3.30$ \\
\hline 301 & Pergonality disorders & 4 & $(3.4)$ & 2 & $(1.5)$ & 2.34 & $0.43-1.2 .85$ \\
\hline 303 & $\begin{array}{l}\text { Alcohol dependence } \\
\text { syndrome }\end{array}$ & 4 & $(3.4)$ & 5 & $(3.7)$ & 0.94 & $0.25-3.53$ \\
\hline 304 & Drug dependence & 2 & $(1.7)$ & 0 & $(0.01$ & - & - \\
\hline 306 & $\begin{array}{l}\text { Physiological malfunc- } \\
\text { tion arising from men- } \\
\text { tal disorders }\end{array}$ & 5 & $(4.3)$ & 12 & $(8.9)$ & 0.49 & $0.17-1.40$ \\
\hline 307 & Anorexia nervosa & $\mathbb{1}$ & $(0.8)$ & - & - & - & - \\
\hline 309 & Adjustment reaction & 54 & $(46.2)$ & 85 & $(63.0)$ & 0.74 & $0.51-1.07$ \\
\hline 310 & $\begin{array}{l}\text { Specific non-psychotic } \\
\text { mental disorders fol- } \\
\text { lowing organic brain } \\
\text { damage }\end{array}$ & - & - & 1 & $(0.7)$ & - & - \\
\hline 311 & $\begin{array}{l}\text { Depressive disorder, } \\
\text { not elsewhere classi- } \\
\text { Eied }\end{array}$ & 3 & $(2.6)$ & 5 & $(3.7)$ & 0.70 & $0.17-2.95$ \\
\hline $\begin{array}{l}\text { ICD } \\
\text { toms } \\
\text { inve } \\
\text { to } 1 \\
\text { axpo }\end{array}$ & $\begin{array}{l}\text { codes fitting the symp- } \\
\text { reported by other } \\
\text { stigators to be related } \\
\text { ong-term organic solvent } \\
\text { sure }(300,309,311)\end{array}$ & 95 & $(81.2)$ & 113 & $(83.7)$ & 0.98 & $0.72-1.33$ \\
\hline Tota & 1 number of cases & 117 & $(100.0)$ & 135 & 1100.09 & 1.01 & $0.76-1.34$ \\
\hline moted & 1 number of controls & 379 & & 443 & & & \\
\hline
\end{tabular}

In general, Table 6 and Table 7 show the same results as appearing from Table 4 and 5. A combination of all ICD-codes does not indicate an increased risk for exposed persons to be disabled because of neuropsychiatric disorders, but the subdivision of neuropsychiatric disorders suggests an association between neuro- 
tic disorders and exposure to organic solvents.

In order to adjust the or for the influence of several confounding factors, a logistic regression analysis was conducted, including 6 variables lage, education level, marital status, alcohol intake, smoking and Quetelet-indexh. Other potential confounders (family history of dementia, head trauma, other diseases) did not change the oR. Inclusion of the variable "stress" in the logistic regression model decreased the OR. Apparently stress is wery strongly associated with mental disorders. Because it can not be excluded that stress is rather a result than a cause of neuropsychiatric disorders, stress was finally not included in the logistic regression model. Table 8 shows the adjusted or for several (groups of) ICD-codes.

Table 8: Odds Ratios for several (groups of) ICD-codes adjusted for differences in age, education level, marital status, smoking, alcohol consumption and quetelet-index.

$\begin{array}{lll}\text { ICD } 300 & 2.30 & 1.19-4.08 \\ \text { ICD } 309 & 0.86 & 0.57-1.29 \\ \text { ICD } 300+309+311 & 1.16 & 0.82-1.63 \\ \text { AIl ICD-COdes } & 1.17 & 0.85-1.61\end{array}$

As can be seen from this Table adjustment for confounding factors results in at slight increase of the Dads Ratios, without altering the trends as appearing from previous Tables.

\section{DISCUSSION}

This study was conducted in order to investigate whether Dutch painters compared to other construction workers are at increased risk for disability due to neuropsychiatric disorders. The results of this study do not confirm, but do also not exclude, the existence of such a risk among painters. While interpreting these 
results it must be kept in mind that several potential sources of bias may have affected the regults of this case-control study. In view of the existence of a large non-response group, a considerable amount af selection bias may have occurred. Yet, the similarity in regults between Table 5 and Table 7 indicates that bias, perhaps introduced by selective non-response, did not essentially affected the results of our study. The classification of neuropsychiatric disorders by social security physician may be a source of potential classification bias. The physicians who grant benefits to insured disabied persons are no psychiatrists and diagnostic difficulties thay easily arise in the field of neuropsychiatric disordess. For example, it is often difficult to distinguish between a "normal" and "disproportionate" reaction to disstressing experience (ICD $309 \mathrm{VS}$. ICD 300). Therefore we can not rule out the possibility that the established relationship between exposure to organic solvents and neurotic disorders is merely the result of "misclassification" bias due to information bias. The results of a further analysis into this relationship are described in chapter 7.

It is of interest to compare our results with the scandinavian case-control studies investigating the same topic, i.e. the relationship between exposure to organic solvents and premature disability due to neuropsychiatric disorders. Axeison et al ${ }^{11}$ and olsen and Sabroe ${ }^{12}$ detected an increased risk for all nonspecific mental disorders, while Lindström et al ${ }^{13}$ could only demonstrate an increased risk among solvent exposed workers for developing neurotic disorders. Although the results of our study resembles Lindströn's study, the strength of the association differs considerably $(O R=2.3$ vs. $O R=5.5)$.

various hypothesis can be postulated that may explain the differences in results between this study and the Scandinavian studies. First it must be noted that the disability pension systems for scandinavian countries and The Netherlands are not identical, with as a possible result some kind of selection bias, which may be responsible for the contradictory results.

Secondly, the control group in the Scandinavian studies consisted of persons receiving disability benefits for reasons other than neuropsychiatric disorders. This choice has been criticized ${ }^{21}$. If some non-solvent occupations are more physically demanding, leading to more disability benefits for instance due to musculo-skeletal disorders, a relative underrepresentation of solvent exposed workers will occur in the control group. Consequently, the calculated oR will artificially increase. Although there were indications in the Scandinavian studies that disorders form the musculoskeletal system had been at least as common among painters as among construction workers, we clearly avoided this hypothetical pitfall by selecting healthy persons, receiving no disability benefits, as controls. 
Thirdy in this study a case was defined as a person receiving benefits coded in the broad category of "neuropsychiatric disorders", while the scandinavian epidemiologists used a more restrictive selection of ICD-codes. However, in view of the classification difficulties arising in this diagnostic area and the vague symptoms associated with long-term organic solvent exposure, it is difficult to decide which ICD-codes should be excluded from the study. Therefore it is not desirable to exclude a priori certain ICD-codes in this type of study design. Additonal support for this view is derived from our study results. The statistically association between neurotic disorders and organic solvent exposure disappeared after a combination was made of various ICD-codes fitting the symptoins reported by other investigators to be related to long-term organic solvent exposure.

Finally, it is possible that Scandinavian painters really are more at risk for neuropsychiatric disorders than Dutch painters. At the moment quite some attention is paid in the Scanainavian countries to reduce the exposure of workers to arganic solvents. However, it is possible that in the past exposure to organic solwents has been very high in these countries because of differences in working conditions.

An advantage of this study compared to most scandinavian studies is the possibility to use more extensive information about several potential confounding factors, as collected by the questionnaires. To control confounding a logistic regression model was used. A remarkable observation concerns the drop of the OR after inciusion of "stress" in the model. It can not be ruled out that stress is the result, rather than the cause of the development of neuropsychiatric disorders. On the other hand we may hypothesize that exposure to organic solvents reduces the ability to cope with stress and thus leads to more disproportionate reactions to distressing experiences among solvent exposed workers. Consequentiy, this hypothesis could perhaps explain the relationship between organic solvent exposure and neuroses, as appearing from this study.

In spite of some improvements in our study design compared to the scandinavian studies, we realize that still objections can be put foreward against this study. Assessment of exposure to organic solvents was merely based on occupational history and no exact quantitative data on this exposure were available. At the moment an analysis is in progress to investigate dose-response relationships within our study population, using supplementary and more detailed information from the questionnaires of exposure to organic solvent of the participants. Results of this analysis are described in Chapter 6.

Furthermore, broad case definitions were used which included a variety of neuro- 
psychiatric disorders. However, more restrictive case-definitions could be used in the andysis by calculating odds Ratios for different (groups of) ICD-codes.

Motw thstanding the above mentioned shortcomings we conclude that our study results suggest that butch painters have no substantially increased risk for being prematurely disabled due to neuropsychiatric disorders. However, facing the fact that misclassification might have occurred both for exposure and diagnoses, the existence of a (small) increased risk among painter to be prematurely disabled due to neuropsychiatric disorders, especially with respect to neurotic disorders, can not be excluded. Furthermore, mild manifestations of organic solvent intoxication do perhaps not lead to prolonged disability and disability benefits. Therefore, the results of this study do not rule out the possibility of the existence of chronic neurotoxic effects, e.g. manifestated by the occurrence of neurasthenic symptoms, due to exposure to organic solvents occurring in the painting industry. A further analysis of neurasthenic symptoms among workers exposed to organic solvents is presented in chapter 8.

\section{REFERENCES}

1. Grasso P, Sharrat M, Davies DM, Irvine D. Neuropsychological disorders and occupational exposure to organic solvents (review section). FD Chem Toxic $1984 ; 22: 819-852$.

2. Anselm-01sen B. Effects of Organic Solvents on Behawioral Performance of Workers in the paint Industry. Neurobehavioral Toxicology and Tetratology 1982 ; 4: 703-708.

3. Elofgson SA, Gamberale F, Hindmarsh T, Iregren A, Isaksson A, Johnsson J, Knave B, LydahI E, Mindus $\mathbb{P}$, Persson HE, Philipson B, Steby M, Struwe G, Soderman E, Wennberg $A$, Widén L. Exposure to organic solvents. A cross-sectional epidemiological investigation on occupational exposed car and industrial spray painters with special reference to the nervous system. Scand $J$ Work Environ Health 1980; 6: 239-273.

4. Hane H, Axelson O, Blume J, Hogstedt C, Sundell L, Ydreborg B. Psychological function changes among house painters. Scand J Work Environ Health 1977; 3 : $91-99$. 
5. Hänninen $\mathrm{H}$, Eskelinen $\mathrm{L}$, Husman $\mathrm{K}$, Nurminen $\mathrm{M}$. Behavioral effects of longterm exposure to a mixture of organic solvents. Scand J Work Environ Health 1976: 4: 240-255.

6. Orbaek $P$, Risberg J, Rosén I, Haeger-Aronson $B$, Hagstadius $S$, Hjortsberg U. Regnell $G$, Rehnström $S$, Svensson $K$, Welinder $F$. Effects of long-term exposure to solvents in the paint industry. A cross-sectional epidemiological study with clinical and laboratory methods. Scand J Work Environ Health 1985; 11: 2.

7. Seppäläinen AM. Applications of neurophysiological methods in occupational medicine. Scand J Work Environ Health 1975; 1: 1-14.

8. Seppäläinen AM, Husman K, Martenson C. Neurophysiological effects of longterm exposure to a mixture of organic solvents. Scand I Work Environ Health $1978 ; 4: 304-314$.

9. Cherry $N$, Autchins $H$, Pace $T$, Waldron HA. Neurobehavioral effects of repeated occupational exposure to toluene and paint solvents. Br J Ind Med 1985; 42: 291-300.

10. Husman K. Symptoms of car painters with long-term exposure to a mixture of organic solvents. Scand $J$ work Enwiron Health 1980; 6: 19-32.

11. Axelson 0 , Hane $M$, Hogstedt $C$. A case-referent study on neuropsychiatric disorders among workers exposed to solvents. Scand J Work Environ Health 1976 ; 2: $14-20$.

12. Olsen J, Sabroe $S$. A case-reference study on neuropsychiatric disorders among workers exposed to solvents in the Danish wood and furniture industry. Sicand I Soc Med 1980; 16: 44-49.

13. Lindström $K$, Riihimăki $H$, Hänninen $K$. Occupational solvent exposure and neuropsychiatric disorders. Scand J work Environ Health $1984 ; 10: 321-323$.

14. Mikkelsen $S$. A cohort study of disability pension and death among painters with special regard to disabling presenile dementia as accupational disease. Scand J Soc Med 1980; 16: $34-43$.

15. Cherry N, Waldron HA. The Prevalence of Psychiatric Morbidity in Solvent workers in Britain. Int J Epidem 1984; 13: 197-200.

16. Triebig G, Claus D, Csuzda $I$, Druschky KF, Holler p, Kinzel $w$, Lehrl $S$, Reichwein P, Weidenhammer $W$, Weitkriecht wU, Weltle D. Erlanger Malerstudie. Multidisziplinåre Querschnittsuntersuchung zur Neurotoxizität von Lösemitteln in Farben und Lacken. ASP - Sonderheft 1986; 9: 1-45.

17. Scheffers TML, Jongeneelen FJ. Arbeidshygiënisch onderzoek naar de blootste1ling van onderhoudsschilders aan oplosmiddelen. Stichting Bedrijfsgezondheidsdienst voor de Bouwnijverheid, Amsterdam, 1981. 
18. Doorgeest T, Meijer PB, Mit de G. Chronische effecten tengevolge van blootateling aan organische oplosmiddelen. Literaturonderzoek, s 29-1. Directoraat-General van de Arbeid, Voorburg, 1986.

19. Schlesselman JJ. Cage-control studies. Design, conduct, analysis. Oxford University Press, New York, 1982.

20. Wilienfeld AM, Lilienfeld DE. Foundations of epidemiology, 2nd ed. Oxford University Press, New York, Oxford, 1980.

21. Hogstedt $C$, Axelson 0 . Long-term health effects of industrial solvents - a critical review of the epidemiological research. Med Lav $1986 ; 77,1: 11-22$. 
CHAPTER 6

DOSE-RESPONSE RELATIONSHIPS BETWEEN ORGANIC SOLVENT EXPOSURE AND NEUROPSYCHIATRIC DISORDERS: RESULTS FROM A DUTCH CASE-CONTROL STUDY*

C van Vliet ${ }^{1}$, GMH Swaen ${ }^{1}$, A Volovies ${ }^{2}$, JJM Slangen ${ }^{1}$, JMM Meljers ${ }^{1}$, Tj de Boorder $^{1}$, F sturmans ${ }^{3}$

1 Dept. of Occupational and Envirommental Health and Toxicology, University of Limburg, PO Box 616, 6200 MD Maastricht, The Netherlands.

2 Dept. of Biostatistics, University of Limburg.

3 Dept. of Epidemiology, University of Limburg. 
ABSTRACT

In this article the material collected for a case-control study is analysed in order to evaluate the existerce of dose-response relationships between organic solvent exposure and the entitement to disability benefits due to neuropsychiatric disorders.

Questionalies were used to collect information on 252 cases receiving compensation due to neuropsychiatric disorders and 822 controls about their occupational history and work practices related to organic solvent exposure. In order to estimate the exposure to organic solvents three exposure indices were used: duration of expogure, painters index and general exposure index. The analysis showed some tendencies indicating positive dose-response relationships. Futhermore some work practices and working conditions associated with high exposure to organic solvents (e.g. poor véntilation, using paint removers) resulted in a marked increase of the risk for receiving disability benefits due to neuropsychiatric disorders.

INTRODUCTION

Several studies indicating chronic neuratoxic effects due to long-term occupational exposure to organic solvents have been published since the early $1970 \mathrm{~s}^{1}$. In spite of this research, there is no international agreement about the nature and the elassifications of disorders thought to be related to organic solvent exposure 2,3 . Furthermore, still a number of other important questions remain unanswered. The underiying pathogenesis is unclear and requires further study ${ }^{3,4}$. Another puzzling issue is the lack of consistent dose-response relationships in epldemiological studies investigating chronic neurotoxic effects of organic solvent exposure 4,5 . If a risk factor is of causal importance in a disease, the risk of developing this disease showld be related to the degree of exposure to this factor, that is, a dose-response relationship should exist ${ }^{6}$. Application of this axiom to long-term neurotoxic effects of organic solvent exposure brings to light conflicting results. The number of neurasthenic symptoms reported in solvent exposed workers was sometimes observed to be related to the degree of solvent exposure ${ }^{7-10}$, while other studies did not confirm such a relationship $5 \cdot 11-15$ 
In neuropsychological tests, the performance of solvent exposed workers was generally not correlated with the duration or degree of solvent exposure $5,10,12,14$, 16-18. However, recent studies suggest a possible dose-response relationship between organic solvent exposure and intellectual impairment 19,20 .

A number of case-control studies investigating the award of disability benefits due to mental disorders among solvent exposed workers docunented varying results. Axelson et $a^{21}$ and olsen and Sabroe ${ }^{22}$ demonstrated indications of a dose-response relationship in terms of an increased risk for persons with longer or higher expasure to organic solvents. On the other hand, Lindström et al 23 could not demonstrate such a correlation. Finaliy, the general prognosis of scandinavian workers, diagnosed as suffering from an "organic solvent syndrome", was not related to their former degree of solvent exposure $17,24,25$.

More recently, various authors suggest that the development of an orgaric solvent syndrome may only occur after approximately ten years of solvent exposure or after repeated periods of acute intoxication ${ }^{9,26-28}$.

From all of the above it is clear that uncertainty remains with regard to the existence of neurotoxic effects due to organic solvent exposure. studies investigating dose-response relationships are hampered by the lack of exact qualitative or quantitative data on solvent exposure and the fact that most workers (e.g. painters) are exposed to a mixture of organic solvents.

Recently a case-control study in The Netherlands investigated whether Dutch painters were at increased risk of developing mental disorders. Overall no relationship was detected between organic solvent exposure and the risk of receiving disability benefits due to neuropsychiatric disorders. However, in that initial analysis exposure was merely defined as "present" or absent".

In this study more detailed information on exposure to organic solvents of the participants, as collected by questionnaires, is analysed in order to evaluate the existence of dose-response relationships between organic solvent exposure and neuropsychiatric disorders with disability benefits entitlement.

\section{MATERIAL AND METHODS}

The study material consisted of information from questionaires as collected in a recently carried out case-control study. From the Dutch Painters and Construction Workers Organizations cases and controls have been selected. Cases were de- 
Ined as nales awarded disability benefits due to neuropsychiatric disorders between 01-07-1984 and 01-07-1986. In whe Netherlands payment of disability benefits is considered after 52 weeks of $i 11$ ness. Diagnoses of persons receiving disability benefits are made by social security physicians. These diagnoses were coded by expert nosologists according to a list based on the 9 th rewision of the International Classification of Diseases. Mental disorders are grouped in categories, which have all been included in the study. Table 1 shows the ICD-codes of the cases included in our analysis.

Table 1: ICD-codes of cases included in the analysis of dose-response relationships.

\begin{tabular}{|c|c|c|c|}
\hline \multicolumn{2}{|c|}{ ICD-Codes } & \multirow{2}{*}{$\frac{\text { N }}{7}$} & \multirow{2}{*}{$\frac{(8)}{(2.8)}$} \\
\hline 296 & Affective psychosis & & \\
\hline 298 & other non-organic psychosis & 1 & $(0.4)$ \\
\hline 300 & Neuratic disorders & 61 & $(24.2)$ \\
\hline 301 & Personality disorders & 6 & $(2.4)$ \\
\hline 303 & Alcohol dependence syndrome & 9 & $(3.6)$ \\
\hline 304 & Drug dependence & 2 & $(0.8)$ \\
\hline 3.06 & Physiological malfunction arising from mental disorders & 17 & $(6.7)$ \\
\hline 307 & Special symptoms or syndromes not elsewhere classified & 1 & $(0.4)$ \\
\hline 309 & Adjustment reaction & 139 & $(55.2)$ \\
\hline 310 & $\begin{array}{l}\text { Specific non-psychotic mental disorders following } \\
\text { organic brain damage }\end{array}$ & 1 & $(0.4)$ \\
\hline 311 & Depressive disorder, not elsewhere classified & 8 & $(3.2)$ \\
\hline & Total & 252 & $(100.0)$ \\
\hline
\end{tabular}

The control population consisted of a random sample of males from the Dutch Painters and Construction workers organizations. Participants received a questionnaire that asked about their occupational history, health complaints and work practices related to organic solvent exposure. Potential confounding factors, such as alcohol intake, education level and stress factors were also examined. In order to estimate the exposure of the participants to organic solvents, three exposure indices were used:

1. The duration of exposure index.

occupational exposure to organic solvents is encountered in many occupations 
within the construction industry. A high degree of exposure exists for painters, carpet layers, paint sprayers and road markers. The number of years worked in one of the above mentioned occupations determined this index.

2. Painters index.

The exposure to organic solvents of an individual painter will depend on his work activities and working conditions. Some work activities, such as paint spraying, using alkyd paints and paint removers, lead to high exposure to organic solvents ${ }^{29}$. Respondents were asked to indicate on a four point scale how often they were involved in the above mentioned painting practices. Furthermore a division was made between current and past situations. The scores for each item $(1,2,3$ or 4$)$ were added up, attributing equal weights to the answers concerning the past and the current situation, to create the value of the painters index. Higher values of this exposure index were thought to indicate higher levels of exposure to arganic solvents.

3. General exposure index.

As mentioned, exposure to organic solvent is not restricted to painters, carpet layers and road markers. Therefore all respondents were asked about the use of paint removers, organic solvents, glues and degreasing agents ii.e. substances probably containing organic solvents). Further, it was asked whether they had worked in one room with painters or carpet layers, hence being simultaneously exposed to organic solvents. Here again a division was made between the current and the past situations. Questions were scored and summed in the same way as the painters index. The total score was thought to be indicative for the exposure to organic solvents of each worker, whether or not he was directly involved in painting activities.

In adition to the exposure indices, information was collected about several other work practices and working conditions of painters. The exposure indices and additional information about painting activities were used to define the "dose" of organic solvent exposure, while the "response" was defined as neuropsychiatric disorders with disability entitlement.

To describe the dose-response relationships mathematical equations were drawn up using logistic regression analysis. Correction for six potential confounding factors (age, education level, marital status, alcohol intake, smoking and Queteletindex) was performed by using the same technique. Odds ratios (OR) and confidence limits were calculated according to schlesselman ${ }^{30}$. The OR is a common neasurement of the strength of the relationship between exposure and illness. 
FESULTS

There were 252 cases (response: 61.6 ) and 822 controls (response: 69.7 ) who participated in our study by returning completed questionnaires. $46.4 \%$ of the cases and 46.1\% of the controls had or had ever worked as a painter, carpet layer or road marker. The mean exposure duration was 20.6 (SD 11.6) years for the cases and 15.6 (SD 10.7) years for the controls. Dose-response relationships were analysed and correction for confounders was performed by applying logistic regression techniques. The results of this analysis are graphically represented by relating each walue of the exposure index under study to the corresponding estimated value of the or.
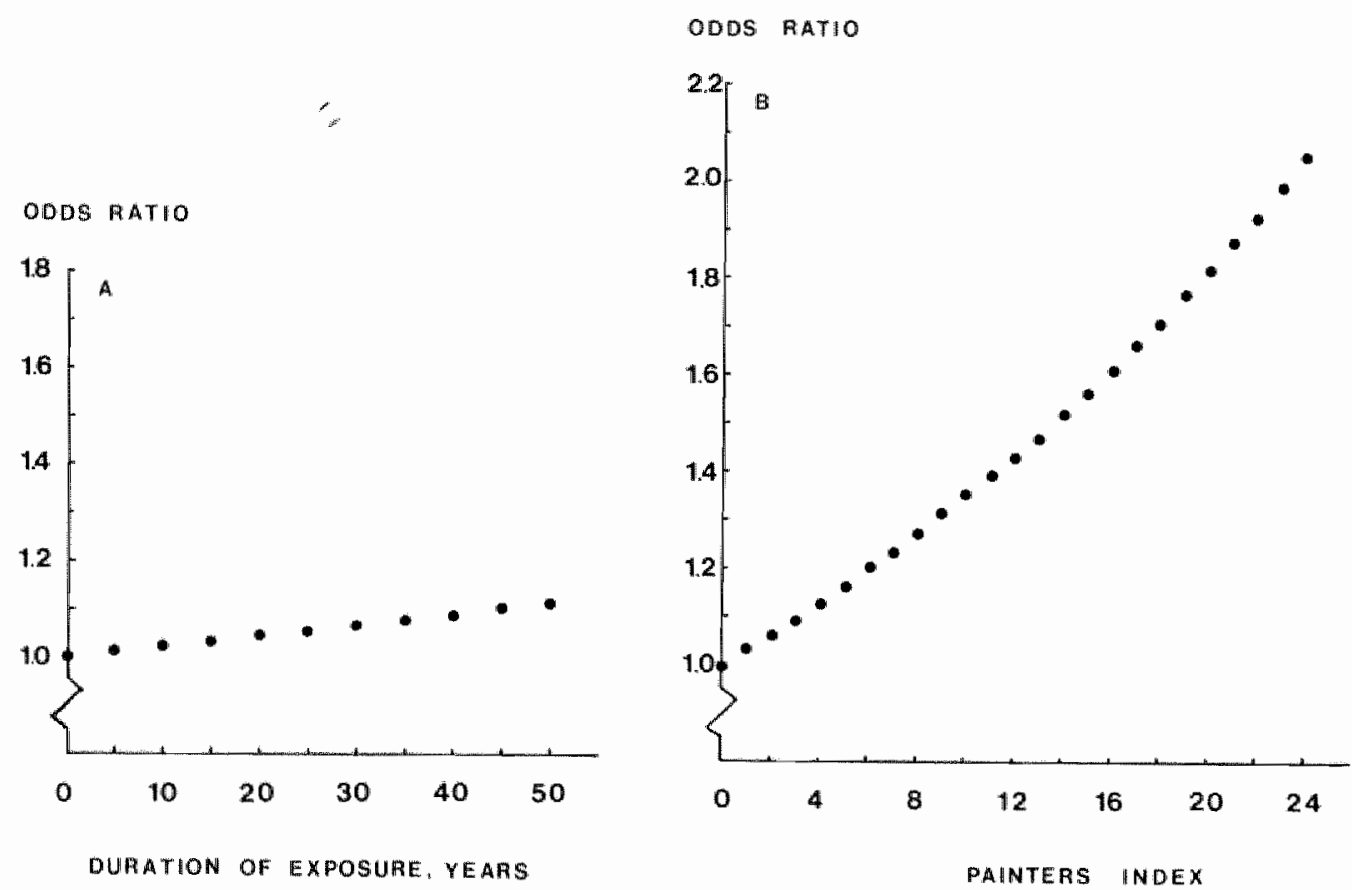

Figure A: Dose-response relationship between duration of exposure (years worked as painter, carpet layer or road marker) and the risk for receiving disability benefits due to neuropsychiatric disorders.

Fiqure B: Dose-response relationship between the painters index and the risk for receiving disability benefits due to neuropsychiatric disorders. 
Figure shows the dose-response relationship for duration of exposure. There is only a small increase of the oR as the duration of exposure increases. This relationship is not statistically significant $(p<0.60)$. An analysis for four different groups of painters (new building, maintenance, construction and "other" painters) revealed no positive dose-response relationship regarding duration of exposure. The relationship between the painters index and the odds Ratio is graphically represented in Figure $B$. In this case a higher walue of the exposure index is accompanied by a steady increase in the oR, indicating a positive dose response relationship ( $\leq 0.05$ ).

ODDS FATHO

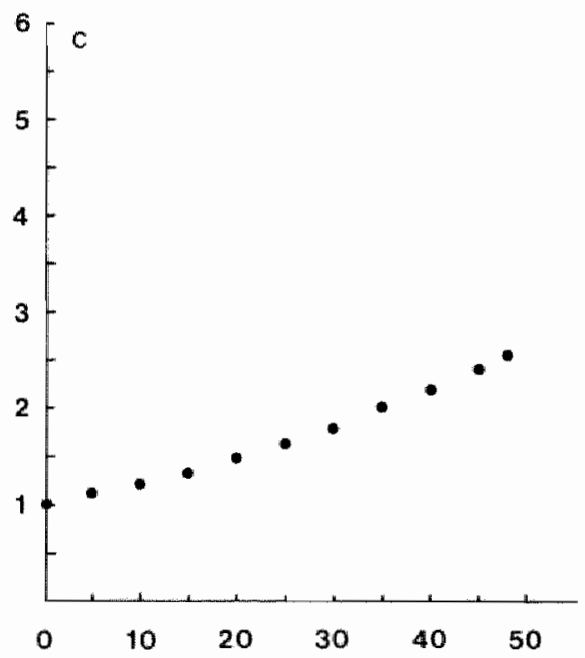

GENERAL EXPOSURE INDEX
ODDS ARTIO

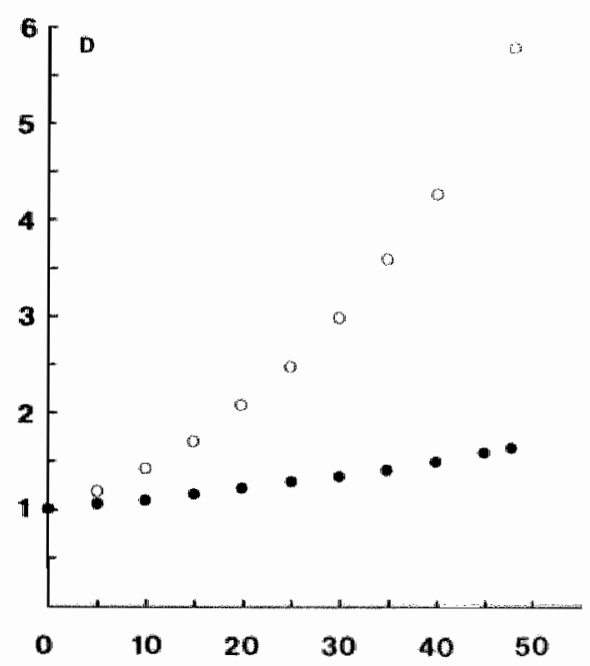

GENERAL. EXPOSUAE INDEX

Figure C: Dose-response relationship between the general exposure index and the risk for receiving disability benefits due to neuropsychiatric disorders.

Figure D: Dose-response relationship of the general exposure index, separately analysed for painters $(0)$ and construction workers $(\bullet)$. 
Plgure $c$ shows the dose-response relationship for the general exposure index. Although this curve also demonstrates a positive trend, the statistical significance of this dose-response relationship is of a lower level (p 60.08$)$. This general exposure index was calculated for all study subjects, whether or not they had been working in one of the above defined solvent exposed occupations.

The relationship between the general exposure index and neuropsychiatric disorders with disability benefits entitlement was separately analysed for painters and for construction workers. The results are shown in Figure D. It appears from this analysis that the strength of the dose-response relationship among the painters $1 \mathrm{~s}$ increased $(\mathrm{p}<0.05)$, while the relationship in the contruction workers is considerably weaker $(p<0.70)$, compared with the results of the combined analysis (Figure $C$.

Table 2 shows the frequency distribution of the painters index and the general exposure index, indicating that high values of these exposure indices are only present among a smáll group of painters and construction workers.

Table 2: Frequency distribution of the painters index and the general exposure index.

\begin{tabular}{rrrrrr}
\hline $\begin{array}{l}\text { Painters index } \\
(\mathbb{N}=496)\end{array}$ & $\mathrm{n}$ & $(8)$ & $\begin{array}{l}\text { General exposure index } \\
(\mathrm{N}=1074)\end{array}$ & $\mathrm{n}$ & (\$) \\
\hline $0-8$ & 203 & $(40.9)$ & $0-20$ & 629 & $(58.6)$ \\
$9-16$ & 281 & $(56.7)$ & $21-30$ & 377 & $(35.1)$ \\
$17-24$ & 12 & $(2.4)$ & $31-40$ & 58 & $(5.4)$ \\
& & & $41-48$ & 10 & $(0.9)$ \\
\hline
\end{tabular}

As described in "Material and Methods", the painters index was based on information of the particlpants about their involvement in work practices with high solvent exposure. However, the choice of the painters activities included in this index was rather crude. Other factors, e.g. the use of respirators and the workplace ventilation, shall also influence the exposure of workers to organic solvents.

Furthermore, other chemical exposures, e.g. lead, associated with other painting activities are associated with chronic neurotoxic effects. On the other hand it is of interest to examine which components of the painters index contributed most to the positive trend of this dose-response relationship. 
Table 3: Odds Ratios of painters activities compared to the non-exposed group. adjusted for differences in age, education level, marital status, smoking, alcohol consumption and puetelet-index.

\begin{tabular}{|c|c|c|c|c|c|c|}
\hline & & & at present" & & "earli & iex" \\
\hline & & OR & $\begin{array}{l}\text { (Confidence } \\
\text { limits, } \\
\alpha=0.05)\end{array}$ & OR & $\begin{array}{l}\text { IConf } \\
\operatorname{limi} \\
\alpha=\end{array}$ & $\begin{array}{l}\text { Eidence } \\
\text { its, } \\
0.051\end{array}$ \\
\hline Latex paints & $\begin{array}{l}\leq 1 \mathrm{day} / \text { week } \\
>1 \mathrm{day} / \text { week }\end{array}$ & $\begin{array}{l}0.97 \\
1.68\end{array}$ & $\begin{array}{l}(0.67-1.41) \\
(1.10-2.58)\end{array}$ & $\begin{array}{l}0.95 \\
1.80\end{array}$ & $\begin{array}{l}10.64 \\
11.19\end{array}$ & $\begin{array}{l}-\quad 1.381 \\
-\quad 2.731\end{array}$ \\
\hline Alkyd paints & $\begin{array}{l}\leq 1 \mathrm{day} / \text { week } \\
>1 \mathrm{day} / \text { week }\end{array}$ & $\begin{array}{l}1.29 \\
1.08\end{array}$ & $\begin{array}{l}(0.89-1.88) \\
(0.71-1.64)\end{array}$ & $\begin{array}{l}1.18 \\
1.30\end{array}$ & $\begin{array}{l}10.81 \\
10.85\end{array}$ & $\begin{array}{l}-1.721 \\
-\quad 1.981\end{array}$ \\
\hline Epoxy paints & $\begin{array}{l}\leq 1 \mathrm{day} / \text { week } \\
>1 \mathrm{day} / \text { week }\end{array}$ & $\begin{array}{l}1.17 \\
1.36\end{array}$ & $\begin{array}{l}(0.84-1.64) \\
(0.70-2.64)\end{array}$ & $\begin{array}{l}1.15 \\
1.77\end{array}$ & $\begin{array}{l}10.82 \\
10.96\end{array}$ & $\begin{array}{l}-\quad 1.601 \\
-\quad 3.287\end{array}$ \\
\hline "other" paints & $\begin{array}{l}\leq 1 \text { day/week } \\
>1 \text { day/week }\end{array}$ & $\begin{array}{l}1.12 \\
1.47\end{array}$ & $\begin{array}{l}(0.79-1.58) \\
(0.88-2.43)\end{array}$ & $\begin{array}{l}1.04 \\
1.91\end{array}$ & $\begin{array}{l}10.73 \\
11.17\end{array}$ & $\begin{array}{l}-\quad 1.481 \\
-\quad 3.11\rangle\end{array}$ \\
\hline Paint brushing & $\begin{array}{l}\leq 1 \mathrm{day} / \text { week } \\
>1 \mathrm{day} / \text { week }\end{array}$ & $\begin{array}{l}2.77 \\
1.04\end{array}$ & $\begin{array}{l}(1.47-5.22 \\
(0.74-1.45)\end{array}$ & $\begin{array}{l}2.12 \\
1.15\end{array}$ & $\begin{array}{l}11.03 \\
10.82\end{array}$ & $\begin{array}{l}-4.321 \\
-\quad 1.591\end{array}$ \\
\hline Paint rolling & $\begin{array}{l}\leq 1 \mathrm{day} / \text { week } \\
>1 \mathrm{day} / \text { week }\end{array}$ & $\begin{array}{l}0.94 \\
1.69\end{array}$ & $\begin{array}{l}(0.65-1.38) \\
(1.11-2.56)\end{array}$ & $\begin{array}{l}1.06 \\
1.70\end{array}$ & $\begin{array}{l}10.74 \\
11.08\end{array}$ & $\begin{array}{l}-1.511 \\
-\quad 2.681\end{array}$ \\
\hline Paint spraying & $\begin{array}{l}\leq 1 \mathrm{day} / \text { week } \\
>1 \mathrm{day} / \text { week }\end{array}$ & $\begin{array}{l}1.16 \\
1.65\end{array}$ & $\begin{array}{l}(0.84-1.61) \\
(0.75-3.59)\end{array}$ & $\begin{array}{l}1.10 \\
2.56\end{array}$ & $\begin{array}{l}10.79 \\
11.32\end{array}$ & $\begin{array}{l}=1.541 \\
-\quad 4.94)\end{array}$ \\
\hline Scouring off paints & $\begin{array}{l}\leq 1 \times / \text { week } \\
>1 \times / \text { week }\end{array}$ & $\begin{array}{l}1.32 \\
1.12\end{array}$ & $\begin{array}{l}(0.86-2.03) \\
(0.78-1.63)\end{array}$ & $\begin{array}{l}1.14 \\
1.27\end{array}$ & $\begin{array}{l}10.71 \\
0.89\end{array}$ & $\begin{array}{l}-1.841 \\
-\quad 1.801\end{array}$ \\
\hline Burning off paints & $\begin{array}{l}\leq 1 \times / \text { week } \\
>1 \times / \text { week }\end{array}$ & $\begin{array}{l}1.03 \\
1.73\end{array}$ & $\begin{array}{l}(0.73-1.47) \\
(1.08-2.77)\end{array}$ & $\begin{array}{l}0.89 \\
1.88\end{array}$ & $\begin{array}{l}10.60 \\
11.25\end{array}$ & $\begin{array}{l}-1.31) \\
-\quad 2.831\end{array}$ \\
\hline Paint removers & $\begin{array}{l}\leq 1 \times / \text { week } \\
>1 \times / \text { week }\end{array}$ & $\begin{array}{l}1.08 \\
1.87\end{array}$ & $\begin{array}{l}(0.77-1.52) \\
(1.07-3.29)\end{array}$ & $\begin{array}{l}0.93 \\
2.22\end{array}$ & $\begin{array}{l}10.65 \\
11.41\end{array}$ & $\begin{array}{l}-1.34) \\
-\quad 3.51)\end{array}$ \\
\hline Respirators & $\begin{array}{l}\leq 1 \times / \text { week } \\
>1 \times / \text { week }\end{array}$ & $\begin{array}{l}1.16 \\
1.42\end{array}$ & $\begin{array}{l}(0.84-1.62) \\
(0.74-2.73)\end{array}$ & $\begin{array}{l}1.25 \\
1.08\end{array}$ & $\begin{array}{l}10.89 \\
10.52\end{array}$ & $\begin{array}{l}-1.741 \\
-\quad 2.241\end{array}$ \\
\hline Rooms: & $\begin{array}{l}1 y \text { ventilated } \\
11 \text { ventilated } \\
\text { Outdoors }\end{array}$ & $\begin{array}{l}2.21 \\
0.73 \\
0.79\end{array}$ & $\begin{array}{l}(1.47-3.32) \\
(0.42-1.63) \\
(0.51-1.21)\end{array}$ & $\begin{array}{l}6.54 \\
1.70 \\
1.02\end{array}$ & $\begin{array}{l}13.28 \\
10.59 \\
10.45\end{array}$ & $\begin{array}{r}-13.031 \\
-\quad 4.891 \\
-\quad 2.311\end{array}$ \\
\hline
\end{tabular}


Therefore, information about these exposures, as collected by the questionnaires, was separately andysed. Odds Ratios were calculated for the relevant working conditions and work practices. In this case the on reflects the risk for receiwing digability benefits due to neuropsychiatric disorders in a certain exposure group compared with this risk in the non-exposed group. As can be seen from Table 3, the on 1 s considerabiy increased for several work practices of painters. The highest values of the odas Ratio are found for sporadic paint brushing, frequent spray painting. frequent use of paint removers, frequently burning off paints and working in poorly ventilated rooms.

\section{DISCUSSION}

The quantification of exposure to organic solvents is one of the difficulties encountered in conducting retrospective epidemiological studies to investigate chronic neurotoxic effects of occupational solvent exposure. Usually no exact exposure data are available and the amount of solvent exposure must be estimated using information from company records or questionnaires. However, there is substantial variation between individual painters regarding work practices and working conditions, which may affect individual solvent exposure. In this study three indices were used to define the exposure to organic solvents: duration of exposure (years), painters index and general exposure index. The exposure indices used in this study can be criticized because the questionnaire design does not permit an accurate estimate of the exposure to organic solvents.

Bias may have influenced our results. Painters with neuropsychiatric disorders tend to blame their work and might therefore indicate more unfavourable work conditions. Recently fidler et a ${ }^{10}$ proposed the use of a more sophisticated exposure index based on information about the total number of gallons of paint used per year, the fraction which would be absorbed by a respirator, the method of application and the presence of ventilation. Although this exposure index might prove to be a useful tool for epidemiological investigations, one has to be aware of the danger to introduce an overestimation of the accuracy of the data collected by means of questionnaires or interviews. For instance, these data are very sensitive to information bias. 
Relationships were investigated between the height of the exposure indices and the risk for receiving disability benefits due to mental disorders. The duration of exposure did not show a dose-response relationship. Duration of exposure is a common surrogate estimation of exposure dose for investigating dose-response relationships $11,16,17,22,31,32$. However, use of this exposure index has been criticized, since it ignores the intensity and type of organic salvent exposure ${ }^{10}$. Furthermore, the strong correlation between age and duration of exposures mekes it difficult to distinguish solvent effects from the effects of aging ${ }^{10}$. Although in our study, age was taken into account as a potential confounding factor, still no dose-response relationship could be detected.

The painters index seemed to be positively associated with the risk for neuropsychiatric disorders. However, high values of this painters index are only present among a small group of painters. A subdivision of this index into the work practices which were included in this index revealed paint spraying and paint removing as potentially important risk factors. Paint removers contain up to $90 \%$ organic solvents, usually methylene chloride. A strong retardation of the evaporation of methylene chloride is effectuated by adding solid paraffin to paint removers. Solid paraffin forms a layer above the applied paint remover "thus retarding evaporation of methylene chloride and promoting the effectivity of the paint remover. However, after scraping off the paint remover containing paint layers, almost all of the methylene chloride will evaporate, leading to high exposure of the involved workers. Studies of workers exposed to methylene chloride showed an excess of self-reported neurological symptoms, although no evidence was found of long-term neuropsychological damage ${ }^{33}$. The analysis of doseresponse relationships with respect to the general exposure index showed some interesting results. It became evident that for each value of this exposuce index, painters were more at $r i s k$ than construction workers.

Various explanations can be put forward in order to explain this difference. First it is possible to assume that at the same level of this index painters are more exposed than construction workers. This exposure index is based on questions about the number of days per week involved in work practices with organic solvent exposure. It is likely that painters indicating the use of organic galvents during five days per week are exposed all day, while non-painters giving the same answers are only exposed during short periods, e.g. cleaning activities. on the other hand, we can not ruie out the possibility that this difference between painters and construction workers indicates the importance af factors other than solvent exposure, that may increase the risk for painters to develop neuropsychiatric disorders. Supplementary evidence for this hypothesis might be deri- 
ved from the 1 int of painters activities which were associated with an increased of. Some factors are clearly asociated with high exposure to organic solvents, for exanple working in badly ventilated rooms. Fiala et al ${ }^{34}$ noted that good ventilation could reduce the exposure to organic solvents as much as 80 percent. However, this possible translation to high organic solvent exposure can not be made for other factors such as using "other paints" or "burning off paints". of course "other paints" is a very wague term and gives no indication about the solvent concentration of the paines used by the participants who answered positively on this item. However, some participants indicated the use of lead containing paints ("lead wite"). In the past, lead exposure has been an important health hazard for painters and lead intoxication is accompanied by neurological and neuropsychiatric symptoms and signs ${ }^{35}$. The amounts of leads used in painting are now largely reduced, yet exposure to lead can occur while burning off old paint coatings ${ }^{36}$.

At first sight, some of the results of the analysis of different painting activities are rather curious; in particular the high or for paint brushing and using latex can not easily be explained. However. it has to be remembered that the statistical analysis of our data limits the interpretation of the results, since the mutual relation between the various painting activities is not taken into account. In view of the great variety of painting activities and the limited number of observations, such an analysis would not produce reliable results. It might be reasonable to assume (and confirmed by simple analysis) that painters with little involvement in brushing activities are more active in paint rolling and paint spraying, hence having higher exposure to organic solvents than painters doing mainly paint brushing. Moreover, our data showed that painters with Ereguent use of latex paints also use more paint removers, thus having high exposure to methylene chloride. Nevertheless, it is unclear whether these explanations totally account for the detected increase of the oR.

In this study, much attention was given to the question how to define the dose of organic solvent exposure. Of course it is of equal importance to pay attention to the validity and reliability of the studied "response". Our study focussed on neuropsychiatric disorders with disability benefits entitlement, thus implying that disability due to neuropsychiatric disorders has been chosen as a parameter of the occurrence of neuropsychiatric disorders. However, disability is the result of process involving both medical and social determinants. The relatively great extent of the disability figures in The Netherlands (in 1986 about 94,000 persons received disability benefits from the Dutch painters and construction workers organizations) supports the existence of social determinants in this 
process, such as the situation on the labour market. Older people, experiencing difficulties in getting new jobs, might be put (wrongly) in disablity categories. These factors introduce the possibility that some dilution of any existing dose-response relationship might have occurred. Furthermore, social security physicians granting these disability benefits are not psychiatrists and dagnostic difficulties may easily arise in the field of neuropsychiatric disorders thus introducing the possibility of classification bias. However, all these potential sources of bias would have affected both painters and construction workers in the same way, since they are covered by one medical department.

on the whole, the following conclusions may be drawn from our study results. The analysis showed some tendencies indicating positive dose-response relationships between organic solvent exposure and neuropsychiatric disorders. Furthermore, some work practices and working conditions resulting in high exposure to organic solvents (using paint removers, working in poorly ventilated rooms) were associaw ted with a marked increase of the oR. Thus, our study results suggest that a small group of painters with high exposure to organic solvents might have an increased risk to be prematurely disabled due to neuropsychiatric disorders. On the other hand, our data suggest that other chemical exposures, perhaps to lead, may also play a role in the development of neuropsychiatric disorders anong painters.

REFERENCES

1. Grasso $P$, Sharrat M, Davies DM, Irwine D. Neurophysiological and psychological disorders and occupational exposure to organic solvents (review section). Fd Chem Toxic 1984; $22: 819-852$.

2. Waldron $\mathrm{HA}$. Solvents and the brain (editorial). Br J Ind Med 1986; 43:73-74.

3. Cranmer JM, Goldberg L. Human aspects of solvent neurobehavioral effects. Report of the Workshop Session on Clinical and Epidemiological Topics. Neurom toxicology $1987 ; 7: 43-56$.

4. Baker EL, Fine LJ. Solvent Neurotoxicity: The Current Evidence (editorial). Journal of Occupational Medicine $1986: 28: 126-129$.

5. Ekberg K, Barregărd $L$, Hagberg $S$, sallsten $G$. Chronic and acute effects of solvents on central nervous system functions in floorlayers. Br if Ind Med $1986 ; 43: 101-106$. 
6. Lliemfeld MM, Lilienfeld DE. "Poundations of Epidemiology"t . New York, Oxford: Oxford University Press, 2nd ed, 1980.

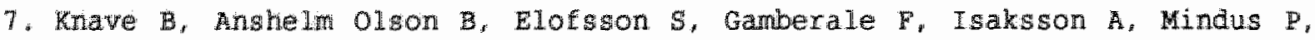
Persion HE, Struwe G, Wentwerg $A$, Westerholin $P$. Long-term exposure to jet fuel: An investigation on occupationally exposed workers ith special reference to the nervous system. Scand J work Environ Health 1976; 3: 152-164.

8. Gregersen P, Angels $\phi$ B, Nielsen TE, Norgaard B, Uldal C. Neurotoxic effects of organic solvents in exposed workers: An occupational, neuropsychological and neurological investigation. Am J Ind Med 1984; 5: 201-225.

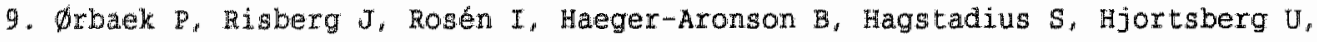
Regnell. G, Rennström $S$, Svensson $K$, Helinder $H$. Effects of long-term exposure to solvents in the paint industry. A cross-sectional epidemiologic study with clinical and laboratory methods. Scand J work Environ Health 1985; 11: 2.

10. Fidler AT, Baker EL, Letz FE. Neurobenavioural effects of occupational exposure to organic solvents among construction painters. Brit I Ind Med 1987: $44: 292-308$.

11. Härkönen $H$, Lindström $\mathrm{K}$, Seppäläinen AM, Asp S, Hernberg S. Exposure-response relationship between styrene exposure and central nervous functions. Scand $\mathrm{J}$ Work Environ Health $1978 ; 4: 53-59$.

12. Elofsson SA, Gamberale F, Hindmarsh $T$, Iregren A, Isaksson $A$, Jahnsson $I$,

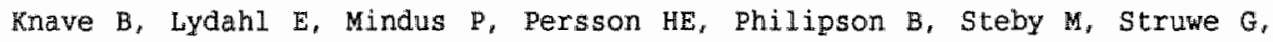
Söderman E, Wennberg A, Widén L. Exposure to organic solvents: A cross-sectional epidemiological investigation on occupationally exposed car and industrial spray painters with special reference to the nervous system. Scand J Work Environ Health 1980; 6: 239-273.

1.3. Husman K. Symptoms of car painters with long-term exposure to a mixture of organic solvents. Scand J Work Enwiron Health 1980; 6: 19-32.

14. Maizlish NA, Fine LJ, Albers JW, Whitehead I, Langolf GD. A neurological evaluation of workers exposed to mixtures of organic solvents. Brit $J$ Ind Med $1987 ; 44: 1.4-25$.

15. Vliet van $C$, Swaen GMH, Slangen JJM, Boorder de Tj, Sturmans $F$. The organic solvent syndrome. A comparison of cases with neuropsychiatric disorders among painters and construction workers. Int Arch Occup Environ Health 1987; 59 : 493-501.

16. Hane $\mathrm{K}$, Axelson 0 , Blume J, Hogstedt C, Sundell L, Ydreborg B. Psychological function changes among house-painters. Scand J Work Environ Health 1977; 3 : 91-99. 
17. Lindström $\mathrm{k}$. Changes in psychological performances of solvent-poisoned and solvent-exposed workers. Am J Ind Med 1980; $1: 69-84$.

18. Valciukas $J A$, Lilis $\mathbb{R}$, Singer RM, Glickman L, Nicholson WJ. Neurobehavioral changes among shipyard painters exposed to solvents. Arch Environ Health $1985 ; 40: 47-52$.

19. Mutti $A$, Mazzucchi $A$, Rustichel1i P, Frigeri G, Arfini G, Franchini I. Exposure-effect and exposure-response relationships between occupational exposure to styrene and neuropsychological functions. Am J Ind wed 1984; 5: 275-286.

20. Gregersen P, Klausen $\mathrm{H}$, Uldal Elsnab C. Chronic toxic encephalopathy in solvent-exposed painters in Denmark 1976-1980: Clinical cases and social consequences after a 5-year follow-up. Am J Ind Med 1987; 11: 399-417.

21. Axelson 0 , Hane $M$, Hogstedt $C$. A case-referent study on neuropsychiatric dis orders among workers exposed to solvents. Scand J Work Environ Health 1976: 2: $14-20$.

22. Olsen J, Sabroe S. A case-reference study of neuropsychiatric disorders among workers exposed to solvents in the Danish wood and furniture industry. Scand I Soc Med 1980; 16:44-49.

23. Lindström $\mathrm{K}$, Ri ihimäk $\mathrm{H}$, Hänninen $\mathrm{K}$. Occupational solvent exposure and neuropsychiatric disorders. Scand $J$ work Environ Health 1984; 10: $321-323$.

24. Antti-Poika M. Prognosis of Symptoms in Patients with Diagnosed Chronic Organic Solvent Intoxication. Int Arch Occup Environ Health 1982-a; 51: 81-89.

25. Antti-Poika M. Overall Prognosis of Patients wiht Diagnosed Chronic Solvent Intoxication. Int Arch Occup Environ Health 1982-b; 51: 127-138.

26. Flodin U, Edling C, Axelson O. Clinical studies of psycho organic syndromes among workers with exposure to solvents. Am J Ind Med 1984; 5: 287-295.

27. Triebig G, Claus D, Csuzda I, Druschky KF, Holler $P$, Rinzel $W$, Lehrl $S$, Reichwein P. Weidenhammer $w$, Weitknecht wu, Welt le D. Erlanger Malerstudie. Multidisziplinäre Querschnittsuntersuchung zur Neurotoxizität von Lösemitteln in Farben and Lacken. ASP - Sonderheft 1986; 9; 1-45.

28. World Health Organisation: Environmental health 5 . "Chronic effects of organic solvents on the central nervous system". Copenhagen: WHO, 1985.

29. Knoll B, kielhorn FW, Doorgeest T. Veilig werken met oplosmiddelen door goed te ventileren. Verfkroniek 1987; 60: 13-20.

30. Schlessleman JJ. "Case-control studies. Design, Conduct, Analysig". New York: Oxford University Press, 1982.

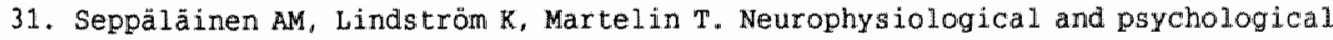
picture of solvent poisoning. Am $\checkmark$ Ind Med $1980 ; 1: 31-42$. 
32. Itegren $\ldots$. Effects on physological test performance of workers exposed to a ingle solvent (toluenel - A comparison with effects of exposure to a mixture of organic solvents. Wevrobehavioral Toxicology and Teratology 1982; 4: 695-701.

33. Cherry $\mathrm{H}$, Venables $H$, waldon HA, wells GG. Some observations on workers exposed to methylene chloride. Br J Ind Med 1981; 38: 351-355.

34. Riala R, Kolliokoski P, DYY L, Wickströn G. Solvent exposure in construction and maintenance painting. Scand J Work Environ Health 1984; 10: 263-266.

35. Doul1 J, Klaassen CD, Amdur Mo. "Toxicology, The Basic science of Poisons". New York, Toronto, London: McMillan Publishing Co, 2nd ed, 1980: pp 415-421.

36. Doorgeest $T$, Meijer PB, Mik de G. "Chronische effecten tengevolge van blootstelling aan organische oplosmiddelen". Literatuuronderzoek, S 29-1: Directoraat-Generaal van de Arbeid, Voorburg, 1986. 


\section{CHAPTER ?}

NEUROTIC DISORDERS DUE TO ORGANIC SOLVENT EXPOSURE:

FACT OR PITFALI? *

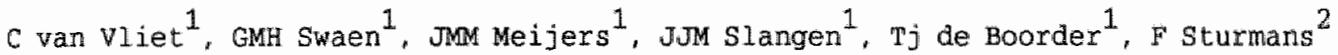

1 Dept. of Occupational and Environmental Health and Toxicalogy, University of Limburg, PO Box 616, 6200 MD Maastricht, The Netherlands .

2 Dept. Of Epidemiology, University of Limburg.

* Submitted for publication 
ABSTRACT

The results of a Dutch case-control study revealed a relationship between organic solvent exposure and premature disability due to neurotic disorders. In order to evaluate the causal character of this relationship, an additional analysis was carried out of symptoms and exposure factors, as reported by persons receiving distuility benefits due to neuropsychiatric aisorders.

No significant differences were detected between persons diagnosed as having neurotic disordexs and person diagnosed as having other neuropsychiatric disorders with respect to the reported symptoms and exposure factors. It is concluded that this study does not support the existence of a causal relationship between organic solvent exposure and neurotic disorders. Consequently it can not be excluded that classification bias is responsible for the detected association.

INTRODUCTION

During the past fifteen years an intensive search has been carried out into the chronic neurotoxic effects of long-term exposure to organic solvents ${ }^{1,2}$. The practical consequences of these neurotoxic effects have been studied in several Scandinavian studies, investigating the relationship between organic solvent

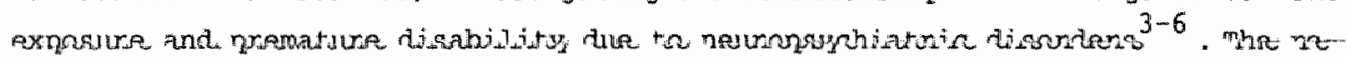
sults of these studies suggested that solvent exposed workers are at increased risk for being prematurely disabled due to neuropsychiatric disorders. Recently, a Dutch case-control study was carried out among Dutch painters and construction workers, investigating the same relationship. This study revealed a statistically significant association between organic solvent exposure and premature disability due to neurotic disorders, while such an association was not detected with respect to other neuropsychiatric disorders. These findings are in accordance with the results of Lindström et $a 1^{6}$.

The objective of the present study is to further examine and evaluate the causal character of the relationship between organic solvent exposure and neurotic disorders. 


\section{MATERIAL AND METHODS}

The study material consisted of information from questionnalres as collected in a recently carried out case-control study. All cases and controls were affliated to the Dutch Painters and Construction Workers Organizations. Cases were defined as male persons receiving disability benefits as from a date between 01-07-1984 and 01-07-1986. In the Netherlands payment of disability benefits is considered after 52 weeks of illness. Diagnoses of persons receiving disability benefits are awarded by social security physicians. These diagnoses are coded by expert nosologists according to a list based on the 9 th revision of the International clas sification of Diseases. The control population consisted of a random sample of male persons from the Dutch Painters and Construction Workers Organizations. From all participating cases and controls completed questionnaires were received. These questionnaires contained information about their occupational history, working conditions and work practices related to organic solvent exposure and the occurrence of neurasthenic symptoms. In accordance with the objective of our present study we further analysed the information collected from the cases group of our study.

In the analyses of the collected data Odds Ratios (OR) and Confidence Limits (two sided, $\alpha=0.05)$ were calculated according to schlesselman ${ }^{7}$. Student's $t$-test was used to analyse the significance of the difference between the compared groups with respect to duration of exposure (years).

RESULTS

252 Persons receiving disability benefits due to neuropsychiatric disorders (response: $61.6 \%$ ) and 322 controls (response: 69.7\%) participated in our tudy. Table 1 shows the distribution of organic solvent exposure and neuropsychiatric disorders within the cases group. This table clearly indicates the association between organic solvent exposure and neurotic disorders $(O R=1.93)$. However, this association disappears as persons diagnosed with adjustment reactions are added to this group $(O R=1.00)$. Further analysis was carried out among the exposed cases group $(\mathrm{n}=117)$. Persons diagnosed as having a neurotic digorder $(\mathrm{n}=38)$ were compared to persons diagnosed as having other neuropsychiatric disorders (n = 79) with respect to several relevant symptoms and exposure factors. 
Table 1: Distribution of exposure to organic solvent and ICD-codes within the cases group.

\begin{tabular}{|c|c|c|c|c|c|c|}
\hline \multirow{2}{*}{$\begin{array}{l}\text { ICD-codes of mental } \\
\text { disorders }\end{array}$} & \multicolumn{2}{|c|}{ Exposed } & \multicolumn{2}{|c|}{ Non-exposed } & \multirow[t]{2}{*}{$\mathrm{OR}^{1}$} & \multirow{2}{*}{$\begin{array}{l}\text { Confidence } \\
\text { limits } \\
(\alpha=0.05)\end{array}$} \\
\hline & $\mathbb{N}$ & (2) & $\mathbb{N}$ & $(8)$ & & \\
\hline 300: neurotic disorders & 38 & $(32.5)$ & 23 & $(17.0)$ & 1.93 & $1.13-3.30$ \\
\hline 309: adjustment reactions & 54 & $(46.2)$ & 85 & $(63.0)$ & 0.74 & $0.51-1.07$ \\
\hline $\begin{array}{l}\text { other ICD-codes with res- } \\
\text { pect to neuropsychiatric } \\
\text { disorders }\end{array}$ & 25 & $(21.4)$ & 27 & $(20.0)$ & 1.08 & $0.62-1.89$ \\
\hline $300+309$ & 92 & $(78.6)$ & 108 & $(80.0)$ & 1.00 & $0.74-1.36$ \\
\hline Tota & 117 & $(100.0)$ & 135 & $(100.0)$ & 1.01 & $0.76-1.34$ \\
\hline
\end{tabular}

I odds Ratios were calculated based on the participation of 379 exposed and 443 non-exposed controls in our study.

The questionnaire contained a list of 33 questions about the occurrence of neurasthenic symptoms. Participants were asked to describe the situation as experienced during the last year. Answers had to be selected from four categorles: never, sometimes (e.g. once a month), regular (e.g. once a week) or often (more than once a week). Persons included in table 2 scored regular or often on the particular question.

As can be seen from this table none of the symptoms revealed a statistically significant difference between cases diagnosed with neurotic disorders and cases diagnosed wh other neuropsychiatric disorders.

The symptoms 1 isted in Table 2 may be grouped into 8 categories. The scores $(1$, 2,3 or 41 on every question within a symptom group were summarized. Persons included in rable 3 scored above $50 \%$ of the maximum score (= number of symptoms times fourl of the relevant symptom group.

Table 3 shows that this approach reveals no statistically significant differences between the compared cases groups.

The exposure of the individual painter to organic solvents will depend on his working conditions and work practices. Some of these factors, such as paint spraying, using alkyd paints or paint removers and working in poorly ventilated rooms, may lead to high exposure to organic solvents. 
Table 2: Responses concerning meurasthenic symptoms associated with long-term organic solvent intoxication among exposed persons diagnosed with neurotic disorders (ICD-300) or other neuropsychiatric disorders.

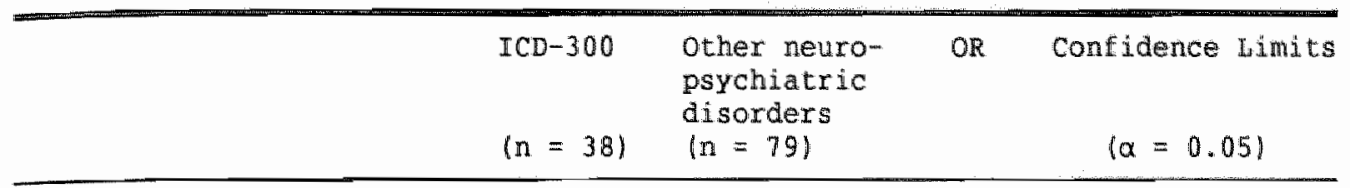

1. Do you get up tired in the morning?

21

20

12

3. Are you forgetful?

4. Do you of ten forget what you intended to do?

2. Do you feel excess tiredness after the workday?

10

50

0.72

$0.33-1.58$

41

1.02

$0.47-2.21$

30

0.75

$0.33-1.70$

29

0.62

$0.26-1.48$

5. Do you have to go back and check wether you turned of the gas, locked the door etc.?

0.57

$0.25-1.31$

6. Do you make notes of things you must remember?

7. Have your relatives or friends told you that you are forgetful?

8. Do your thoughts stray when you try to concentrate?

9. Do you fall asleep when watching television?

10. Are you lost in your own thoughts?

11. Do you notice that you are "daydreaming"?

12. Do you have difficulties understanding what you read in newspapers or books?

13. Do you have difficulties falling asleep?

14. Do you wake at night?

15. Do you have nightmares?

16. Does your mood chance without reason?

0.70

$0.23-2.11$ 


\begin{tabular}{|c|c|c|c|c|}
\hline & $\begin{array}{l}I C D-300 \\
(n=38)\end{array}$ & $\begin{array}{l}\text { Other neuro- } \\
\text { psychiatric } \\
\text { disorders } \\
(\mathrm{n}=79)\end{array}$ & OR & $\begin{array}{l}\text { Confidence Limits } \\
\qquad(\alpha=0.05)\end{array}$ \\
\hline 17. Are you depressed? & 12 & 38 & 0.50 & $0.22-1.13$ \\
\hline 18. Hre you irritated? & 14 & 31 & 0.90 & $0.40-2.00$ \\
\hline 19. Are you restless? & 23 & 46 & 1.10 & $0.50-2.42$ \\
\hline 20. Are you afraid? & 13 & 26 & 1.06 & $0.47-2.40$ \\
\hline 21. Are you listess? & 13 & 32 & 0.76 & $0.33-1.74$ \\
\hline 22. Are you drowsy? & 20 & 25 & 0.77 & $0.32-1.83$ \\
\hline $\begin{array}{l}\text { 23. Do you become tired } \\
\text { among other people? }\end{array}$ & 14 & 23 & 1.42 & $0.63-3.22$ \\
\hline $\begin{array}{l}\text { 24. Do you have difficul- } \\
\text { ties in starting a con- } \\
\text { versation with others? }\end{array}$ & 10 & 20 & 1.05 & $0.43-2.58$ \\
\hline $\begin{array}{l}\text { 25. Do you suffer from } \\
\text { headaches? }\end{array}$ & 11 & 31 & 0.63 & $0.27-1.45$ \\
\hline $\begin{array}{l}\text { 26. Do you suffer from } \\
\text { dizziness? }\end{array}$ & 6 & 23 & 0.45 & $0.17-1.22$ \\
\hline $\begin{array}{l}\text { 27. Do you sweat wi thout } \\
\text { exerting yourself? }\end{array}$ & 15 & 29 & 1.12 & $0.51-2.48$ \\
\hline $\begin{array}{l}\text { 28. Do you have palpita- } \\
\text { tions without exerting } \\
\text { yourself? }\end{array}$ & 8 & 12 & 1.49 & $0.55-4.02$ \\
\hline $\begin{array}{l}\text { 29. Do your hands tremble? } \\
\text { 30. Do you feel as though } \\
\text { you have something in } \\
\text { your throat? }\end{array}$ & 11 & 17 & 1.05 & $0.45-2.47$ \\
\hline $\begin{array}{l}\text { 31. Do you feel an oppres- } \\
\text { sion on your chest? }\end{array}$ & 11 & 22 & 1.05 & $0.45-2.47$ \\
\hline $\begin{array}{l}\text { 32. Do you suffer from a } \\
\text { diminished sexual } \\
\text { interest? }\end{array}$ & 11 & 27 & 0.78 & $0.34-1.81$ \\
\hline $\begin{array}{l}\text { 31. Do your legs feel numb } \\
\text { or tingle? }\end{array}$ & 10 & 24 & 0.82 & $0.34-1.95$ \\
\hline
\end{tabular}


Table 3: Symptom groups: number of persons diagnosed with neurotic disorders (ICD-300) or other neuropsychiatric disorders scoring more than 50 of the maximum summarized group score.

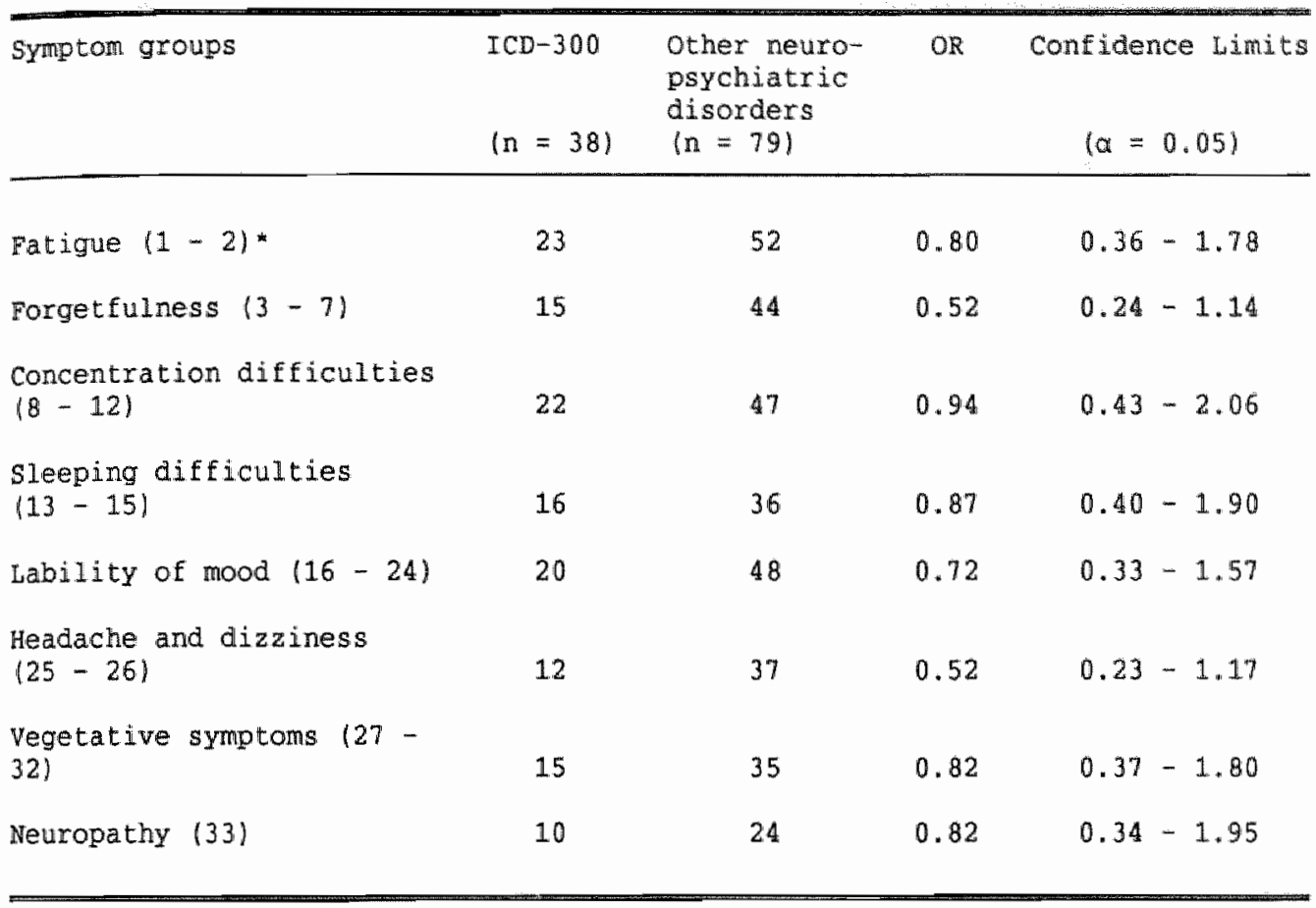

* Numbers refer to the symptoms as listed in Table 2 " that are included in the relevant symptom groups.

Table 4 shows the number of exposed persons diagnosed with neurotic disorders or "other neuropsychiatric disorders", who are frequently imore than one day per weeky involved in the above mentioned workpractices and working conditions. Here again the comparison between the two groups of cases revealed no statistically significant differences.

In addition, the number of years worked as a painter is a commonly used, although not very accurate measure of exposure.

The mean exposure duration of cases diagnosed with neurotic disorders was longer (22.8 years) than the mean exposure duration of cases diagnosed with other neuropsychiatric disorders $(19.6$ years). However, this difference did not reach a statistically significant level (student"s t-test: $p=0.17$ ). 
Table Painters activities associated with high exposure to organic solvents: a comparison of the scores from persons diagnosed with neurotic disorders (ICD-300) and persons diagnosed with other neuropsychiatric disor ders.

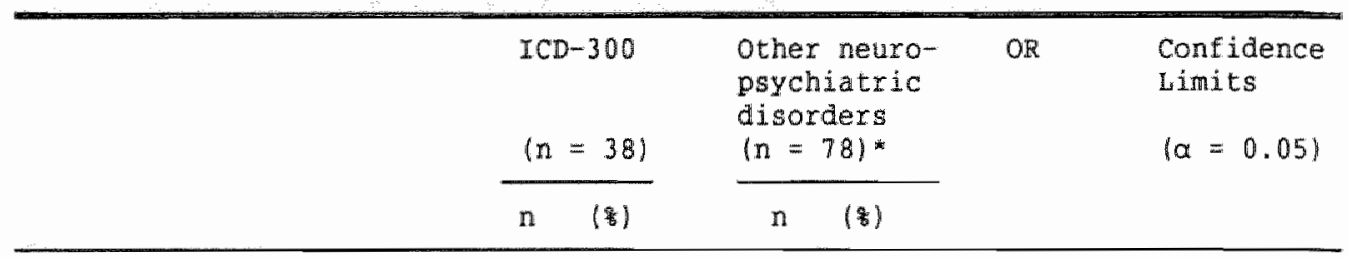

Working at present (last

working year) with/in:

- Alkyd paints \1 day/ week)

$4(10.5) \quad 11(14.1) \quad 0.72 \quad 0.21-2.43$

- Paint spraying 1 day/ week.

$3(7.9)$

$9(11.5)$

0.66

$0.17-2.59$

- Paint removers (> 1 day/ week)

$3(7.9)$

10 (12.8!

0.58

$0.15-2.24$

- Poorly ventilated rooms

$24(63.2)$

41 (51.9)

1.55

$0.70-3.34$

Working earlier with/in:

- Alkyd paints (> 1 day week]

$16\langle 42.1\rangle$

$31(39.7)$

1.10

$0.50-2.42$

- Paint spraying (> 1 day/ week)

$13(16.7)$

0.76

$0.25-2.31$

- Paint remover: (\$ 1 day/ week!

$14(36.8)$

$32(41.0)$

0.84

$0.38-\mathbb{1} .87$

- poorly ventilated rooms

$24(63.2)$

$39(50.0)$

1.71

$0.77-3.79$

* One person from the exposed cases group had worked as a carpet layer. Subsequently 118 cases (in stead of 119) were incorporated in this analysis. 
DISCUSSION

The results of a recentiy carried out Dutch case-control study revealed a statistically significant relationship between organic solvent exposure and premature disability due to neurotic disorders. Several hypothesis can be put forward in order to explain this relationship. possibly persons predisposed to develop neuropsychiatric disorders are more likely to choose occupations inwolving exposure to organic solvents 4.5 . However, it is also possible that exposure to organic solvents impairs the ability of the involved workers to cope with stress, thus leading to disproportionate ("neurotic") reactions to disstressing experiences. of course, diagnostic difficulties may easily arise in the field of neuropsychiatric disorders. In particular, the distinction between neurotic disorders and adjustment reactions may be difficult. Whether a reaction to a distressing experience is judged as more or less normal ("adjustment reaction") or disproportionate ("neurotic") depends on a lot of factors, partly linked up with the frame of reference of the physicians involved in this judgement. In view of this diagnostic difficulties we hypothesized that classification bias was responsible for the detected association between organic solvent exposure and neurotic disorders. The effect of random misclassification would be to underestimate the true assom ciation between organic solvent exposure and neurotic disorders ${ }^{8}$. Hence hypothezising that misclassification bias has lead to an overestimation of the odds Ratio, implies that selective misclassification with respect to neurotic disorders must have occurred.

Yet, exposed and non-exposed persons applying for disability benefits were examined and diagnosed by social security physicians from the same medical departments, diminishing the probability of the occurrence of selective misclassification. An explanation could be that social security physicians hold some sort of prejudice against painters, leading to an inclination to diagnose their neuropsychiatric disorders as neurotic. It is also possible that knowledge of the relationship between organic solvent exposure and neuropsychiatric disorders leads to an "overdiagnosing" of neurotic disorders anong painters. However, it is not clear why painters shoud be diagnosed as suffering from neurotic disorders IICD$300)$ in stead of suffering from adjustment reactions (ICD-309). In fact "the decreased risk for painters to receive disability benefits due to adjustment reactions $1 O R=0,86)$, whereas the combination of newrotic disorders (ICD-300) and adjustment reactions (ICD-309) shows no relationship with organic solvent exposure is a rather puzzling issue. Misclassification among painters towards 
neurotic disorders and (reversed) among construction workers towards adjustment reactions is as posible explanation of our study results that can not be excluded nor confirmed. Yet the existence of classification bias can not be proved by these considerations, nor by any additional analysis of our studymaterial. However, it is possible to further investigate the relationship between neuroses and organic solvent exposure. This investigation was carried out by analysing information about symptoms and organic solvent exposure of persons diagnosed with neuropsychiatric disorders, as collected by questionnaires.

Complaints and symptoms reported by patients play an important part in the diagnostic proces of neuropsychiatric disorders, the more so as these disorders are usually not accompanied by objective physical signs. If there is a causal relationship between neurotic disorders and organic solvent exposure the symptoms reported by persons diagrosed as having a neurotic disorder ought to be more or less in line with the symptoms associated with chronic neurotoxic effects due to long-term organićsolvent exposure ${ }^{2}$.

Unfortunately, a comparison of the occurrence of these (neurasthenic) symptoms among persons diagnosed as having a neurotic disorder and persons diagnosed as having other neuropsychiatric disorders did not reveal statistically significant differences between these two groups. In fact, 22 out of 33 neurasthenic symptoms (66.7) indicated a weak association ith non-neurotic disorders, as the calculated odds Ratio is lower than one. Furthermore, none of the symptom groups showed an association with neurotic disorders.

The existence of a causal relationship between the development of neurotic disorders among painters and their exposure to organic solvents would be supported if their accupational history indicated higher levels or longer exposure to organic solvents than the occupational history of painters diagnosed with other neuropsychiatric disorders. Therefore, we compared the occurrence of some painters activities associated with high exposure to organic solvents between these two groups. With regard to the factors used in this analys is no significant differences were found.

Critical observation might be added with respect to this analysis. First of all the small numbers of the compared groups certainly limitates the interpretation of the results. Consequently, signficant differences can only be expected in case of very large differences between the compared groups with respect to for instance, the occurrence of neurasthenic symptoms. Furthermore, it is questionable whether the information about the relevant working conditions, as collected by questionnaires, actually reflects high levels of organic solvent exposure. In spite of these shortcommings we may conclude that further analysis of our 
study material certainly does not support the existence of a causal relationship between neurotic disorders and organic solvent exposure. Furthermore, the lack of difference between the symptoms reported by the compared groups indicates the existence of an owerlap with regard to the symptoms associated with neurotic disorders and other neuropsychiatric disorders.

Consequently this study is not in contradiction with our hypothes is that classification bias is responsible for the, at first sight, statisticaliy signiticant relationship between neurotic disorders and organic solvent exposure.

\section{REFEREMCES}

1. Grasso P, Sharrat M, Davies DM, Irvine D. Neurophysiological and psychological disorders and occupational exposure to organic solvents (review section). Fd Chem Toxic 1984; 22, 10: 819-852.

2. World Health Organisation. Environmental Health 5 . Chronic effects of organic solvents on the central nervous system and diagnostic criteria. Copenhagen, WHO, 1985 .

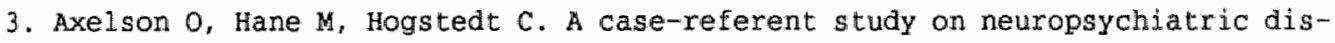
orders among workers exposed to solvents. Scand J Work Environ Health 1976 ; 2 : $14-20$.

4. Mikkelsen S. A Cohort Study of Disability Pension and Death among Painters with special Regard to disabling presenile Dementia as an occupational Disease. Scand J Soc Med 1980; $16: 34-43$.

5. Gisen $J$ and Sabroe 5. A Case-Reference Study of Neuropsychiatric Disorders among Workers Exposed to Solvents in the Danish wood and Furniture Industry. Scand J Soc Med 1980; 16: 44-49.

6. Lindström $K$, Rílhimâki $H_{*}$ Hănninen $K$. Occupational solvent exposure and neuropsychiatric disorders. Scand J Work Environ Health $1984: 10: 321-323$.

7. Schlesselman JJ. Case-control studies. Design, conduct, analysis, oxford university Press, New York, 1982.

8. Monson RR, Occupational epidemiology. CRC Press, InC. Boca Raton, Florida, 1980 . 
CKAPTER B

PRENARCOTIC AND MEURASTHENIC SYMPTOMS AMONG DUTCH WORKERS EXPOSED TO ORGANIC SOLVEWTS. *

C van Wliet ${ }^{1}$, GMH Swaen $^{1}$, JMM Meijers $^{1}$, J Slangen $^{1}$, Tj de Boorder ${ }^{1}$, F Sturmans $^{2}$

1

Dept. of Occupational and Environmental Health and Toxicology, University of Limburg, PO Box 616, 6200 MD Maastricht, The Netherlands.

2 Dept. of Epidemiology, University of Limburg.

* Published in British Journal of Industrial Medicine 1989; 46:586-590. 


\section{ABSTRACT}

In this study a population of Dutch organic solvent exposed workers $(n=379)$ was compared with a non-exposed population $(n=443)$ with regard to the prevalence of prenarcotic and neurasthenic symptoms. Participants completed a questionnaire to collect information about their occupational history, exposure to organic solvents and the occurrence of symptoms. The results of this stuay indicated that solwent exposed workers have a higher reporting rate of prenarcotic symptoms than workers not exposed to solvents. However, the prevalence of chronic neurotoxic effects, in the form of neurasthenic symptoms, was only weakly associated with reported exposure to organic solvents. The influence of workstress in the development of these symptoms is perhaps more important than the role of organic solvent exposure. It is concluded that the organic solvent syndrome type $I$, as defined by an international working group, is not an important health hazard among Dutch painters.

\section{INTRODUCTION}

Exposure to organic solvents frequently occurs in various types of industries and constitutes a potential health hazard to millions of workers throughout the wor $1 d^{1}$. Before the 1970 s some knowledge existed of the acute (narcotic) effects of various organic solvents on the central nervous system (CNS), but little attention was given to the possible chronic effects of long-term exposure to relatively low concentrations of organic solvents ${ }^{2}$. However, this situation has significantly changed over the past fifteen years. Several studies have reported adverse effects on the central nervous system among workers with long-term exposure to organic solvents ${ }^{3,4}$. Despite these findings there is still no international agreement about the classification and categorization of the chronic neurotoxic effects supposed to be induced by long-term organic solvent exposure 5,6 . one of the mast consistent findings in studies investigating these chronic neurotoxic effects is an increase in the number of reported neurasthenic symptoms, such as concentration difficulties, emotional lability and sleep disturbances among solvent exposed workers. It is proposed that symptom questionnaires are a useful tool for screening workers who may be at higher risk to be effected by 
exposure to organic solvents ${ }^{2.7}$. Workers with high scores should be further examined by specially trained physicians.

one of the difficulties encountered in constructing these questionnaires was the existing overlap between the symptoms of acute organic solvent intoxication (prenarcotic symptoms and the symptoms which might be part of chronic organic solvent intoxication ${ }^{5}$. Furthermore, whereas cross-sectional study designs are commonly used in studies of these neurotoxic effects, it is of ten difficult to determine whether the reported symptoms reflect acute or chronic neurotoxic ef$\operatorname{fects}^{8}$.

Symptoms associated with acute effects, also called prenarcotic symptoms, are for example, sleepiness, nausea, vertigo, headache, incoordination and alcohol intolerance ${ }^{5}$.

Symptoms supposed to be associated with chronic neurotoxic effects may be classified in "core" and "additional" symptoms 5 . Core symptams are fatiguebility, bad memory, difficulties in concentration and loss of initiative. Additional symptoms often present are depression, dysphoria, emotional lability, headache, irritation, sleep disturbances, paraesthesia and vertigo ${ }^{5}$.

These symptoms might be the first signs of organic solvent intoxication. An international working group suggested that workers suffering from these symptoms, without any other objective evidence of neurological damage, should be diagnosed as suffering from organic solvent intoxication, type $I^{5} .6$. The objective of the present study is to compare a population of Dutch solvent exposed workers with a non-exposed population with regard to the prevalence of prenarcotic and neurasthenic symptoms in order to investigate the existence of acute and chronic neurotoxic effects due to exposure to organic solwents.

\section{MATERIAL AND METHODS}

A case-control study was conducted in The Netherlands to investigate whether Dutch painters are at increased risk of developing mental disorders due to organic solvent exposure. Both cases and controls were selected from Dutch painters and construction workers organizations. These organizations were founded by employers and employees to execute several social laws. Cases were defined as men receiving disability benefits because of mental disorders. The control population consisted of a random sample of 1000 non-disabled men from the total population 
of the painters and construction workers organizations.

Cases and controls were approached by telephone. Participants received a questionnatre. Questions were asked about their occupational history and exposure to organic solvents. Furthermore attention was given to the occurrence of prenarcotic and neurasthenic symptoms related to exposure to organic solvents. The list of symptons used in this investigation was based on Scandinavian symptom lists developed for that purpose 9 .

In the present study a comparison was made between the reported symptoms of the exposed and non-exposed control population. Similar data from the cases were not included in this study. Logically, cases suffering from mental disorders, whether or not this mental disorder was caused by organic solvent exposure, would report a high number of neurasthenic symptoms. Therefore, a comparison of cases and controls with regard to symptom reporting would not show useful additional information.

To compare the prevalence of symptoms and symptom groups between exposed and nonexposed workers Odds Ratios (OR) and confidence limits were calculated according to schlesselman ${ }^{10}$. The statistical significance of differences between mean scores of symptom groups was tested by using student's t-test. Pearson's coefficients of correlation were calculated to describe the association between symptom scores, age, workstress and three indices for the level of organic solvent exposure.

RESULTS

Data from 822 respondents, collected by means of questionmaires, were included in the study. At first a subdivision was made into two groups, based on information from the questionnaires about their accupational exposure to organic solvents. Exposure to organic solvents is encountered in several occupations in the construction industry. The highest levels of exposure within the construction industry are present among painters, carpet layers and road markers. Therefore only those who had worked for at least one year as a painter, carpet layer or road marker $(n=379)$ were classified as exposed to organic solvents; all athers were classified as non-exposed $(n=443)$.

A comparison was made between the occurrence of prenarcotic symptoms among exposed and non-exposed persons. Participants were asked to describe the situation 
as experienced during the last year. Answers had to be chosen out of four categories: never, sometimes (e.g. once a month), regular (e.g. once a week) or often (more than once a week). Persons included in Table 1 scored regular or often on that particular question.

Table 1: Frequency distribution of prenarcotic symptoms among exposed and nonexposed subjects.

\begin{tabular}{|c|c|c|c|c|}
\hline & $\begin{array}{l}\text { Exposed } \\
(\mathrm{n}=379)\end{array}$ & $\begin{array}{l}\text { Non-exposed } \\
(\mathrm{n}=443)\end{array}$ & OR & $\begin{array}{c}\text { Confidence Limits } \\
(\alpha=0.05)\end{array}$ \\
\hline Nausea & 20 & 7 & 3.47 & $(1.45-8.28)$ \\
\hline Vomiting & 3 & 4 & 0.88 & $(0.20-3.96)$ \\
\hline Dizziness & 18 & 14 & 1.53 & $(0.75-3.12)$ \\
\hline Drunken feeling & 12 & 7 & 2.04 & $(0.79-5.24)$ \\
\hline Headache & 36 & 34 & 1.26 & $(0.77-2.05)$ \\
\hline Shortness of breath & 31 & 19 & 1.99 & $(1.11-3.58)$ \\
\hline Absent mindedness & 15 & 11 & 1.62 & $(0.74-3.56)$ \\
\hline \multicolumn{5}{|l|}{ Misunderstanding of in- } \\
\hline structions and jobs & 4 & 6 & 0.78 & $10.22-2.781$ \\
\hline Ear tingling & 18 & 28 & 0.74 & $(0.40-1.36)$ \\
\hline Difficulties with talking & 3 & 5 & 0.70 & $(0.17-2.95)$ \\
\hline Loss of appetite & 22 & 8 & 3.35 & $(1.48-7.60)$ \\
\hline Drowsiness & 53 & 47 & 1.37 & $(0.90-2.08)$ \\
\hline Alcohol intolerance & 20 & 20 & 1.18 & $(0.62-2.23)$ \\
\hline
\end{tabular}

As may be seen from this Table three symptoms were significantly more frequent among the exposed persons: "nausea", "shortness of breath" and "loss of appetite". Those who had scored often on one or more of the prenarcotic symptom ques tions were asked whether their complaints ceased during weekends and holidays. This question was positively answered by $50(13.2)$ of the exposed and $33(7.4$ 8) of the non-exposed subjects.

The questionnaire contained 33 questions about the occurrence of newrasthenic symptoms. Scoring procedures were identical with those described in assocation with prenarcotic symptoms. The results are shown in Table 2 , Only three out of these 33 symptoms were significantly more frequent among the exposed subjects. 
Table 2: Responses: concerning neurasthenic symptoms associated with long-term organic solvent intoxication among exposed and nom-exposed subjects.

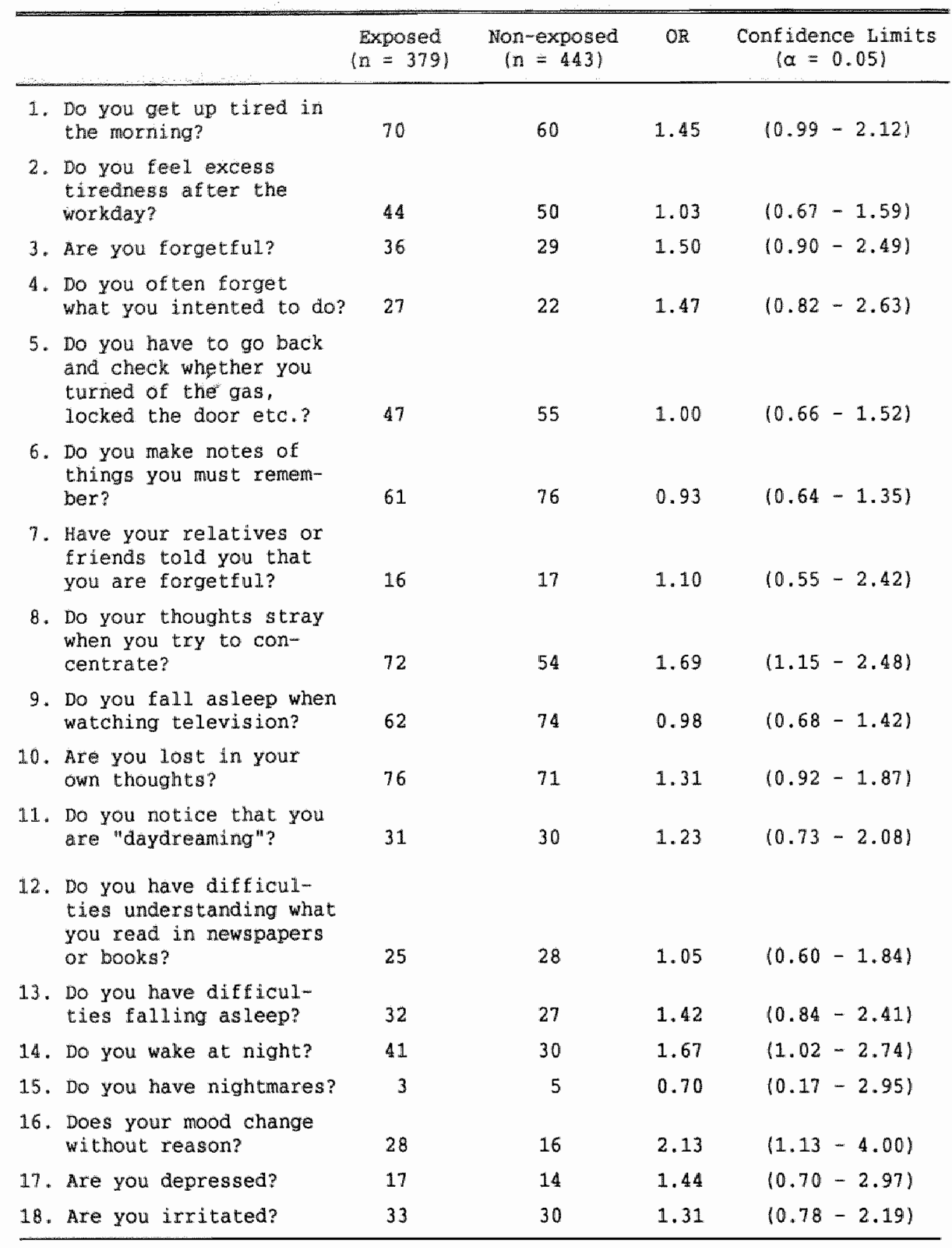


Table 2 continued

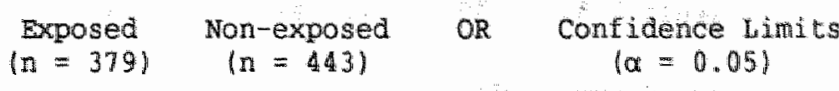

19. Are you restless?

46
14
15
47

20. Are you afraid?

21. Are you listless?

22. Are you drowsy?

23. Do you become tired among other people?

21

4650

1.09

$(0.71-2.67)$

24. Do you have difficulties in starting a conversation with others?

2. 09

$(0.87-5.04)$

15

8

0.75

$(0.38-1.46)$

47

43

1.32

$10.85-2.05 \mid$

25. Do you suffer from headaches?

1. 94

$(0.96-3.94)$

26. Do you suffer from dizziness?

27. Do you sweat without exerting yourself?

1.22

$(0.78-1.92)$

28. Do you have palpitations without exerting yourself?

12

21

29. Do your hands tremble?

30. Do you feel as though you have something in your throat?

31. Do you feel an oppression on your chest?

32. Do you suffer from a diminshed sexual interest?

33. Do your legs feel numb or tingle?
15

24

11

23

15

2

9

1.58

$(0.66-3.79)$

26

0.94

$(0.52-1.70)$

16

1.10

$(0.54-2.26)$

20

1.43

$(0.78-2.63)$

16

0.80

$(0.37-1.74)$

34

0.78

$(0.45-1.35)$

The symptoms listed in Table 2 may be grouped into eight categories: fatigue, forgetfulness, concentration difficulties, sleeping difficulties, lability of mood, headache and dizziness, vegetative symptoms and neuropathy. For every person the scores (1, 2, 3 or 4 ) on every question within a symptom group were summarized. Subjects included in Table 3 scored above $50 \%$ of the maximum score that 1s, number of symptoms times 4 ) of the relevant symptom group. Table 3 shows that using this approach a significant difference between exposed and non-exposed persong exists only with respect to "lability of mood" (OR $=1.69)$. 
Table 3: Symptom groups: number of exposed and nom-exposed subjects scoring more than 50 of the maximum summarized group score.

\begin{tabular}{|c|c|c|c|c|}
\hline & $\begin{array}{l}\text { Exposed } \\
\{n=379\}\end{array}$ & $\begin{array}{l}\text { Non-exposed } \\
(\mathrm{n}=443)\end{array}$ & OR & $\begin{array}{c}\text { Confidence Limits } \\
(\alpha=0.05)\end{array}$ \\
\hline Fatigue $(1-2)$ & 85 & 76 & 1.40 & $(0.99-1.99)$ \\
\hline Forgetfulnegs $(3-7)$ & 50 & 45 & 1.34 & $(0.88-2.05)$ \\
\hline $\begin{array}{l}\text { Concentration difficul- } \\
\text { ties }(8-12)\end{array}$ & 69 & 65 & 1.29 & $(0.89-1.87)$ \\
\hline $\begin{array}{l}\text { Sleeping difficulties } \\
(13-15)\end{array}$ & 29 & 24 & 1.45 & $(0.83-2.54)$ \\
\hline Lability of mood $(16-24)$ & 44 & 32 & 1.69 & $(1.05-2.72)$ \\
\hline $\begin{array}{l}\text { Headache and dizzimess } \\
(25-26)\end{array}$ & 31 & 31 & 1.18 & $(0.70-1.98)$ \\
\hline $\begin{array}{l}\text { vegetative symptoms } 127- \\
32)\end{array}$ & 20 & 20 & 1.18 & $(0.62-2.23)$ \\
\hline Neuropathy (33) & 23 & 34 & 0.74 & $(0.45-1.35)$ \\
\hline
\end{tabular}

* Numbers refer to the symptoms as listed in Table 2 that are included in the relevant symptom groups.

Table 4: Comparison of mean scores of various symptom groups.

\begin{tabular}{lccc}
\hline & Exposed & Non-exposed & $\begin{array}{c}\text { P-value } \\
\text { (Student"s t-test) }\end{array}$ \\
\hline Prenarcotic score & 17.59 & 15.73 & 0.000 \\
Symptom score & 49.54 & 47.95 & 0.052 \\
Fatigue & 3.59 & 3.45 & 0.163 \\
Forgetfulness & 7.70 & 7.62 & 0.653 \\
Concentration difficul- & 8.43 & 8.11 & 0.070 \\
ties & 4.20 & 4.11 & 0.325 \\
Sleeping difficulties & 13.31 & 12.74 & 0.041 \\
Lability of mood & 3.02 & 2.85 & 0.026 \\
Headache and dizziness & 7.93 & 7.74 & 0.233 \\
Vegetative symptoms & 1.36 & 1.33 & 0.477 \\
Neuropathy & & & \\
\hline
\end{tabular}


To make a more eiaborate comparison between exposed and non-exposed subjects, mean scores of the symptom groups and of the total narcotic and prenareotic symptom scores were compared. The significance of the difference was tested using student's t-test. The results of this analysis, as shown in table 4 , indicate significant differences with respect to "prenarcotic score", "lability of mood" and "headache and dizziness" $(p<0.05)$. The differences between two other groups, total symptom score and concentration difficulties, are on the borderline of sigmificance $(p<0.10)$.

Table 5: Correlation matrix (Pearson's coefficients of correlation) of prenarcotic score (PS), symptom score (SS), age (A), workstress (WS), duration of exposure (E), painters index (PI) and general exposure index (GEI).

I Exposed subjects $(n=379)$

\begin{tabular}{|c|c|c|c|c|c|c|c|}
\hline & PS & SS & $\mathrm{A}$ & WS & $\mathbb{E}$ & $\mathbb{P I}$ & $\mathrm{GEI}$ \\
\hline PS & 1.0000 & $0.7182^{\star *}$ & -0.0771 & $0.3437^{* *}$ & -0.0891 & $0.1464 * *$ & $0.2238^{*}$ \\
\hline SS & & 1.0000 & 0.0032 & $0.2961^{* *}$ & -0.0516 & 0.0727 & 0.1134 \\
\hline A & & & 1.0000 & 0.0432 & $0.8496 * *$ & 0.0507 & 0.0390 \\
\hline WS & & & & 1.0000 & 0.0486 & $0.1402^{\star}$ & $0.1666^{\star}$ \\
\hline$E$ & & & & & 1.0000 & 0.2128 ** & 0.1302 \\
\hline PI & & & & & & 1.0000 & $0.4976 * *$ \\
\hline GEI & & & & & & & 1.0000 \\
\hline
\end{tabular}

II Non-exposed subjects $(n=443)$

\begin{tabular}{|c|c|c|c|c|c|}
\hline & PS & ss & $A$ & WS & GEI \\
\hline PS & 1.0000 & $0.6036^{* *}$ & -0.0170 & $0.2443^{* *}$ & $0.1546^{\star}$ \\
\hline Ss & & 1.0000 & 0.0358 & $0.4226^{* *}$ & 0.0988 \\
\hline $\mathrm{A}$ & & & 1.0000 & -0.0052 & -0.0367 \\
\hline WS & & & & 1.0000 & 0.1589 \\
\hline GEI & & & & & 1.0000 \\
\hline
\end{tabular}

* $=p<0.05$ (twa-sided)

$*=p<0.01$ (two-sided) 
Finaldy, we examined whether the level of prenarcotic and neurasthenic sympton repoxting was associated with other factors "besides organic solvent exposure, wich as age, workstress, duration of exposure, painters index and general exposure index. The patnter index was based on information from the questionnaires about the involvenent of painters in panting practices, such as paint spraying, using alkyd paints and paint removers, that may lead to high exposure to organic solvents. The general exposure index, calculated for all participants contained information about working activities and conditions associated with organic solvent exposure, but not exclusively related to the painting profession. Detailed information of these indices will be published elsewhere.

As shown in the correlation matrix (Table 5 ) a strong correlation exists among exposed and non-exposed subjects between the prenarcotic and the neurasthenic symptom score. Furthermore, for both groups a correlation was observed between the symptom scores, and workstress. No correlation was found between the neurasthenlc symptom score and the level of organic solvent exposure as defined by the exposure indices. However, the prenarcotic symptom score was correlated ith the palinters index and the general exposure index, but not with the duration of exposure to organic solvents.

\section{DISCUSSION}

The analysis of our study material shows some indications for a relation between organic solvent exposure and the occurrence of neurasthenic and prenarcotic symptoms. A rough comparison between exposed and non-exposed participants with respect to the occurrence of all separate prenarcotic and neurasthenic symptoms shows a weak assocation between these symptoms and exposure to organic solvents. Because long lists of symptoms were used some comparisons of symptom reporting between exposed and non-exposed persons will (purely as a result of chance) elicit statistical significant differences. However, nine out of thirteen prenarcotic symptoms $(69.28)$ and 23 out of 33 neurasthenic symptoms $(69.78)$ indicate weak associations with organic solvent exposure, while the calculated odds Ratio is greater than one. The fact that more exposed tham non-exposed participants reported a decrease of prenarcotic symptoms during weekends and holidays, points to the role of a work related factor, such as organic solvent exposure, in the origin of their symptoms. 
After classifying the 33 neurasthenic symptoms in 8 sympton groups only "1ability of mood" was reported statisticaliy significantly more often by the exposed respondents. Here again the majority of the calculated odds Ratios (87.5\%) indicated weak associations between symptoms and organic solvent exposure. A more elaborate approach using mean scores in stead of sumarized scores to compare the symptom groups elicit greater differences between exposed and non-exposed participants. Particularly the differences between the mean total prenarcotic score $(p<0.0001)$ and mean total neurasthenic symptom score $(p \leq 0.05)$ attract attention. Apparently the prenarcotic sympton score is associated with the various exposure indices, while this assocation can not be confirmed for the neurasthenic symptom score. Furthermore the neurasthenic and prenarcotic symptom score are both mutually related and related to the level of workstress.

While interpreting these results the shortcommings of this study should be kept in mind. Firstly, information bias may have influenced our results. Before our investigation attention was given in The Netherlands to the risks of neurological damage from long-term organic solvent exposure. Thus, solvent exposed workers might have had a tendency to report more complaints. Secondly, the detection of positive associations between symptoms and organic solvent exposure, as reflected by statistically significant raised odds Ratios or correlation coefficients "does not prove the existence of a causal relationship. Finally the "exposure indices" and "workstress" as introduced in the correlation matrix may be criticized because, as always, they are imperfect measures of the real situation. However, compared with other studies the introduction of these factors in the analysis of symptom reporting is an improvement.

In conclusion our study confirms the existence of acute neurotoxic effects among solvent exposed workers, as reflected by the occurrence of prenarcotic symptoms. However the study gives only Iimited evidence for the existence of chronic neurotoxic effects as reflected by the occurrence of neurasthenic symptoms, due to long-term exposure to organic solvents. Compared with Scandinavian studies the detected associations are rather weak. Furthermore the nature of these symptoms is not consistent with the classification of the wHo ${ }^{5}$, the relations are stronger for additional symptoms (lability of mood, headache, vertigo) as for the real core symptoms (memory and concentration difficulties). Besides, the role of workstress in the development of these neurasthenic symptoms among both exposed and non-exposed workers should be further examined.

Therefore it seems justifiable to conclude that the organic solvent syndrome type I, characterized by the occurrence of these symptoms without any neurological damage $^{6}$, is not a frequently occurring occupational disease among Dutch solvent exposed workers. 
TEFIRZNES

1. Akelson $O$, Hane $N$, Hogstedt $C$. Current aspects of solvent-related disorders. In: zenz c, ed. Developnents in occupational medicine, Chigaco. Year Book Medical publishers $1980: 237-240$.

2. World Health Organisation. Environmental Health 5. Chronic effects of organic solvents on the central nerwous system. Copenhagen, WHO, 1985.

3. Grasso P, Sharrat M, Davies DM, Irwine D. Neurophysiological and psychological disorders and occupational exposure to organic solvents freview section). Fd chen Toxic 1984; 22, 10: 819-852.

4. Baker Eu, Fine LJ. Solvent Neurotoxicity: The current evidence feditoriall. J Occup Med 1986; $28: 126-129$.

5. Waldron HA. Solvents and the brain (editorial). Brit J Ind Med 1986; 43: 7374.

6. Cranmer JM, Goldberg L. Human aspects of solvent neurobehavioral effects. Report of the workshop Session on Clinical and Epidemiological Topics. Neurotoxicology $1987 ; 7: 43-56$.

7. Hogstedt $C$. Hane $M$, Axelson $O$. Diagnostic and Health Care Aspects of Worker Exposed to Solvents. In: Zenz $C$, ed. Developments in occupational medicine, Chicago. Year Book Medical Publishers 1980: 249-257.

8. Fidler AT, Baker EL, Letz RE. Neurobehavioural effects of occupational exposure to organic solvents among construction painters. Brit I Ind Med 1987; 44: $292-308$.

9. Husman K. Symptoms of car painters with long-term exposure to a mixture of organic solvents. Scand $J$ Work Environ Health $1980 ; 6: 19-32$.

10. Schlesselman JiJ. Case-control studies. Design, conduct, analysis. Oxford Undwersity press, New York, 1982 . 


\section{CHAPTER 9}

ORGANIC SOLVENT EXPOSURE AND PREMATURE DISABIUITY

DUE TO NEUROFSYCHIATRIC DISORDERS:

State of the art in epidemiological research.*

C van Vliet ${ }^{1}$, GMH Swaen $^{1}$, JMM Meijers $^{1}, \mathrm{Tj}^{\mathrm{d}}$ de Boorder ${ }^{1}, \mathrm{~F}$ sturmans $^{2}$

1

Dept. of Occupational and Environmental Health and Toxicology, University of Limburg, PO Box 616, $6200 \mathrm{MD}$ Maastricht, The Netherlands.

2 Dept. of Epidemiology, University of Limburg.

* Submitted for publication 
ABSTRACT

A review 19 presented of all epidemiological studies investigating the relationship between organic solvent exposure and premature disability due to neuropsychiatric disorders. The overall relative risk for exposed workers compared with non-expoged workers was calculated to be 1.64 for all neuropsychiatric disorders and 2.40 for neurotic disorders. However, the results of the concerned studies might be influenced by a considerable amount of bias, hampering the interpretation of the presented data. Despite all critical notes that can be expressed with respect to the applied study designs and the validity of the results, the existence of an increased risk for disability benefits, especially among highly exposed workers, can not be excluded.

\section{INTRODUCTION}

Chronic neurotoxic effects due to long-term organic solvent exposure have received substantial scientific and public interest during the past fifteen years. Several articles thouroughly reviewing this issue have been published ${ }^{1,2}$. However, there is still a lack of international agreement with respect to the existence and the nature of these effects ${ }^{3}$.

From the nature of the syndromes supposed to be associated with long-term exposure to organic solvents, such as presenile dementia and the psycho-organic syndrome, emerges the question whether the involved exposed workers are at higher risk for being prematurely disabled due to neuropsychiatric disorders.

so far the relationship between organic solvent exposure and premature disability due to neuropsychiatric disorders has been investigated in 4 scandinavian and 1 Swiss gtudy ${ }^{4-8}$. Recently a Dutch case-control study has been carried out investigating the same relationship ${ }^{9}$. All scandinavian studies reveal positive relationships, whereas the studies conducted outside scandinavia do not reveal such clear positive relationships between organic solvent exposure and neuropsychiatric disorders. The objective of this study is to compare and to discuss the various study designs and study results in order to find indications for the origin of these contradicting results and to determine the validity of the studies involved. 


\section{THE EPIDEMIOLOGICAL STUDIES}

The epidemiological studies discussed in this review have either a case-control or a cohort design. Both study designs can be classified as forms of observational longitudinal epidemiological research. Prior to a short description of each study, some general information regarding the relevant study designs will be provided.

In the case-control approach the investigator must first define the disease of interest. Subsequently it must be established who are the cases of the particular disease and what group will serve as the control group. Next, information should be collected on past exposure of the cases and controls. In this approach the epidemiologist seeks to uncover differences in exposure between cases and controls. In the cohort approach the investigator first identifies a population that has experienced a particular exposure and then determines the subseguent health outcome. Morbidity or mortality rates in the cohort are then compared with those in some less exposed section of the cohort. with those in another non-exposed cohort or with the health experience in the general population ${ }^{10}$.

\section{CASE-CONMROL STUDIES}

The first case-control study on neuropsychiatric ajsorders anong workers exposed to solvents was conducted in sweden, using data from a regional pension fund ${ }^{4}$. A restriction was made to skilled workers in various trades with some connection to the construction industry. Cases were defined as individuals receiving a disability pension because of some type of mental disorder, whether or not in combination with somatic disorders. Mental disorders of obvious somatic origin, such as dementia from a traumatic brain injury, encephalitis etc, and primary disability, schizophrenia or manic-despressive psychosis were excluded from the study. However, cerebral atrophy, headache of unknown origin and unspecified vertigo were accepted as cases. If other neuropsychiatric disorders occurred in combination with alcoholim, alcoholism was considered as the main diagnosis. The cases were classified by the authors, according to the WHO-Classification (ICD-8). Referents received a disability pension on the basis of some other disease, whereas the information in the register showed no indication of any kind of mental disorder. 
The age criteria for cases and controls were set at 35 and 64 years. The timespan covered the years 1969 through 1973. Exposure was defined as years of painting. varnishing or carpet laying, as obtained fron the pension register filles. The sudy included 151 cases and 248 controls. The odds Ratio was 1.8 for neuropsychiatric aisorders and did not change when the cases of alcoholism were excluded from the analysis. A dose response relationship was indicated by the elevated odds Ratio with increasing duration of exposure.

A similar study design was applied in a Finnish case-control study ${ }^{6}$. Cases and controls were selected from the register of the Finnish Employment Pension Fund. The age limits were set at 35 and 64 years. The cases comprised of all male construction workers who had been granted a disability pension because of certain neuropsychiatric disorders during the period 1978-1980. The disease categories included in this study were the same as in the investigation by Axelson et $a 1^{4}$. Alcoholism was also treated similarly to the former study. The referents were selected from the construction workers who had been granted a disability pension for reasons other than neuropsychiatric disorders. Cases and controls were matched pairwise with regard to the starting dace of pension and age at that date within the range of two years. The material consisted of 374 pairs. Information on accupation, as obtained from the registers, was used as indicator of solvent exposure. Painters and carpet layers were regarded as being exposed. The results of this study indicated that solvent exposure increases the risk of being prematurely disabled due to neuroses, but early pensioning due to alcoholism or other neuropsychiatric disorders is not increased by solvent exposure. Furthermore no dose response relationship was found.

Another case-control study on neuropsychiatric disorders among workers exposed to solvents was conducted in Denmark ${ }^{8}$. Data were obtained on all members of the carpenter and cabinet makers trade union who received disability or early old age pensions during the period January 1, 1971 to December 31, 1975. Diagnoses were obtained from official hospital records through linkage. Cases were selected as disability and early old age pensioners with the following primary or secondary diagnoses: psychoses, neuroses, changes of character, oligophrenia, mental retardation and diseases of the nervous system or sensory organs. Controls, matched on type of pension and age, were selected from union members with other diseases who were also pensioned during the same time period.

From a total of 412 eligible study subjects, 342 li.e. 287 disability pensioners and 55 old age pensioners) could be located in 1978. Information regarding occu- 
pational exposure and vocational training was obtained both directly from the study subjects by means of a questionnaire and from the files of the trade union. An employment history suggesting 4,000 hours of work with organic solvents was the criterion used to define highly exposed subjects. The results are presented for different groups of pensioners, different sets of case entities and diferent criteria of exposure. The Odds Ratio for neuropsychiatric disorders in former enployees with high indoor exposure was 2.8. Cabinet makers, and especially cabinet makers with high exposure to lacquers and glues, had a higher risk of receiving a disability pension for a neuropsychiatric disease than carpenters. The calculated Odds Ratios were adjusted for differences in age, alcohol consumption and previous head injuries.

Recently a Dutch case-contral study was undertaken to verify the results obtained in Scandinavian countries and to determine the current situation in the Netherlands $^{9}$. The population base was defined as the Dutch painters and construction Workers Organizations that are responsible for the payment of disability benefits. Cases were defined as male persons receiving disability benefits due to some neuropsychilatric disorder as from a date between 1 July 1984 and 1 July 1986. All diagnoses, as described in group $\mathrm{V}$ of the wHO-classification of Diseam ses (9th revision), were accepted as cases. The control population consisted of a random sample of 1,000 persons from the total population base, taking into account the differences in population size and age distribution between the painters and construction workers organizations.

Questionnaires were used to collect information about vocational training, occupational history, exposure to organic solvents and the presence of potential confounding factors. 252 Cases (response: 61.6\%) and 822 controls (response: 69.75) participated in the study by returning completed questionnaires. Painters. carpet layers and road markers were classified as the exposed group, while ald other occupations were considered non-exposed.

The Odds Ratio for all neuropsychiatric disorders (OR $=1.17$ ) did not reveal an increased risk for painter to receive disability benefits due to neuropsychiatric disorders. An increased $O R$ was detected with respect to neuroses $(O R=2.3)$. whereas the risk to become disabled due to another frequently diagrosed neuropsychiatric disorder, adjustment reactions was decreased among painters $(O R=0.86)$. The odds Ratios were adjusted for differences in age, education level, marital status, smoking habits, alcohol consumption and Quetelet-index. The analysis of dose-response relationships showed no elevated risk with increasing duration of exposure. However, using more detailed information about organic solvent exposure, some tendencies towards positive dose response relationships were revealed. 
A cohort study of the risk of disability among painters with special regard to disabing presenile dementia as an occupational disease was conducted in Denmark ${ }^{7}$.

A cohort of 2,601 male painters and 1,790 male brick layers from the copenhagen area was identified and followed during the period January 1, 1971 - December 31. 1975. In this period the incidence of disability pensioning was examined for the two occupational groups and for a referent population of all copenhagen men over 30 years of age.

The painters were found to have an increased relative risk to three neuropsychiatric diagnostic groups, namely psychosis, diseases of the nervous system lexcluding epilepsy) and neurosis, personality disorders etc. The increase was significant in all three diagnostic groups in comparison to both referent groups. The pension diagnoses were later reclassified by the authors in order to extract all cases of "presenile dementia" from the neuropsychiatric diagnoses. According to the author's reclassification half of the painters had a diagnosis of presenile dementia and the risk ratio was 2.8 compared to the brick layers.

Recenlty the results have been published of a Swiss cohort study among Geneva painters and electricians ${ }^{5}$. The 1,916 painters and 1,948 electricians who resided in the Canton of Geneva at the time of the 1970 census, were identified and followed up to 1984 . During the study period 121 disability pensions were awarded to painters and 59 to electricians. Disability due to neuropsychiatric disorders gave a risk among painters of 1.8 relative to the risk among electricians. Solvent exposure, however, was confounded with alcoholism which was associated with neuropsychiatric disorders in 12 of 20 painters and only one of 10 electricians. The results of the six studies discussed above are sumarized in Table 1.

\section{RISK ASSESSMENT}

The results of the epidemiological studies indicate an increased risk for organic solvent exposed workers to be prematurely disabled due to neuropsychiatric disorders. 


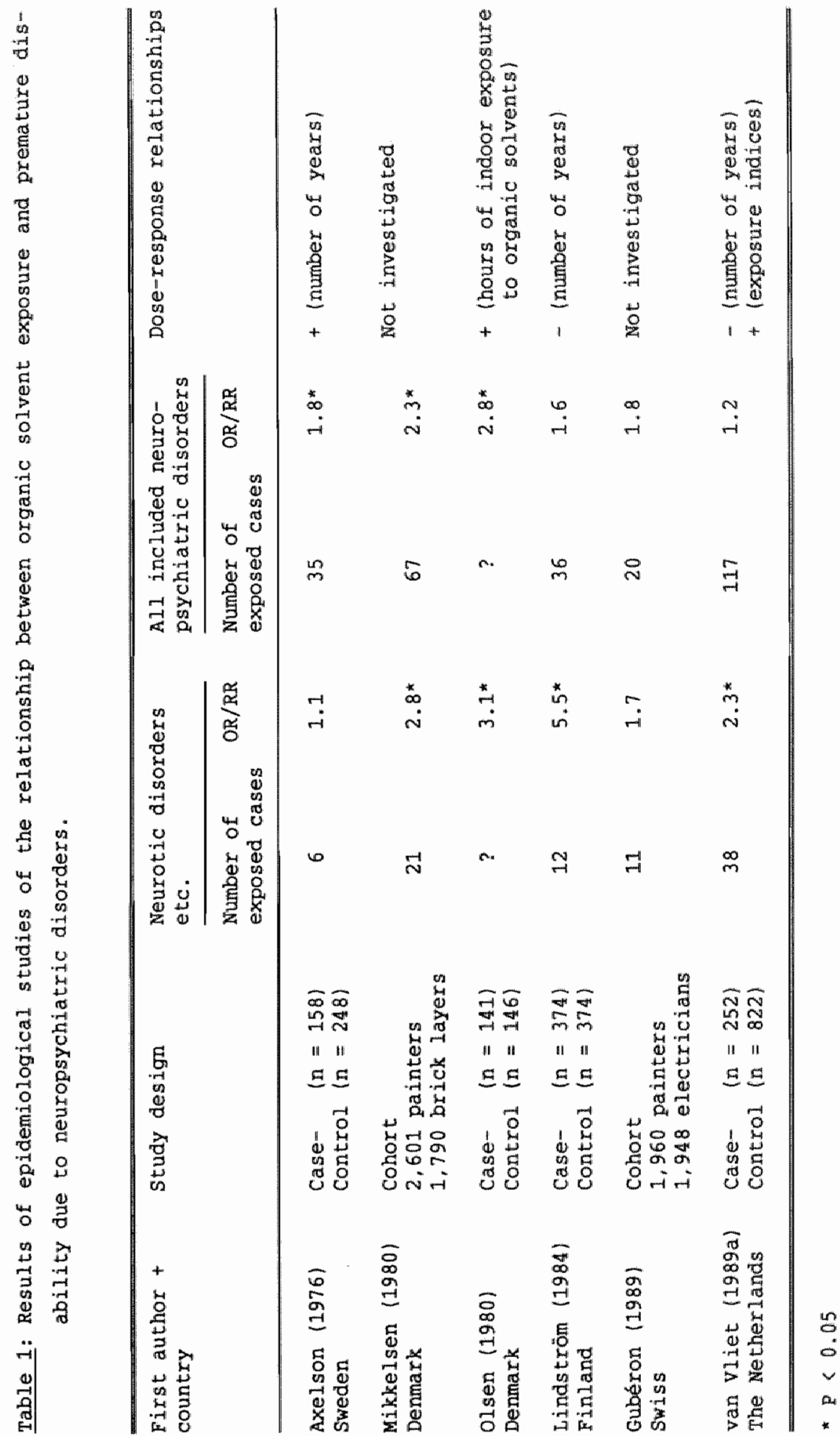


However, the estimate of the strength of this relationship varies considerably fram one study to another.

It ig possible to combine these separate risk estimates into one overall risk assessment. Therefore a weighing factor can be applied in accordance to the study size. In this instance, the number of exposed cases of respectively neurotic disorders and all included neuropsychiatric disorders was used as the weight for each study (Table 1). Unfortunately, the relevant data were not available from the gtudy of olsen and sabroe ${ }^{8}$. The combined relative risk was obtained by dividing the sum of product of the weight and the relative risk (OR/RR) by the sum for the weights. By this procedure an overall relative risk for all neuropsychiatric diagnoses was calculated to be 1.64 and for neurotic disorders 2.70 ."

GENERAL DISCUSSION

As stated earlier, the results of the epidemiological studies described in this paper seem to indicate an increased risk for premature disability due to neuropsychiatric disorders among workers exposed to organic solvents. However, the results of these studies could be influenced by a considerable amount of bias which hampers the interpretation and the validity of the presented data.

The control groups used in the Scandinavian case-control studies consisted of persons receiving disability benefits for reasons other than neuropsychiatric disorders. If some non-solvent occupations, e.g. brick laying, demands greater physical excercise, this could lead to more disability benefits due to for instance muskulo-skeletal disorders among the non-exposed group. Consequently, a relative underrepresentation of solvent exposed workers will accur in the control group, leading to an artificial increase of the odds Ratio ${ }^{41}$. This, perhaps rather hypothetical pitfall, was avoided in the Dutch case-control study by selecting healthy persons receiving no disability benefits as controls.

* Neuropsychiatric disorders:

Overal $\mathrm{RR}=\frac{(35 \times 1,8)+(67 \times 2,3)+(36 \times 1,6)+(20 \times 1,8)+(117 \times 1,2)}{35+67+36+20+117}=1,64$

Neurotic disorders:

Overal $\mathrm{RR}=\frac{(6 \times 1,1)+(21 \times 2,8)+(12 \times 5,5)+(11 \times 1,7)+(38 \times 2,3)}{6+21+12+11+38}=2,70$ 
Furthermore the choice of the type of occupation may introduce blas. It can not be excluded that determinants for later disability pension, such as education, intelligence, personality, health, are associated with the earlier choice of occupations. Bias may result if persons predisposed to psychiatric diseases are more likely to choose occupations involving exposure to organit solvents ${ }^{7,8}$. Another possible source of bias could have occurred if solvent exposed workers suffering from neuropsychiatric symptoms are more likely to change jobs than solwent exposed workers without these symptoms. This so called "healthy worker effect" may conceal an existing association 7,8 .

otherwise, selection bias can result from a large non-response among the appraached cases and controls, as occurred in the Dutch case-control study. However, the non-response of cases and controls was equally divided among the painters (mainly exposed) and construction workers (mainly non-exposed) organization, thus diminishing the probability that selection bias has influenced the study results. The classification of neuropsychiatric disorders by social security physicians is another source of potential bias. The physicians granting disability benefits are no trained psychiatrists and diagnostic difficulties may easily arise in the broad field of neuropsychiatric disorders. Furthermore, awareness of the association between organic solvent exposure and neuropsychiatric disorders among the physicians might facilitate diagnosing neuropsychiatric disorders among solvent exposed workers. This effect, leading to an overestimation of the risk, could have influenced the results of studies conducted after the publication of the Scandinavian reports, introducing the organic solvent syndrome as an "occupational disease". However, the concerning studies $5,6,9$ show compared to the former studies, no increased risk for neuropsychiatric disorders among solvent exposed workers.

Except for the study of Van Vliet et al ${ }^{9}$, diagnostic codes related to the bith revision of the International Classification of Diseases were used to classify the cases. However, the codes or groups of codes included in the studies varied, thus restricting the comparibility of the results. Furthermore, reclassification by the authors, with awareness of exposure status, might have introduced further possibilities towards the occurrence of classification bias 4.7 .

Union files and registers or information from participants were used to collect information about the presence or absence of solvent exposure. Existing knowledge of the neurotoxic effects of organic solvents may have biased the selfreported. information of the cases. Again, this bias could have influenced in particular the recently conducted case-control study ${ }^{9}$.

The possible influence of confounding factors has not been thoroughly examined 
in most sudies. Only two studies ${ }^{8}, 9$ have included other factors than age in the analysid. Evaluation of the role of alcohol consumption which is an important neurotoxic agent, leads to contradictory results. The scandinavian authors more or less exclude alcohol abuse as an important confounding factor, whereas the Swiss study suggests that the association between solvent exposure and neuropsychiatric disorders was confounded by alcoholism. There is no clear explanation for this discrepancy. Perhaps the officially propagated negative attitude towards alcohol consumption in scandinavian countries promotes underreporting of alcohol consumption. The possible synergism of solvents effect and alcohol emphasizes the importance of considering the effect of alcohol as a possible confounding factor. Beside alcohol consumption, other factors such as gender, ethnicity, constitutional factors, are recommended to be studied in relation to neuropsychiatric disorders and organic solvent exposure ${ }^{12}$. The Dutch case-control study indicated the importance of workstress as a confounding factor.

The andysis concerning dose-response relationships revealed warying results. However, it must be emphasized that the number of years is a very crude estimate of the intensity of exposure. The use of more detailed and accurate data of solvent exposure may yield different results as became evident in the Dutch casecontrol study.

Certainly, a comparison between the results of studies conducted inside and outside scandinavia shows some differences. The Swiss authors conclude that their data reveal inadequate evidence to support the existence of a solvent related neuropsychiatric syndrome among Geneva painters. The Dutch authors do not rule out the possibility of a neuropsychiatric effect among a small group of highly exposed painters. However, they are not convinced that the increased risk among painters with respect to disability due to neurotic disorders is related to organic solvent exposure. Misclassification bias has been postulated to be an alternative explanation for this relationship ${ }^{13}$.

There is no clear explanation for the discrepancy described above. Differences in study design (e.g. including of healthy controls and more potential confounding factors in the Dutch case-control study) might play a role. Furthermore, it must be kept in mind that disability is the result of a process involving both medical and social factors. The disability systems differ from one country to another, thus perhaps introducing varying amounts of selection bias. On the other hand, some authors ${ }^{14}$ state that in the past exposure to organic solvents has been very high in Scandinavian countries compared with other European countries due to differences in working conditions (more interior work and spray painting). 
CONCLUSIONS

The results of the studies investigating the relationship between organic solvent exposure and premature disability due to neuropsychiatric aisorders may be influenced by a considerable amount of bias. Selection-, information- and misclassification bias may have worked in various directions, leading to overestimations or underestimations of true associations.

An overall estimation indicates stronger association with neurotic disorders than with all neuropsychiatric disorders included in the relevant studies. "rhis trend is confirmed by a recent case-control study carried out in the Netherlards, which took into account some of the criticisms against the scandinavian studies. However, the relationship between organic solwent exposure and neurotic disorders evokes some questions. It might be taken as an indication for some preexposure susceptibility towards neuropsychiatric disorders among persons choosing occupations involving organic solvent exposure, because neurotic disorders are related to character and personality characteristics.

on the other hand, it is possible that neurotoxic effects of organic solvent exposure diminish the ability of the irvolved workers to cope with stress. This could lead to disproportionate (neurotic) reactions to daily life stress among the affected solvent exposed workers.

All in all, the existence of chronic neurotic effect of organic solvent exposure leading to premature disability can not be excluded, especially not among highly exposed subjects. In view of the seriousness of the effects, efforts should be made to control organic solvent exposure among solvent exposed workers.

\section{REFERENCES}

1. Grasso $P$, Sharrat $M$, Davies DM, Irvine D. Neurophysiological and psychological disorders and occupational exposure to organic solvents (review section). Fd Chem Toxic 1984; 22; 10: 819-852.

2. Baker EL, Smith TJ and Landrigan PJ. The Neurotoxicity of Industrial Solvents: A Review of the Literature. Am J Ind Med 1985; 8: 207-217.

3. Waldron HA. Solvents and the brain leditorial). Br J Ind Med 1986; 43: 7374. 
4. Holson 0 , hane $\mathrm{k}$, hogstedt $C$. A case-reference study on neuropsychiatric disorders among workers exposed to solvents. Scand J Work Environ Health $1976 ; 2: 14-20$.

5. Guberan $E$, Usel $M$. Raymond $L$, Tissot $R$, Sweetnam PM. Disability, mortality and Incidence of cancer among Geneva painters and electricians: A historical prospective study. Br J Ind Med 1989; 46: 16-23.

6. Lindströn $K$, Riihimäk $H$, Hănninen $K$. Occupational solvent exposure and neuropsychiatric disorders. Scand J Work Environ Health 1984; 10: 321-323.

7. Mikkelsen S. A Cohort study of Disability Pension and Death among Painters with special Regard to disabling presenile Dementia as an occupational Disease. Scand J Soc Med 1980; $16: 34-43$.

8. Olsen J, Sabroe S. A case-reference study of neuropsychiatric disorders among workers exposed to solvents in the Danish wood and furniture industry. Scand J Soc Med 1980: 16: 44-49.

9. Vliet van $C$, Swaen GMH, Volovics $A$, Tweehuysen $M$, Meijers MM, Boorder de Tj, Sturmans $F$. Neuropsychiatric disorders among solvent exposed workers. First results of a Dutch case-control study. This dissertation, 1989.

10. Sturmans F. Epidemiologie. Theorie, methoden en technieken. 2de Druk, Dekker d.d. Vegt, Nijmeger, 1984.

11. Hogstedt $C_{*}$ Axelson 0 . Long-term health effects of industrial solvents. A critical review of the epidemiological research. Med Lav 1986; $77: 11-22$.

12. Cranmer JM, Goldberg L. Human aspects of solvent neurobehavioral effects. Report of the Workshop session on Clinical and Epidemiological Topics. Neurotoxicology $1987 ; 7: 43-56$.

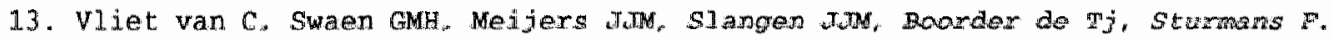
Neurotic disorders due to organic molvent exposure: Fact or pitfal1? This dissertation, 1989.

14. Triebig G, Claus D, Csuzda J, Druschky KF, Holler P, Kinzel $W$, LehrI $S$, Reichwein $\mathrm{P}$, Weidenhammer $W$, Weitknecht WU, Weltle $D$. Erlanger Malerstudie. Multidiszipl inăre Querschnittsuntersuchung zur Neurotoxizitat von Lösemitteln in Farben und lacken. ASP - Sonderheft 1986; 9: 1-45. 
CHAPTER 10

SUMMARY AND CONCLUDING REMARKS 
SUMARY AND COMCUUDTNO REMARS

A case-control study has been carried out in order to investigate the relationship between premature disability due to neuropsychiatric disorders and organic solvent exposure, as experienced by Dutch painters.

The population base consisted of persons affiliated to the Dutch Painters organization (SFB) and twenty percent of the persons affiliated to the Dutch Construction workers organization (SFB). Cases were defined as persons receiving disability benefits due to a diagnosis from the diagnostic main group of neuropsychiatric disorders. The control population consisted of a stratified sample from the population base (non-cases) taking into account differences in population size and age distribution between the painters- and construction workers organization. 252 cases and 822 controls participated in the study.

By means of questionnaires information was collected from the participants about their occupational history, exposure to organic solvents, prenarcotic and neurasthenic symptoms and the presence of potential confounding factors, such as education level and alcohol abuse. The risk to receive disability benefits due to neuropsychiatric disorders was not increased for exposed workers, compared to nonexposed workers $(O R=1.01)$. Adjustment for a number of confounding factors increased the odds Ratio $(O R=1.17)$, but not to a level indicating a statistically significant association between occupational exposure to organic solvents and neuropsychiatric disorders leading to long-term disability.

A subdivision of the main group of neuropsychiatric disorders in different diagnostic categories revealed a statistically significant increased risk among exposed workers to receive disability benefjts due to neurotic disorders lOR = 2.301. However, other diagnoses that may not be readily distinguishable from neurotic disorders (e.g. ICD-309: adjustment reactions) were more often awarded to non exposed persons. A combination of these diagnoses did not show an increased risk for painters. Therefore it can not be excluded that the detected association between organic solvent exposure and disability due to neurotic disorders may have been the result of classification bias.

In the Scandinavian countries three case-control studies with a somewhat similar study objective and study design have been carried out. Axelson et a ${ }^{1}$ and olsen and Sabroe ${ }^{2}$ observed an increased risk among solvent exposed workers to be prematurely disabled due to all (non-specific) neuropsychiatric disorders. The study of Lindström et al ${ }^{3}$ revealed an association with neurotic disorders, but not with other neuropsychiatric disorders. The results of the study reported here are in 
close agreement with the study carried out by Lindstrom et a ${ }^{3}$. However the association detected in this Finnish study $(O R=5.5)$ is stronger than the association emerging from our study $(\mathrm{OR}=2,3)$.

Beside resemblances in study design with these scandinavian studies some differences can be mentioned:

- The use of different ICD-codes for the cases (ICD-8 versus ICD-9):

- Differences between The Netherlands and Scandinavia in organization and execution of the disability pension system;

- The choice of a different control group ("healthy" versus "disabled" persons).

Therefore caution must be taken while comparing our study results with the Scandinavian studies.

The detection of a statistically significant association between organic solvent exposure and neuropsychiatric disorders is no guarantee for the existence of a causal relationship. The final proof for a causal association can only be given by experimental research. In view of the lack of experimental data a judgement must be made by weighing the available evidence 4 . This weighing should include additional information beside the strength of the association as revealed by the study. Always, great value is given to the existence of a dose-response relationship. In case of a causal relationship one might assume that the risk to develop an 'organic solvent syndrome' increases with higher and longer' exposure to organic solvents. From the literature a number of indications point to the existence of such dose-response relationships ${ }^{1,2}$. Orbaek et $1^{5}$ stated that the organic brain syndrome due to organic solvent exposure could develop after at least 10 years of occupational solvent exposure. Our study did not show a relationship between exposure dose, expressed in duration of exposure (years) and the risk of premature disability due to neuropsychiatric disorders. Lindstrom et al who also, as mentioned before, detected an increased risk for neurotic disorders, likewise did not abserve a positive dose-response relationship. However the translation of exposure dose into the number of working years is a crude estimate of exposure. Not every painter will be exposed to the same level of organic solvents. In the analys is of our data an effort has been nade to quantify this individual variation by the introduction of the painters index. This painters index is based on information from the questionnaires about painters activities assumed to be associated with high exposure to organic solvents.

Not only painters, but also other construction workers may regularly work with organic solvents or organic solvent containing products (such as glues). Therefore a "general" exposure index, taking into account these exposures, was con- 
structed. With regard to the painters index a positive dose-response relationship was detected. A higher wave of this exposure index appeared to be associated with a higher risk of receiving disability benefits due to neuropsychiatric disorders. However, high values of this painters index were only found among a small group of painters.

Strikingly, a positive dose-response relationship of the general exposure index could be demonstrated for painters, but not for other construction workers. Possibly the exposure of painters to organic solvents is, even at the same level of this general exposure index, more intensive than anong construction workers. A construction worker indicating that he worked four or more times a week with organic solvents may for instance mean four brief moments, while a painter giving the same answer to this questions might have worked four whole days with organic solvents. Further analysis into the contributing elements of the painters index elucidated that the increased risk to be prematurely disabled due to neuropsychiatric disorders was mainly connected to "working with the paintspray" and "working with paint removers". Some other painting activities were also associated with elewated odds ratios, particularly working in poorly ventilated rooms. Poor ventilation can certainly contribute to the development of high concentrations of organic solvents in the workplace. However, in view of the limitations of this analysis no far-reaching conclusions may be drawn from this data.

The analysis revealed some indications that the possible increased risk of painters to be prematurely disabled due to neuropsychiatric disorders is not, or not exclusively, caused by exposure to organic solvents. Perhaps the workstress among painters is an important factor. Design and contents of the questionnaire used in this study were not primarily directed to establish the level of workstress to which the participants were exposed. The questions included in the questionnaire with regard to workstress can only give a superficial impression of the present workstress. Furthermore, decompensation by stressfactors needs not to contradict a possible neurotoxic effect of long-term exposure to organic solvents. Symptoms arising from this neurotoxic effect (such as forgetiulness, concentration disturbances, loss of initiative) may introduce problems in work-and private live, while on the other hand the neurotoxic effect of organic solvents may lead to a decreased stresstolerance, thus leading to earlier decompensation. Another finding emerging from this study concerns the statistical significant increased $O R$ of "working more than one day a week with other paints" and "more than one day a week burning off paints". As stated earlier no far reaching conclusions may be drawn from this part of the analysis. However, these results raise the question whether within the painting trade other potentially neurotoxic 
exposures (such as lead exposure) play a role in the development of neuropsychiatric disorders.

The analysis of prenarcotic and neurasthenic symptoms indicated that these symptoms occur more often among the exposed control population than among the non exposed control population. The occurrence of such symptoms anong workers occupationally exposed to organic solvents is in accordance with internationally published study results ${ }^{5-8}$. Within the exposed control population a correlation was found between the prenarcotic (acute) symptom score and the various exposure indices. However, such a correlation was not detected between the neurasthenic (chronic) symptom score and the painters- and general exposure index. None of the symptom scores were correlated to the duration of exposure. The strong correlation among the exposed and non-exposed control population between workstress and the acute/prenarcotic symptom scores was a remarkable finding.

In the above, it has been suggested that the relationship between organic solvent exposure and neurotic disorders, as emerging from our study results, may have been caused by classification bias. An additional analysis using information from the questionnaires revealed no indication to support the existence of a causal relationship between neurotic disorders and organic solvent exposure. The exposure of cases diagnosed as suffering from neurotic disorders did not appear to be higher or more intense than the exposure of cases diagnosed as suffering from other neuropsychiatric disorders. Furthermore, the symptoms reported by cases with neurotic disorders were not more in accordance with the symptoms attributed to the "organic solvent syndrome" 9 than the symptoms reported by cases with other neuropsychiatric disorders. The development of neurotic disorders might be rellated to some predisposing character structure ${ }^{10}$. Perhaps people with susceptibility to develop neuropsychiatric disorders tend to choose a job as a painter. However, on the basis of this study no pronouncement can be done with regard to the existence of differences in character structure between painters and construction workers.

Self-evidently attention must be given to the limitations of the study design. The case-control study design is rather sensitive to bias. This bias might have lead to an overestimation, but certainly also to an underestimation of the detected association between organic solvent exposure and neuropsychiatric disorders. Another limitation concerns the choice of the cases group. Attention was focussed on persons with neuropsychiatric disorders who receive disability benefits, indicating the existence of a prolonged and serious neuropsychiatric disease. It is possible that minor manifestations of the organic solvent syndrome not leading to prolonged disability were not detected in this study. 
To conclude, It rust be stated that the existerce of a small increased risk anong painters to be prematurely disabled due to neuropsychiatric disorders can not be excluded. The increased risk applies especially to painters who are exposed to high concentrations of organic solvents due to their working conditions or working practices. However, the detected associations are weaker than those emerging from the Scandinavian studies. Furthermore, the increased risk is restricted to the small group of painters with the highest organic solvent exposure. Among exposed workers the existence of prenarcotic lacutel symptoms due to organic solvent exposure is more clearly demonstrable than the occurrence of neurasthenic (chronic) symptoms. Furthermore it must be taken into account that other factors (e.g. workstress) might play a role in the increase of the risk among painters to be prematurely disabled due to neuropsychiatric disorders.

\section{REFERENCES}

1. Axelson 0 , Hane $M$, Hogstedt $C$. A case-referent study on neuropsychiatric disorders among workers exposed to solvents. Scand J Work Environ Health 1976; 2: $14-20$.

2. Olsen J, Sabroe S. A case-Reference Study of Neuropsychiatric Disorders among Workers Exposed to Solvents in the Danish Wood and Furniture Industry. Scand J Soc Med $1980 ; 16: 44-49$.

3. Lindström $K$, Riihimäki $H$, Hänninnen $K$. Occupational solvents exposure and neuropsychiatric disorders. Scand J Work Environ Health 1984; 10: 321-323.

4. Sturmans F. Epidemiologie, theorie, methoden en toepassing. Dekker \& van de vegt, Nijmegen, 1984.

5. Qrbaek P, Risberg I, Rosen I, Haeger-Aronsen B, Hagstadius $S$, Hjortsberg U, Regne11 $G$, Rehnström $S$, Svensson $K$, Welinder $H$. Effects of long-term exposure to solvents in the paint industry. A cross-sectional epidemiologic study with clinical and laboratory methods. Scand J Work Environ Health 1985; 11: 5-28.

6. Elofsson SA, Gamberale F, Hindrarsh I, Iregren A, Isaksson A, Johnsson I. Knave $B$, Lydahl $\mathbb{E}_{\text {, Mindus }} \mathrm{P}_{\text {, Persson } \mathrm{HE}}$, Philipson $\mathrm{B}$, Steby $\mathrm{M}$, Struwe $\mathrm{G}_{\text {。 }}$ Söderman E, Wennberg A, Widén $\mathbb{L}$. Exposure to organic solvents. A cross-sectional epidemiological investigation on occupational exposed car and industrial spray painters with special reference to the nervous system. Scand $J$ Work Environ Health 1980; 6: 239-273. 
7. Husman $K$. Symptoms of car painters with long-term exposure to a mixture of organic solvents. Scand J Work Environ Health 1980; 6: 19-32.

8. Seppäläinen AM, Husman $K$, Martenson $C$. Neurophysiological effects of longterm exposure to a mixture of organic solvents. Scand J Work Environ Health $1978 ; 4: 304-314$.

9. World Health Organisation. Environmental Health 5 . Cronic effects of organic solvents on the central nervous system and diagnostic criteria. Copenhagen, WHO, 1985.

10. Curran D, Patridge M, Storey P. Psychological medicine: An introduction to psychiatry. 8th ed. Edinburgh, London, Churchill Livingstone, 1976. 
CHAPTER 11

PSYCHISCHE AANDOENINGEN ONDER SCEILDERS; RESULTATEN VAN EEN PATIENTY-KONTROLE ONDERZOEK" (NEDERLANDSE SAMENVATTING)

C van Vliet ${ }^{1}$, GMH Swaen ${ }^{1}$, A Volovics ${ }^{2}$, JM Slangen ${ }^{1}$, JMM Meijers ${ }^{1}$, F sturmans $^{3}$, Tj de Boorder ${ }^{1}$

1 Vakgroep Arbeidsgeneeskunde, Milieugezondheidkunde en Toxicologie, Rijksuniversiteit Limburg, Postbus 616, 6200 MD Maastricht.

2 Vakgroep Medische Informatica en statistiek, Rijksuniversiteit Limburg.

3 Vakgroep Epidemiologie, Rijksuniversiteit Limburg. 
SAMENVATING

On na te gaan of ex ven verband bestat tussen vroegtijdige arbeidsongeschiktheid (Wao-intrede) op grond van psychische aandooningen en het werken met organische middelen is een patiënt-kontrole onderzok verricht onder personen die zijn aangesloten bij het sociaal Fonds schildersbedrijf en het Sociaal Fonds Bouwnijwerheid.

Het risiko woor schilders op wa-intrede tengevolge van psychische aandoeningen is, vergeleken met andere bouwvakkers, niet statistisch signifikant verhoogd loR $=1.17 \%$. Als er al sprake is van een verhoogd risiko bij schilders op neurotoxische effekten die tot WAO-intrede leiden, dan is het verhoogde risiko beperkt tot de (kleine) groep schilders met de hoogste blootstelling aan organische oplosmiddelen.

Onder blootgestele werknemers uit de kantrolepopulatie is het bestaan van akute (prenarkotischel klachten tengevolge van blootsteliing aan organische oplosmiddelen duidelijker aantoonbaar dan het optreden van chronische (neurasthene) klachten. Bovendien moet rekening worden gehouden met het feit dat andere faktoren (bijv. werkstress) een rol kunnen spelen in het ontstaan van deze klachten en in een eventuele verhoging van het risiko voor schilders op WAO-intrede door psychische aandoeningen.

\section{INLEIDING}

Schilders vormen binnen Nederland een beroepsgroep van cirka 35.000 werknemers ${ }^{1}$. Gezien de aard van hun werkzaamheden worden zij vrijwel dagelijks blootgesteld aan organische oplosmiddelen. In een voorgaand artikel is uitgebreid ingegaan op de akute en chronische neurotoxische effekten van langdurige blootstelling aan organische oplosmiddelen ${ }^{2}$.

Het meeste onderzoek naar chronische neurotoxische effekten van langdurige blootstelling aan organische oplosmiddelen is uitgevoerd in scandinavië, alwaar het 'organic solvent syndrome' t.g.v. blootstelling aan organische oplosmiddelen in de zeventiger jaren als een officiële beroepsziekte is erkend en kriteria zijn uitgewerkt voor het stellen van deze diagnose ${ }^{3}$. op een bijeenkomst van een whowerkgroop in copenhagen, waar in de oplosmiddelenproblematiek centraal stond, werd 
de uitvoering van epidemiolagisch onderzoek, net name in landen waar het 'organic solvent syndrome' nog niet is erkend, genoemd als ển van de "needs for further research" ${ }^{4}$. Bovendien was nader onderroek in Nederland met betrekking tot de relatie tussen blootstelling aan organisch oplosmiddelen en het ontstatan van neuropsychiatrische aandoeningen gewenst toen scheffers e.a. ${ }^{5}$ hun. in opdracht. van de stichting Arbouw, uitgevoerde verzuimonderzoek publiceerden. Uit dit onderzoek kwam naar voren dat schilders een 35 hogere kans liepen dan bouwvakkers om de maximale uitkeringstermijn van de ziektewet te halen op grond van psychische aandoeningen.

Bij het onderzoek van Scheffers e.a. ${ }^{5}$ zijn een aantal kanttekeningen te maken die

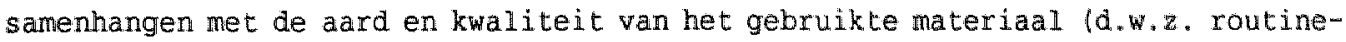
matig verzamelde verzuimstatistieken). Bij de interpretatie van de onderzoeksresultäten moet dan ook de nodige voorzichtigheid in acht worden genomen. De stichting Arbouw heeft daarom opdracht verleend aan de vakgroep Arbeldsgeneeskunde van de Rijksuniversiteit Limburg om een diepgaander onderzoek wit te voeren naar de relatie tussen blootsteling aan organische oplosmiddelen en het ontstaan van psychische aandoeningen bij schilders.

De centrale vraag waarop dit onderzoek antwoord tracht te geven is of de Nederlandse schilders tengevolge van deze blootstelling aan organische oplosmiddelen een verhoogd risiko lopen op wa-intrede tengevolge van psychische aandoeningen. Tevens tracht dit onderzoek antwoord te geven op de vraag of onder aan organische oplosmiddelen geëxponeerde werknemers meer neuras thene en prenarkotische klachten woorkomen.

\section{ONDERZOEKSOPZET}

Dit onderzoek heeft de vorm van een patient-kontrole onderzoek. De eerste stap in de opzet van een patiënt-kontrole onderzoek is het afbakenen van de doelpopulatie, hier wordt bedoeld de populatie waaruit patienten en kontrolepersonen atkomstig zullen ziju. Het patient-kontrole onderzoek is uitgevoerd onder werknemers die zijn aangesloten bij het sociaal Fonds schildersbedrijf (SFS) er het Sociaal Fonds Bouwnijuerheid (SFB). Het is van belang dat er binnen de onderzoekspopulatie variabiliteit bestaat voor wat betreft blootstelling aan de mogelijke etiologische faktor, i.c. organimche oplosmiddelen. De power (d.w.z. de statistische kans om een in werkelijkheid aanwezig verband in het onderzoek te 
vinden) van een patient-kontrole onderzoek is o.a. afhankelijk van het adntal In het onderzok betrokken cases en kontrolepersonen en van het percentage kontrolepersonen dat is blootgesteld (geweest) aan de mogelijke etiologische faktor (1.c. organische oplosmiddelen). De efficiêntie van een patiënt-kontrole onderzoek, gedefinteerd als een situatie warbij zo min mogelijk cases en kontrolepersonen nodig zijn om in kombinatie met een hoge power een aanwezig werband te vinden, is optimaal als ongeveer de helft van de kontrolepopulatie is blootgesteld aan de nogelijke etiologische faktor en de andere helft niet.

Er van uitgaande dat bij het SFS aangeslotenen in principe geëxponeerd zijn en de bij het SFB aangeslotenen in principe niet en dat het SFB ongeveer $7 \times$ groter is dan het SFS, hoeft slechts $1 / 7$ van de SFB-populatie in het onderzoek betrokken te worden.

Deze situatie is benaderd door van het SFB alleen werknemers in het onderzoek te betrekken wens zesde cijfer van het registratienumer een 6 of 7 is (d.w.z. geboren op dag $06,07,16,17,26,27$ van enige maand). Op deze manier is slechts énviffde van de SFB-populatie in de onderzoekspopulatie betrokken.

\section{SELEKTIE VAM CASES EN KONTROLES}

Patiënten (cases) zijn gedefinieerd als personen (mannen) uit de doelpopulatie die met ingang van een datum gelegen tussen 01-07-1984 en 01-07-1986 een arbeidsongeschiktheidsuitkering ontvingen op grond van een psychische aandoening. Bij ziekte van een werknemer melat een bedrijf het ziektegeval bij zijn Sociaal. Fonds. Het ziekteverzuim van schilders en bouwvakkers wordt begeleid door verzekeringsgeneeskundigen van de sociale Fondsen. Bij voortdurende ziekte heeft men in de regel na 52 weken recht op een arbeidsongeschiktheidsuitkering.

De mate van arbeidsongeschiktheid wordt voor schilders en bouwvakkers vastgesteld door de Gemeenschappelijke Medische Dienst (GMD). De verzekeringsgeneeskundigen van de GMD kennen een diagnose toe die vervolgens, door speciaal hiervoor opgeleid administratief personeel, wordt ongezet in een diagnosekode. Voor deze kodering wordt gebruik gemaakt van de "International classification Diseases" (ICD, 9de revisie, 1975). De ziekten worden ingedeeld in 17 hoofdgroepen, waarvan hoofdgroep $\mathrm{v}$ de psychische aandoeningen omvat.

De kontrolepopulatie is opgebouwd uit een representatieve steekproef van 1.000 personen (mannen) uit de doelpopulatie, rekening houdend met de verschillen in 
grootte en leeftijdsopbouw tussen SFS en SFB. Personen uit de kontrolepopulatie ontvingen gến WAO/AAW-uitkering.

\section{DATAVERZAMELING}

De verzameling van gegevens vond in dit onderzoek plaats met behulp van een vragenlijst. De vragenlijst die bij de uitwoering van het patiënt-kontrole onderzoek is gebruikt bestaat uit 44 vragen (Appendix 4).

In deze vragenlijst komen de volgende onderwerpen aan de orde:

- Personalia;

- WAO/AAW-vragen;

- Opleiding:

- Beroep:

- Werkomstandigheden en expositie aan organische oplosmiddelen bij schilders;

- Expositie aan organische oplosmiddelen in overige beroepen;

- Klachten gerelateerd aan het werk (prenarkotische klachten);

- Gezondheidstoestand;

- Symptomen passend bij het 'organic solvent syndrome';

- Potentiële verstorende variabelen: Quetelet-index, alkoholgebruik, roken.

De cases en kontrolepersonen zijn schriftelijk én telefonisch benaderd met de vraag of zij aan dit onderzoek hun medewerking wilden verlenen. De keuze voor een gekombineerde schriftelijke en telefonische benadering werd ingegeven door de wens een zo hoog mogelijke respons (d.w.z. percentage van de benaderde personen die deelnemen aan het onderzoek) te bereiken.

\section{RESPONS}

In de periode tussen 01-7-1984 en 01-07-1986 zijn 505 mannen uit de totale onderzoekspopulatie arbeidsongeschikt geworden door psychische aandoeningen. Naast de steekproef van 1.000 kontrolepersonen kwamen dus 505 cases in aanmerking om aan dit onderzoek deel te nemen. Bij de benadering van de respondenten is uitgegaan 
van personen die telefondsch bereikbar waren. Het besluit om het onderzoek tot de telefonisch bereikbare groep te beperken is genomen toen bleek dat de respons bimen de niet telefonisch bereikbare groep op een bijzonder laag nivo bleef steken $(\mathrm{ca}, 20$ d $30 \%$ ).

Van de cases waren 409 personen (81:) en van de kontroles waren 822 personen $(82,2 \%)$ telefonisch bereikbaar. De respons van de personen die werden benaderd voor deelname aan het onderzoek lag voor de cases op 61,6\% en voor de kontroles op 69,7\%. Voor de kontrolepersonen die wel telefonisch bereikbaar waren, maar niet dan het onderzoek wilden meedoen, zijn niewwe kontrolepersonen getrokken, zodat de kontrolepopulatie uiteindelijk 822 personen omvat. Aangezien voor cases deze mogelijkheid niet bestond, bedraagt het aantal in het onderzoek betrokken cases 252 .

RESULTATEN

1. Odds Ratios

De eerste stap in de analyse van de gegevens van het patiënt-kontrole onderzoek was na te gaan hoeveel van de in het onderzoek betrokken cases en kontrolepersonen blootgesteld zijn geweest aan de eventuele causale faktor. Toegepast op dit onderzoek: hoeveel cases en kontrolepersonen zijn beroepsmatig blootgesteld geweest aan organische oplosmiddelen?

Niet alle werknemers die zijn aangesloten bij het SFs zullen blootgesteld zijn geweest aan organische oplosmiddelen. Bovendien komt blootstelling aan organische oplosmiddelen ook voor in verschillende beroepen binnen de bouwnijverheld. De hoogste blootstelling treft men echter aan in de volgende beroepsgroepen:

- schilders

- wegmarkeerders

- tapijtleggers

- autospuiters

In het kader van dit onderzoek zijn werknemers die ooit werkzaam zijn geweest in éen van de bovenstaande beroepen gedefinieerd als "blootgesteld aan organische oplosmiddelen". Werknemers uit alle andere beroepsgroepen zijn hier gerangschikt onder de niet-geëxponeerden. 
Hoofdgroep $\mathrm{v}$, psychische aandoeningen, omvat een zestiental ICD-kodes. Het is niet duidelijk onder welke ICD-kode personen met een "organic solvent syndrome" t.g.v. Iangdurige expositie an organische oplosmiddelen gediagnostiseerd zullen worden. Daarom is voor alle ICD-kodes afzonderlijk, en poor verschillende groepen ICD-kodes, nagegaan of er een relatie met de expositie aantoonbaar is. Tabel 1 geeft een overzicht van de resultaten. Uit deze tabel blijkt dat alleen de ICD-kode "300" (neurosen) statistisch signifikant vaker aan de geëxponeerden (patiënten) is toegekend. Er zijn echter ook rcD-kodes. zoals "309" (situatieve of exogene reaktie), die vaker aan de niet-geexponeerden zijn toegekend.

De relatie tussen blootstelling aan organische oplosmiddelen en het optreden van psychische aandoeningen kan worden vertekend door de inwerking van verstorende variabelen (confounders). Verstorende variabelen kunnen een in we werkelijkheid niet bestaande associatie suggereren, dan wel een reëel bestaande associatie maskeren. Het is daarom belangrijk om verstorende variabelen te identificeren en in de analyse te betrekken. Met behulp van de vragenlijsten is informatie verzameld omtrent een aantal faktoren die als "potentiële confounders" kunnen worden gezien ten aanzien van de relatie tussen blootstelling aan organische oplosmiddelen en het ontstaan van psychische aandoeningen. Het betreft hier: leeftijd, burgerlijke staat, opleiding, Quetelet-index, alkoholgebruik en roken. Een statistische methode om deze faktoren in de analyse te betrekken is de logistische regressie-analyse. Door middel van deze analyse wordt de Odds Ratio (OR) gekorrigeerd voor de invloed van deze variabelen. In Tabel 2 is de gekorrigeerde Odds Ratio weergegeven voor een aantal Igroepen) ICD-kodes. Uit deze tabel komen dezelfde trends naar voren: alleen het risiko voor schilders om arbeidsongeschikt te worden t.g.v. neurosen IICD$300)$ is statistisch signifikant verhoogd.

\section{Dosis-respons relatie}

De mate waarin werknemers zijn blootgesteld aan organische oplosmiddelen kan onderling sterk variëren. Bij de anwezigheid van een causaal verband tussen blootstelling aan organische oplosmiddelen en het optreden van psychische aandoeningen mag worden verwacht, dat het risiko hoger is voor werknemers die een hogere blootstelling aan organische oplosmidaelen hebben ondervonden. Er zijn gén exakte kwalitatieve en kwantitatieve gegevens voorhanden ontrent de blootstelling van de in dit onderzoek betrokken personen. 
Tabe 1. Odde Ratios voor verschillende (groepen) ICD-kodes van de in het onderzoek betrokken populatie.

\begin{tabular}{|c|c|c|c|c|c|c|}
\hline \multirow[t]{2}{*}{ ICD-kode } & \multicolumn{2}{|c|}{ Geëxponeerden } & \multicolumn{2}{|c|}{$\begin{array}{l}\text { Wiet-geëxpo- } \\
\text { neerden }\end{array}$} & \multirow[t]{2}{*}{$\mathrm{OR}$} & \multirow{2}{*}{$\begin{array}{l}\text { Betrouwbaar- } \\
\text { heidsinterval } \\
(\alpha=0,05)\end{array}$} \\
\hline & $n$ & 11 & $n$ & $(1)$ & & \\
\hline $\begin{array}{l}\text { 296: Manisch-depressieve } \\
\text { psychose/inwolutie } \\
\text { depressie }\end{array}$ & 5 & $(4,3)$ & 2 & $(1,5)$ & 2.92 & $0.56-15.13$ \\
\hline 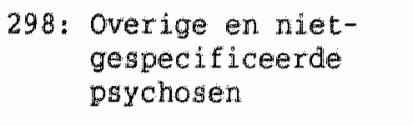 & 1 & $(0,8)$ & 0 & $(0,0)$ & - & - \\
\hline 300: Neurosen & 38 & $(32,5)$ & 23 & $(17,0)$ & 1,93 & $1,13-3,30$ \\
\hline $\begin{aligned} \text { 301: } & \text { Persoonlijkheids- } \\
& \text { stoornissen }\end{aligned}$ & 4 & $(3,4)$ & 2 & $(1,5)$ & 2,34 & $0.43-12,85$ \\
\hline 303: Alkoholverslaving & 4 & $(3,4)$ & 5 & $(3.7)$ & 0,94 & $0,25-3.53$ \\
\hline 304: Drugvers laving & 2 & $(1,7)$ & 0 & $(0,0)$ & $-\infty$ & - \\
\hline $\begin{array}{l}\text { 306: Fysiologische } \\
\text { funktiestoornissen } \\
\text { door psychische } \\
\text { oorzaken }\end{array}$ & 5 & $(4.3)$ & 12 & $(8,9)$ & 0.49 & $0,17-1,40$ \\
\hline $\begin{array}{l}\text { 307: Speciale symptomen } \\
\text { en syndromen, niet } \\
\text { elders vermeld }\end{array}$ & 1 & $(0,8)$ & 0 & $(0,0)$ & - & - \\
\hline $\begin{array}{l}\text { 309: Situatieve of exo- } \\
\text { gene reaktie }\end{array}$ & 54 & $(46,2)$ & 85 & $(63,0)$ & 0.74 & $0,51-1,07$ \\
\hline $\begin{aligned} \text { 310: } & \text { Psychische reaktie } \\
& \text { t.g. } v_{\text {. organisch }} \\
& \text { hersenletsel }\end{aligned}$ & 0 & - & 1 & $(0,7)$ & $\infty$ & - \\
\hline $\begin{aligned} \text { 31: } & \text { Depressite niet } \\
& \text { elders vermeld }\end{aligned}$ & 3 & $12,6 y$ & 5 & $(3,7)$ & 0,70 & $0,17-2,95$ \\
\hline $\begin{array}{l}296+298^{1} \\
303 t / m 311^{2} \\
300+309+311^{3} \\
\text { Totaal:290t/m } 311\end{array}$ & $\begin{array}{r}6 \\
69 \\
95 \\
117\end{array}$ & $\begin{array}{r}(5,1) \\
(58,9) \\
(81,2) \\
(100,0)\end{array}$ & $\begin{array}{r}2 \\
108 \\
113 \\
135\end{array}$ & $\begin{array}{r}(1,5) \\
(80,0) \\
(83,7) \\
(100,0)\end{array}$ & $\begin{array}{l}3,51 \\
0,75 \\
0,98 \\
1,01\end{array}$ & $\begin{array}{l}0,70-17,49 \\
0,54-1,05 \\
0,72-1,33 \\
0,76-1,34\end{array}$ \\
\hline $\begin{array}{l}\text { Totaal antal kontrole- } \\
\text { personen }\end{array}$ & 379 & & 4.43 & & & \\
\hline
\end{tabular}

ad 1: 'psychosen'

ad 2: "overige niet psychotische staornissen"

ad 3: ICD-kodes passend bij de symptomatologie van het 'organic solvent syndrome" 
Tabe1 2: Ongekorrigeerde en gekorrigeerde voor leeftijd; burgerlijke stabt, opleiding, roken, alkoholgebruik en quetelet-index) odds katios voor verschillende groepen ICD-kodes.

\begin{tabular}{|c|c|c|c|c|}
\hline & $\mathrm{OR}^{1}$ & $\begin{array}{l}\text { Betrouwbaarheids- } \\
\text { interva]. } \\
(\alpha=0,05)\end{array}$ & $\mathrm{OR}^{2}$ & $\begin{array}{l}\text { Betrouwbaarheids- } \\
\text { interval } \\
(\alpha=0,05\rangle\end{array}$ \\
\hline Alle cases & 1,01 & $(0.76-1.34)$ & 1,17 & $(0.85-1.61)$ \\
\hline $\operatorname{ICD}-300$ & 1,93 & $(1,13-3,30)$ & 2,30 & $(1,19-4,08)$ \\
\hline$I C D-309$ & 0.74 & $(0.51-1.07)$ & 0,86 & $(0.57-1.29)$ \\
\hline$I C D-300+309+311$ & 0,98 & $(0.72-1.33)$ & 1,16 & $(0.82-1.63)$ \\
\hline $\operatorname{ICD}-300 \mathrm{t} / \mathrm{m} \quad 311$ & 0.75 & $(0.54-1.05)$ & 0,85 & $(0,59-1,24)$ \\
\hline
\end{tabular}

1

2

Ongekorrigeerde adds Ratio

Gekorrigeerde Odds Ratio

Wel is het mogelijk on met behulp van een antal vragen uit het enquêteformulier een schatting te maken van de blootsteling aan organische oplosmiddelen. voor deze analyse is de blootstelling "vertaald" in een drietal indices:

1. Het aantal jaren werkzaam in én van de beroepen die gepaard gaan met hoge blootstelling aan organische oplosmiddelen (schilder, tapijtlegger, wegmarkeerder, autospuiter);

2. Schildersindex. Deze index bestaat uit de summatie van een aantal scores op vragen over werkzaamheden van schilders welke gepaard gaan met een hoge blootstelling aan organische oplosmiddelen. Het betreft het werken met alkydwerven, afbijtmiddelen en de verfspuit. Een hoge score is een aanduiding voor een hogere blootstelling aan organische oplosmiddelen " De maximale score bedraagt 24 .

3. Algemene expositie-index. Veel bouwvakkers komen, alhoewel zij niet in én van de "blootgestelde beroepen" werkzaam zijn, toch regelmatig in kontakt met organische oplosmiddelen. zij werken bijv. in én ruimte met schilders of maken gebruik van lijmen, afbijtmidalen, oplosmiddelen en ontvetters. De scores van de vragen die op deze faktoren betrekking hebben, zijn bij elkaar opgeteld. De maximale score is 48 . Deze vragen zijn door alle respondenten, inklusief de schilders, beantwoord. Een hogere score is een aanduiding voor een hogere blootstelling aan organische oplosmiddelen. 
Voor lk van deze expositie-indices is gekeken naar het bestaan van een dosisrespons relatie. Daarbij is gekorrigeerd voor een antal verstorende variabelen, te weten leeftijd, burgerlijke stat, opleiding, alkoholgebruik, roken en quetelet-index. De analyse is uitgevoerd met behulp van logistische regressie. Er lijkt vrijwel gén verband te zijn tussen het aantal jaren dat men werkt onder blootstelling aan organische oplosmiddelen en het $r$ siko arbeidsongeschikt te worden tengevolge van een psychische aandoening. Wel is een duidelijke relatie aantoonbaar tussen de hoogte van de "schildersindex" en het risiko om arbeidsongeschikt te worden t.g.v. psychische aandoeningen. Deze trend is statistisch signifikant ( $\leq 0,05)$. Ook voor de algemene expositieindex is deze trend, zij het minder sterk, aanwezig $(P \leq 0,08)$. Hoge warden van deze expositie indices komen echter alleen voor in een kleine groep schilders en bouwvakkers.

Deze resultaten wijzen erop dat mogelijk de aard en/of intensiteit van de blootstelling an organische oplosmiddelen een rol spelen in het ontstaan van chronische neurotoxische effekten. Het is daarom van belang te onderzoeken of bepaalde werkzaamheden van schilders een verhoogd risiko veroorzaken ten aanzien wan het arbeidsongeschikt worden tengevolge van psychische aandoeningen. Uit de betreffende analyse komen als belangrijkste risikofaktoren naar voren: werken met afbijtmiddelen, met de verfspuit en werken in slecht geventileerde ruimten.

\section{Gezondheidsklachten}

Het enquêteformulier bevat een aantal vragen die betrekking hebben op neurasthene gezondheidsklachten, welke in de literatuur in verband zijn gebracht met het 'organic solvent syndrome" 4 .

Bij de analyse van deze symptomen is in eerste instantie gekeken naar de scores op deze vragen binnen de kontrolepopulatie. De onderliggende vraagstelling bij deze analyse is of onder blootgestelde werknemers (die niet arbeidsongeschikt $z i j n$ verklaard op grond van een psychische aandoeningl meer neurasthene klachten voorkomen dan bij de niet-blootgestelde werknemers uit de kontrolepopulatie. Bij het woorkomen van meer neurasthene klachten is het risiko wellicht groter om ooit afgekeurd te worden op grond van een "psychische aandoening". Het is echter niet goed mogelijk om door middel van deze symptomenlijst onderscheid te maken tussen akute en chronische neurotoxische effekten. 
In Tabel $3 \mathrm{zijn}$ de vragen weergegeven warop de blootgestelae werknemers ignifikant meer klachten aangeven dan de niet-blootgestelde werknemers.

Tabe 1 3: Neurasthene en prenarkotische klachten die signifikant vaker worden gerapporteerd door aan organische oplosmiddelen blootgestelde kontrolepersonen dan door de niet-blootgestelde kontrollepersonen.

\begin{tabular}{|c|c|c|c|}
\hline $\begin{array}{c}\text { Blootgestelde } \\
\text { kontrales } \\
\ln =379)\end{array}$ & $\begin{array}{l}\text { Niet-bloot- } \\
\text { gestelde } \\
\text { kontroles } \\
(n=443)\end{array}$ & OR & $\begin{array}{l}\text { Betrouwbaar- } \\
\text { heids interval } \\
\{\alpha=0.05\}\end{array}$ \\
\hline
\end{tabular}

Neuras thene klachten:

- Snel afgeleid als men probeert zich te koncentreren

- 's Nachts vaak wakker worden

- Stemingsverminder ing zonder direkte aanleiding

Prenarkotische klachten:

- Misselijk gevoel

- Kortademigheid

- Gebrek an eetlust

$\begin{array}{rrr}7 & 3,47 & 1,45-8,28 \\ 19 & 1,99 & 1,11-3,58 \\ 8 & 3,35 & 1,48-7,60\end{array}$

Door middel van de vragenlijst is tevens informatie verzameld omtrent het op treden van een skala aan prenarkotische klachten "tijdens of vlak na het werk". Prenarkotische klachten kunnen een weerspiegeling zijn van de akute neurotoxische effekten van organische oplosmiddelen. Uit tiabel 3 blijkt dat de geëxponeerde kontrolepersonen signifikant vaker positief scoren op een drietal klachten, te weten: "misselijk gevoel", "kortademigheid" en "gebrek aan eetlust". Kenmerkend voor prenarkotische klachten is dat de klachten snel verdwijnen als de expositie aan organische oplosmiddelen verdwijnt. Van de geexponeerde kontroles geeft 13,2 een vermindering van de klachten aan tijdens het weekend of vakantie, voor de niet-geëxponeerden bedraagt dit percentage 7,42. Dit statistisch signifikante werschil suggereert dat de door de 
blootgestelde kontroles gerapporteerde prenarkotische klachten ook in werkeij jheid sarienhangen met de blootstelling aan organische oplosmiddelen.

Binnen de blootgestelä kontrolepopulatie is géen korrelatie gevonden tussen de neurasthene klachtenrapportage en de diverse expositie-indices. Een korrelatic was wel aarwezig tussen de prenarkotische (akute) klachtenrapportage en de schilders- en algernene expositie-index. Opvallend was tenslotte de korrelatie die binimen de blootgestelde en niet-blootgestelde kontrolegroep bestond tussen werkstress en prenarkotische en neuras thene klachtenrapportage.

\section{Neurasen}

In het voorafgande is gesuggereerd dat er een relatie bestat tussen blootstelling aan organische oplosmiddelen en neurosen. Een aanvullend onderzoek met behulp var, informatie uit de vragenlijsten bracht géén aanwijzingen aan het licht die het bestaan van een kausale relatie tussen blootstelling aan organische oplosmiddelen en het ontwikkeler van neurosen ondersteunen. De blootsteling van cases met "neurosen" bleek niet hoger en/of intensiever te zijn geweest dan de blootstelling van cases gediagnostiseerd met andere psychische adadoeningen. De gerapporteerde klachten van de cases met neurosen waren niet meer in overeensteming met de klachten die volgens de literatur bij het organic solvent syndroom passen ${ }^{4}$, dan de gerapporteerde klachten van cases met andere psychische aandoeningen.

\section{BIAS}

Bij de interpretatie van de onderzoeksresultaten is het noodzakelijk aandacht te besteden aan de bias (vertekening), welke in dit onderzoek een rol kan hebben gespeeld. Sturmans ${ }^{6}$ onderscheidt twee belangrijke vormen van bias: selektie bias en informatie bias. Selektie bias kan zijn opgetreden als de niet in het onderzoek betrokken groep (weigeraars, telefonisch niet bereikbare personen) kwa blootstelling en/of diagnosekodes verschilt van de wel in het onderzoek betrokken groep. Van de niet in het onderzoek betrokken cases en kontroles is bekend bij welk sociaal fonds (SFS of SFB) ze zijn aangesloten. Tevens is van de cases de ICD-kode bekend. Op grond van deze gegevens kon worden gekonkludeerd dat met 
betrekking tot deze twee faktoren (sociale fondsen en ICD-kodes) geen belangrijke selektie bias was opgetreden.

Een andere potentiële bron van selektie bias wordt mogelijk gevorma door de toekenning van diagnoses door de verzekeringsarts aan de patienten. Hoofdgroep $v$, psychische aandoeningen, vornt een moeilijk diagnostisch terrein. zo zal bijwoorbeeld bij een reaktief beeld tengevolge van "stress" een keuze moeten worden gemakt tussen ICD 300 (meurosen) en ICD 309 (situatieve of exogene reaktie). De vraag of men met een "normale" of een "neurotische" reaktie op stress te maken heeft, zal niet door alle verzekeringsartsen op dezelfde wijze worden beantwoord. Bedacht dient echter te worden dat schilders én bouwvakkers zijn gezien door de artsen van éen medische dienst, zodat deze misklassifikatie de blootgestelden en de niet-blootgestelden in gelijke mate treffen.

Arbeidsmarktfaktoren kunnen ook een rol spelen in het risiko op Wa-intrede. Net name oudere en werkloze werknemers komen soms ten onrechte (?) in de wao terecht. Deze situatie speelde vooral in de zeventiger jaren, maar de anwezigheid van deze arbeidsmarktfaktoren tijdens de onderzoeksperiode (april 1984 - april 1986) kan zeker niet worden uitgesloten. Deze vorm van bias zal echter zowel bij de blootgestelden als bij de niet-blootgestelden zijn opgetreden. Het vinden van verbanden tussen blootstelling aan oplosmiddelen en psychische aandoeningen zal door dit soort faktoren echter worden bemoeilijkt.

In een onderzoek waarbij door middel van vragenlijsten informatie wordt verzameld, moet altijd rekening worden gehouden met het optreden van informatie bias. Bovendien is in Nederland in 1984 via een perskonferentie meer bekendheid gegeven aan de relatie tussen psychische aandoeningen en blootstelling aan organische oplosmidielen. Een vorm van informatie bias, waarbij schilders die op de hoogte zijn van deze relatie geneigd zijn om meer klachten aan te geven, is dus niet uitgesloten.

\section{BESCHOUTHING EN KONKLUSIES}

Het risiko dat schilders in vergelijking met andere bouwvakkers lopen op wAOintrede tengevolge van psychische aandoeningen, is ook na korrektie voor werstorende variabelen niet statistisch signifikant verhoogd $\operatorname{COR}=1,17)$. De onderzoekers zijn echter van mening dat op basis van de resultaten van dit onderzoek niet zonder meer gesproken kan worden van een negatieve studie. Deze konlusie is 
gebaseerd op de gevonden positieve trends roor diverse dosis-respons relaties. Tevens is een verhoogd isiko op Who-intrede tengevolge van psychische aandoeningen gekonstateerd voor schilders die door de aard van hum werkaamheden aan hoge koncentraties organische oplosmiddelen blootstaan (bijw. werken in slecht geventileerde rutmten, werken met afbijtmiddelen). Een verdeling van de hoofdgroep "psychische aandoeningen" in verschillende diagnosegroepen brengt aan het licht dat de diagnose "neurogen" (ICD 300) vaker bij schilders als diagnose wordt gebruikt (OR $=2,3)$. De diagnose "situatieve of exogene reaktie" (ICD 309) die niet scherp te onderscheiden is van de diagnose "neurosen" wordt echter minder waak aan schilders toegekend, terwijl de kombinatie van beide diagnosekodes geen verhoogd risiko voor schilders laat zien. Het is dan ook mogelijk dat de gevonden associatie tussen blootstelling aan organische oplosmiddelen en "neurosen" het gevolg is van een klassifikatie-artefact.

Alhoewel het bestaan van een (licht) verhoogd risiko op wa-intrede tengevolge van psychische aandoeningen op grond van deze onderzoeksresultaten niet uitgesloten kan worden, zijn de gevonden associaties in leder geval zwakker dan uit overeenkomstig scandinavisch onderzoek naar voren komt ${ }^{7-9}$. Als er al sprake is van een verhoogd risiko bij schilders op neurotoxische effekten die tot wa-intrede leiden, dan is het verhoogde risiko beperkt tot de (kleine) groep schilders met de hoogste blootstelling aan organische oplosmiddelen.

Naast de overeenkomsten in onderzoeksopzet met de scandinavische onderzoeken, zijn echter ook enkele verschillen te noemen:

- Het gebruik van een andere ICD-kodering voor de cases (ICD-9 versus ICD-8);

- Verschillen tussen Nederland en Scandinavie met betrekking tot de criteria voor het toekennen van een arbeidsongeschiktheidsuitkering;

- De keuze van een andere kontrolegroep (gezonden versus arbeidsongeschikten).

Bovendien bestaat de mogelijkheid dat de Scandinavische schilders in het verleden aan hogere koncentraties oplosmiddelen blootgesteld zijn geweest dan hun Nederlandse kollega's 10 .

Tenslotte komt uit dit onderzoek naar voren dat onder blootgestelde werknemers uit de kontrolepopulatie het bestaan van akute (prenarkotische) klachten tengevolge van blootstelling aan organische oplosmiddelen duidelijker aantoonbaar is dan het optreden van chronische (neurasthene) klachten. Niet uitgesloten kan worden dat andere faktoren (zoals bijv. werkstress) een belangrijke rol spelen in het ontstaan van deze klachten en in het mogelijk aanwezige licht verhoogde risiko voor schilders op wa-intrede door psychische aandoeningen. 
LITERATUUR

1. Econamisch Instituut voor de Bouwnjuverheid (EIB), Het werknemersbestand in het schildersbedrijf in 1985, Amsterdam, 1986.

2. Vliet van $C$, Swaen GMH, Meijers JMM, sturmans F, Boorder de Tj. The organic solvent syndrome among painters: Fact or fiction? This dissertation. 1989.

3. Juntunen J, Hupli $W$, Hernberg $S$, Luisto $M$. Neurological picture of organic solvent poisening in industry. Int Arch Occup Environ Health 1980; 46: 219231.

4. World Health Organisation, Environmental Health 5. Chronic effects of organic solvents on the central nervous system and diagnostic criteria. Copenhagen, 1985.

5. Scheffers TML, Wit de JMF, Saris-Wijnands MJ, Ziekteverzuim van schilders in de bouwnijverheid. Stichting Bedrijfsgezondheidsdienst voor de Bouwnijverheid, Amsterdam, 1984.

6. Sturmans F. Epidemiologie. Theorie, methoden en toepassing. Dekker van de Vegt, Nijmegen, 1984.

7. Axelson 0 , Hane $M$, Hogstedt $C$. A case referent study on neuropsychiatric disorders among workers exposed to solvents. Scand $J$ Work Environ Health 1976; 2: $14-20$.

8. Olsen J. Sabroe S. A case-reference study of neuropsychiatric disorders anong workers exposed to solvents in the Danish wood and furniture industry. Scand J Soc Med 1980; suppl 16: 44-49.

9. Lindström $K$, Riihimảki $H$, Hänninen $K$. Occupational solvent exposure and neuropsychiatric disorders. Scand $J$ work Environ Health $1984 ; 10: 321-323$.

10. Triebig G, Claus D, Csuzda I, Druschky KF, Holler P, Kinzel W, Lehrl $S$, Reichwe in $P$, weidenhammer $W$, Weitbrecht WU, Weltle $D$, Schaller $\mathrm{KH}$, Valentin H. Cross-sectional epidemiological study on neurotoxicity of solwents in paints and lacquers. Int Arch Occup Environ Health 1988; 60: 233-241. 


\section{WOORD WAN DANK}

Het onderzoek dat in dit proefschrift wordt beschrewen is tat stand gekonen en tot een goed einde gebracht dankzij de medewerking van een groot aantal personen en enkele stichtingen:

- De stichting Arbouw heeft de uitvoering van dit onderzoek gesubsidieerd. Dearnaast hebben de heren van Duivenbooden, Koningsveld en Ligteringen een aktieve rol gespeeld in de begeleiding van het onderzoek.

- De Stichting Sociaal Fonds Schildersbedrijf (SFS) en de Stichting Sociaall Fonds Bouwnijverheid (SFB) hebben door middel van hun koöperatieve opstelling een essentiële bijdrage geleverd aan de realisatie van dit onderzoek. De heren vergers, Visser en de kieviet van het SFB en de heren Mos, Quint en zweerts van het SFS wil ik op deze plaats met name noemen.

- Ruim duizend schilders en bouwvakkers uit het gehele land ben ik erkentelijk voor het invullen van de vragenlijsten, danwel hun toestemming voor de inzage van hun medische dossiers.

- Binnen de Vakgroep Arbeidsgeneeskunde, Milieugezondheidkunde en Toxicologie zijn meerdere mensen te noemen die een belangrijke rol hebben gespeeld bij de realisatie van dit onderzoek. Co-promotor Gerard Swaen, mijn mentor op het gebied van de arbeidsepidemiologie, is de initiator van dit onderzoek geweest. en was zeer naw betrokken bij alle fasen van het onderzoek. Jos Siangen heeft een belangrijke bijarage geleverd aan de automatisering en verwerking van de data. Marliese van Missen ben ik bijzonder dankbaar voor de niet te evenarer. wijze warop $z$ ij dit proefschrift op tekstverwerker heeft gezet en de gehele lay-out heeft verzorgd. Marianne Tweehuysen heeft als onderzoeksassigtente mij bijgestaan in de verzameling van de data. Kamergenoot Jan Meijers heeft met een geduldig oor en opbeurende woorden alle "ups en downs" van het onderzoeksgebeuren meegemakt. Ook de overige kollega's van de vakgroep hebben door het kreëren van een prettige werksfeer mijn dank verdiend.

- De Vakgroep Medische Informatica en Statistiek is in de personer van Lex volowics en Marion de Leeuw behulpzaam geweest bij de analyse van de data. 
- Mijn Promotores, de hooggeleerde heren de Boorder en Sturmans hebben allebei op hun eigen wijze een opbowende en konstruktiewe rol gespeeld als begeleiders en kwaliteitsbewakers van het onderzoek.

- De leden van de beoordel ingscomissie dank ik voor de voortwarende wijze waarop $z$ if bij de beoordeling van het manuscript te werk $z$ ijn gegaan.

- Tenslotte wil ik peter noemen die in de latste fase van de promotieperikelen heeft gezorgd voor een stabiel en "relativerend" thuisfront.

Het noemen van namen brengt altijd het risiko met zich mee dat een aantal personen ten onrechte niet worden genoemd. Als u tot deze vergeten kategorie mocht behoren, bied ik u bij voorbaat mijn oprechte excuses aan. Een promovendus is ook maar een feilbáar mens. 
CURRICULUM VITAE

Volgens de Burgerlijke stand ben ik op 11 juli 1959 te Noordwijkerhout geboren. Mijn middelbare schoolopleiding heb ik genoten op het pieter Groen college te Katwijk, alwaar ik in juni 1977 het wo-diploma behaalde. In september 1977 begon ik met de studie Geneeskunde aan ce Rijksuniversiteit Leiden $(=$ RUL $)$. Na het kandidaatsexamen (juni 1980) en het doktoraalexamen loktober 1982) volgde de periode van senior co-assistentschappen. In mei 1984 werd deze periode afgesloten met het behalen van het artsexamen (cum laude). Gedurende de periode september 1984 tot en met januari 1985 ben ik werkzaam geweest bij de Rijks Geneeskundige Dienst (thans: Rijks Bedrijfsgezondheids- en Bedrijfsveiligheids Dienst). Hoofdafdeling Medische Zaken te Den Haag. In het kader van een arbeidservaringsprojekt hield ik mij bezig met de standaardisatie en operationalisering van de histamineprovokatietest. Mijn werkzaamheden bij de vakgroep Arbeidsgeneeskunde, Milieugezondheidkunde en Toxicologie (AMT) van de Rijksuniversiteit Limburg ( $=$ RL), aanvankelijk als wetenschappelijk assistent en later als universitair docent, vingen aan in februari 1985.

De uitvoering van het in deze dissertatie beschreven onderzoek vormde een belangrijk onderdeel van mijn werkzaamheden. Andere onderzoeksaktiviteiten lagen op het. terrein van "Arbeid en Gezondheid", met een duidelijk accent op de arbeidsepidemiologie. Daarnaast participeerde ik in het onderwijs aan studenten van de Faculteit der Geneeskunde en de Faculteit der Gezondheidswetenschappen.

In januari 1985 ben ik begonnen met de vierjarige oplejding tot sociaal-geneeskundige, tak arbeids-en bedrijfsgeneeskunde, door middel van een medewerkerschap aan een uniwersiteit (i.c. de vakgroep AMT van de $\mathbb{R L}$ ). 
APPENDICES

Appendix 1: List of Three-digit Categories of mental disorders (ICD-9) Appendix 2: Letter of introduction

Appendix 3: Letter accompanying the questionnaire Appendix 4: Questionnaire 
APTENDIX is LIST OF THREE-DIGIT CATEGORIES OF MENTAL DISORDERS (ICD-9)

\section{MENTAL DTSORDERS}

oxganic psychotic conditions (290-294)

290* Senile and presenile organic psychotic conditions

291 Alcoholic psychoses

292 Drug psychoses

293 Transient organic psychotic conditions

294 Other organic psychotic conditions (chronic)

Other psychoses (295-299)

295* Schizophrenic psychoses

296* Affective psychoses

297 Paranoid states

298* Other nonorganic psychoses

299 Psychoses with origin specific to childhood

Neurotic disorders, personality disorders and other nonpsychotic mental disorders

$(300-316)$

$300^{*}$ Neurotic disorders

$301^{\star}$ Personality disorders

302 Sexual deviations and disorders

303* Alcohol dependence syndrome

$304^{*}$ Drug dependence

305 Nondependent abuse of drugs

306* Physiological malfunction arising from mental factors

307* Special symptoms or syndromes not elsewhere classified

308 Acute reaction to stress

309* Adjustment reaction

310* Specific nonpsychotic mental disorders following organic brain damage

31.* Depressive disorder, not elsewhere classified

312 * Disturbance of conduct not elsewhere classified

313 Disturbance of emotions specific to childhood and adolescence

314 Hyperkinetic syndrome of childhood

315 Specific delays in development

316 Psychic factors associated with diseases classified elsewhere 
Mental retardation $(317-319)$

$317^{\text {* }}$ Mild mental retardation

$318^{*}$ Other specified mental retardation

319 Unspecitied mental retardation

* ICD-codes included in the list of diagnostic codes as operated by the federation of Dutch industrial insurance boards. 


\section{APBENEIX 2: LETTER OF INTRODUCTON}

Dear sir,

The University of Limburg, in collaboration with the Dutch Organization for the Improwement of working Conditions in the Construction Industry (stichting Arboww), intends to carry out an investigation regarding health and working conditions among painters and construction workers.

Persons receiving disability benefits, previously working as painter or construction worker, will also be included in this study. The objective of this project is to investigate relationships between working conditions among painters and construction workers and the development of health complaints.

Since you are or haye been working as construction worker or painter, we request you to participate in this study. If you are willing to participate in this study, you will be sent a questionnaire. This questionnaire includes items about your education, (former) occupations and health conditions. Altogether it will take 30 to 60 minutes to answer all the questions.

In a few days you will be contacted by telephone by an employee of the university of Limburg to hear if you are willing to participate in the study. Selfevidently carefulness and privacy protection will be maintained at the processing of your data. At the university your name will only be known to the undersigned and my immediate collegue. The questionnaires will be anominised, so your name can not be mentioned in the reporting of the data.

Thanking you in advance for your cooperation.

Yours faithully,

C. van vijet, physician

Department of Occupational Medicine

university of Limburg

Maastricht 


\section{APPENDIX 3: LETTER ACCONPANYING THE QUESTIONWMIRE}

Dear sir,

Herewith you receive, as agreed by telephone, a questionnaire for the project: "Health and working conditions among painters and construction workers". The investigation is carried out by the University of Limburg, in collaboration with the Dutch Organization for the Improvement of Working Conditions in the construction Industry (Stichting Arbouw).

The questionnaire includes items about your education, the occupations you have practised and your health conditions. Most questions can be answered by marking the fixed round corresponding to your choice of the given answers of the relevant guestion. For some other questions you are requested to write down your answer. Read all questions carefully and take your time for completing the questionnaire. It is very important that you completely answer all questions referring to you. If you are in doubt about the meaning of a question, please contact the undersigned. You can return the questionnaire in the enclosed prepostaged envelope.

Thanking you in advance for your co-operation.

Yours faithfully,

C. van vilet, physician

Department of Occupational Medicine

University of Limburg

Maastricht 
APPEADTX 4: QUESTIOMNAIRE

1) What is your age?

..... years.

2) What is your current marital status?

o Single

- Living together

o Married

- Divorced

o Widower

3) Do you receive disability benefits?

a Yes

o No

If so, since when?

$19 . .$.

THE QUESTIONS 4, 5 AND 6 NEED ONLY TO BE ANSWERED IF YOU RECEIVE DISABILITY BENEFITS. IF YOU DO NOT RECEIVE DISABILITY BENEFITS, YOU MAY CONTINUE TO QUESTION NUMBER 7 .

4) For what percentage are you disabled at the moment?
- Less than 15\%
o 55/65:
o $15 / 25 \%$
o $65 / 80$ :
o $25 / 35$
o $80 / 100$ 8
o $35 / 45$
o I do not know
o 45/55:

5) By which cause or disease have you become disabled? 0

6) Do you think that working conditions have contributed to your disability for work?

o Yes

O No

o I do not know 
If yes, which working conditions?

MEXT SOME QUESTIONS ARE ASKED ABOUT YOUR EDUCATION.

7) Have you finished primary school?
0 Yes
o No

8) Have you ever failed a year in primary school?
0 Yes
o No

9) Have you, after primary school, taken and/or finished one or more of the following educations?

- Junior secondary techical school

$\begin{array}{cc}\text { Followed } & \text { Finished (diploma) } \\ 0 & 0 \\ 0 & 0\end{array}$

- Senior secondary technical school 0

- School for lower general secondary

- Pre-university education

0

- Higher vocational education

0

- university

0

0

- other schools or educations:

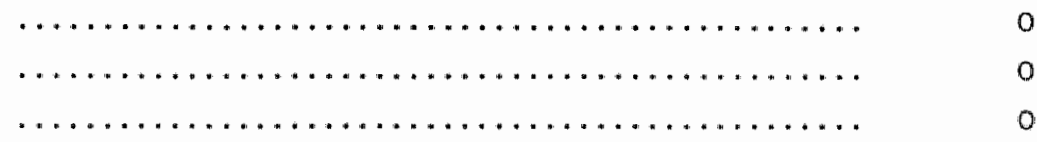

NEXT SOME QUESTIONS ARE ASKED ABOUT YOUR OCCUPATION.

10) Have you ever practiced the following occupations?

If yes, how many years?

- Brick layer

- Carpenter

- Tiler

$\begin{array}{ccc}\text { Yes } & \text { No } & \text { Number of years } \\ 0 & 0 & \ldots \ldots \\ 0 & 0 & \ldots \ldots \\ 0 & 0 & \ldots \ldots \\ 0 & 0 & \ldots \ldots \\ 0 & 0 & \ldots \ldots\end{array}$


- Carpet layer

- Engineer

$0 \quad 0$

....

- Road marker

o $\quad 0$

- Ground worker

$0 \quad 0$

- Asphalt worker

0

- other trades:

$0 \quad 0$

11) Have you ever been unemployed?

o Yes

0 มั

If yes, when was your latest unemployment period?

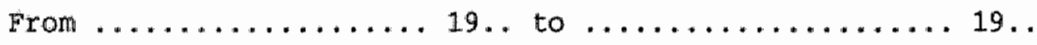

THE QUESTIONS 12 TO 24 NEED ONLY TO BE ANSWERED BY YOU IF YOU EVER WORKED AS A PAINTER. IF YOU HAVE NEVER WORKED AS PAINTER, YOU MAY CONTINUE TO QUESTION NUMBER 25.

12) In what year did you start working as a painter? 19. .

13) How many years have you worked as a painter?

..... years

14) Have you been unemployed and/or ill for more than one year during this period?

0 res

$0 \mathrm{NO}$

If yes, how many years?

..... . years

15) Yes No Number of years

- Have you worked in maintenance paintung?

$0 \quad 0$ If yes, how many years?

o 0

- Have you worked in newbuilding painting? If yes, how many years? 
- Have you worked in construction painting? 00 If yes, how many years?

- Did you do other painting work?

$0 \quad 0$

IN THE QUESTIONS 16 TO 24 A DISTINCTION IS MADE BETWEEN YOUR WORKING ACTIVITIES AND WORKING CONDITIONS "DURING THE PAST YEAR" AND "PREVIOUSLY". IF YOU ARE CURRENTLY NOT WORKING AS A PAINTER (E.G. BECAUSE YOU ARE DISABLED OR NOW PRACTICE ANOTHER OCCUPATION), YOU SHOULD CONSIDER "DURING THE PAST YEAR" AS YOUR LAST WORK YEAR AS PAINTER AND "PREVIOUSLY" AS THE PRECEDING YEARS.

16) How many hours a week have you worked during the past years? ..... hours a week
And previously?
o Just as many hours a week
o Fewer hours a week
o More hours a week

17) Last year" how many hours did you spend painting in your spare time at your own house or for others?

..... hours a week
And previousiy?
0 Just as many hours a week
o Fewer hours a week
o More hours a week

18) Last year, what percentage of your time did you spend on other activities than painting (e.g. preparation, wall papering, filling, sanding etc.)?
a $0-10 \%$
- $10-20 \%$
o $20-30 \%$
o More than $30 \%$
And previously?
o As much time
o Less time
o More time 
19) Last year, how often have you worked with the following paints?

$\begin{array}{cccc}\text { Never or } & \text { one day } & 2 \text { or } 3 & 4 \text { or more } \\ \text { almost never } & \text { a week } & \text { days a week } & \text { days a week } \\ 0 & 0 & 0 & 0 \\ 0 & 0 & 0 & 0 \\ 0 & 0 & 0 & 0 \\ 0 & 0 & 0 & 0 \\ 0 & 0 & 0 & 0\end{array}$

And previousiy?

$\begin{array}{llll}\text { Never or } & \text { One day } & 2 \text { or } 3 & 4 \text { or more } \\ \text { almost never } & \text { a week } & \text { days a week days a week }\end{array}$

- Latex o 0

0

- Alkyd o 0

0

0

- Epoxy

0

0

0

o

- athers.

$\ldots \ldots \ldots \ldots \ldots$

0

o 0

o

0

o

0

20) Last year, with what equipment did you paint?

$\begin{array}{llll}\text { Never or } & \text { One day } & 2 \text { or } 3 & 4 \text { or more } \\ \text { almost never } & \text { a week } & \text { days a week } & \text { days a week }\end{array}$

Paint brush

0

0

0

Paint roller/sweeper

0

0

0

Paint spray

0

0

0

0

And previousiy?

$\begin{array}{llll}\text { Never or } & \text { one day } & 2 \text { or } 3 & 4 \text { or more } \\ \text { almost never } & \text { a week } & \text { days a week } & \text { days a week }\end{array}$

Paint brugh 0

0

0

0

Paint roller/sweeper

0

0

0

0

paint spray

0

0

0

o

21) Last year, which paint trademark did you use mostly? 
22) Last year, how often did you perform the following activities?

$\begin{array}{lcccc} & \begin{array}{l}\text { Never or } \\ \text { almost never }\end{array} & \begin{array}{c}\text { One day } \\ \text { a week }\end{array} & \begin{array}{c}2 \text { or } 3 \\ \text { days a week ays week }\end{array} & \begin{array}{c}\text { or more } \\ \text { - Scouring off old }\end{array} \\ \begin{array}{l}\text { paint coats } \\ \text { - Burning off old }\end{array} & 0 & 0 & 0 & 0 \\ \begin{array}{l}\text { paint coats } \\ \text { - Stripping old paint } \\ \text { coats }\end{array} & 0 & 0 & 0 & 0\end{array}$

And previously?

$\begin{array}{llll}\text { Never or } & \text { One day } & 2 \text { or } 3 & 4 \text { or more } \\ \text { almost never } & \text { a week } & \text { days a }\end{array}$

- Scouring off old paint coats

0 a week days a week days a week

- Burning off old paint coats

o

0

0

- stripping old paint coats

0

0

0

0

0

0

0

23) Last year, did you use a respirator?

o Never or almost never

- One day a week

o Two or three days a week

o Four or more days a week

And previously?

o Never or almost never

o one day a week

o Two or three days a week

o Four or more days a week

24) Which description corresponds best to your working conditions during the past year?

- Generally inside, small rooms, well ventilated.

- Generally inside, small rooms, poorly ventilated

o Generally inside, large rooms, well ventilated

o Generally inside, large rooms, poorly ventilated

o Generally outside

o otherwise 


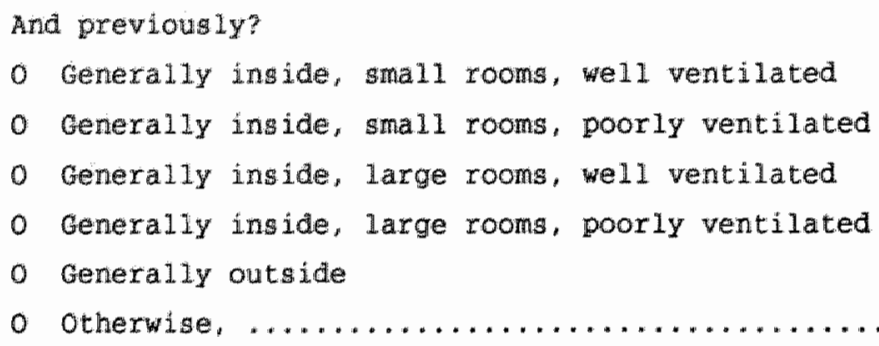

IN THE QUESTIONS 25 AND 26 A DISTINCTION IS MADE BETWEEN YOUR WORK ACTIVITIES AND WORKING CONDITIONS "DURING THE PAST YEAR" AND "PREVIOUSLY". IF YOU ARE CURRENTLY NOT WORKING (E.G. BECAUSE YOU ARE UNEMPLOYED OR DISABLED) YOU SHOULD CONSIDER "DURING THE PAST YEAR" AS YOUR LAST WORK YEAR AND "PREVIOUSLY" AS THE PRECEDING YEARS.

25) Last year, did you do your work in one room with:

$\begin{array}{cccc}\text { Never or } & \text { one day } & 2 \text { or } 3 & 4 \text { or more } \\ \text { almost never } & \text { a week } & \text { days a week } & \text { days a week } \\ 0 & 0 & 0 & 0 \\ 0 & 0 & 0 & 0\end{array}$

And previously?

- Painters
- Carpet layers

$\begin{array}{cccc}\begin{array}{c}\text { Never or } \\ \text { almost never }\end{array} & \text { a week } & \begin{array}{c}2 \text { or } 3 \\ \text { days a week }\end{array} & \begin{array}{c}4 \text { or more } \\ \text { days a week }\end{array} \\ 0 & 0 & 0 & 0 \\ 0 & 0 & 0 & 0\end{array}$

26) Last year, did you use during your work:

- Paint removers

$\begin{array}{llll}\text { Never or } & \text { One day } & 2 \text { or } 3 & 4 \text { or more } \\ \text { almost never a week } & \text { days a week } & \text { days a week }\end{array}$

- Solvents (such as White spririts)

0

0

0

0

- Glues

0

0

0

0

- Degreasing agents

0

0

0

0

o

0

0 
And previous ly?

\begin{tabular}{|c|c|c|c|c|c|}
\hline $\begin{array}{l}\text { Never or } \\
\text { almost never }\end{array}$ & $\begin{array}{l}\text { One day } \\
\text { a week }\end{array}$ & $\begin{array}{l}2 \text { or } \\
\text { days }\end{array}$ & 3 & $\begin{array}{l}4 \text { or } \\
\text { days }\end{array}$ & $\begin{array}{l}\text { more } \\
\text { a week }\end{array}$ \\
\hline 0 & 0 & & 0 & & 0 \\
\hline 0 & 0 & & 0 & & 0 \\
\hline 0 & 0 & & 0 & & 0 \\
\hline 0 & 0 & & 0 & & 0 \\
\hline
\end{tabular}

NEXT QUESTION REFERS TO THE PAST (WORK) YEAR. IF YOU ARE CURRENTLY NOT WORKING, YOU SHOULD CONSIDER THE PAST YEAR AS YOUR LAST WORK YEAR. YOU CAN CHOOSE FROM FOUR ANSWERS:

- NEVER

- SOMETIMES (ONCE A MONTH)

- REGULAR (ONCE A WEEK)

- OFTEN (MORE THAN ONCE A WEEK)

27) During or right after my work I suffer from:

$\begin{array}{cccc}\text { Never } & \text { Sometimes } & \text { Regular } & \text { Often } \\ 0 & 0 & 0 & 0 \\ 0 & 0 & 0 & 0 \\ 0 & 0 & 0 & 0 \\ 0 & 0 & 0 & 0 \\ 0 & 0 & 0 & 0 \\ 0 & 0 & 0 & 0 \\ 0 & 0 & 0 & 0 \\ 0 & 0 & 0 & 0 \\ 0 & 0 & 0 & 0 \\ 0 & 0 & 0 & 0 \\ 0 & 0 & 0 & 0 \\ 0 & 0 & 0 & 0 \\ 0 & 0 & 0 & 0\end{array}$

28) If you marked once or more times "often" at the preceding question, did you notice a decrease of your complaint(s) during the weekends or holidays?
- Yes
o No 
SUBSEQUEYTLY A NUMBER OF QUESTIONS ARE ASKED ABOUT YOUR HEALTH CONDITIONS.

29) Have you ever been treated by a physician for one or more of the diseases or disorders mentioned below? Please, indicate the year of first treatment and whether or not you are still treated for that disease/disorder.

- Diabetes

- High blood pressure

- Heart alisease (e.g. heart attack)

- Vascular disease (e.g " thrombosis)

- overweight

Yes to Year still treated
Yes No

- Sleeplessness

$0 \quad 0 \quad \cdots \cdots$

- overstranned.

- Epilepsy

- Skin disease

- Bronchitis or asthma

$\begin{array}{llllll}0 & 0 & \ldots & 0 & 0\end{array}$

- Rheumatism

$\begin{array}{llllll}0 & 0 & \ldots & 0 & 0\end{array}$

- Muscle or joint complaints

- Neck or back complaints

- stomach

- Gal1-bladider

- Kidneys or bladder

a $\quad 0 \quad \ldots .000$

- Accident

0

$\begin{array}{lllll}0 & 0 & \ldots & 0 & 0\end{array}$

$\begin{array}{lllll}0 & 0 & \ldots & 0 & 0\end{array}$

$\begin{array}{lllll}0 & 0 & \ldots & 0 & 0\end{array}$

$\begin{array}{lllll}0 & 0 & \ldots & \ldots & 0\end{array}$

- Concussion

- "hyroid gland disease

- Other disease/complaint

$\begin{array}{lllll}0 & 0 & \ldots & 0 & 0\end{array}$

$\begin{array}{llllll}0 & 0 & \ldots & \ldots & 0 & 0\end{array}$

$\begin{array}{lllll}0 & 0 & \ldots & 0 & 0\end{array}$

o $\quad 0 \quad \ldots . .000$

If yes, which disease?

$\begin{array}{lllll}0 & 0 & \ldots & 0 & 0\end{array}$

$\begin{array}{lllll}0 & 0 & \ldots & 0 & 0\end{array}$

$\begin{array}{lllll}0 & 0 & \ldots & 0 & 0\end{array}$

$\begin{array}{lllll}0 & 0 & \ldots & \ldots & 0\end{array}$

o $\quad 0 \quad \ldots .000$

o $\quad 0 \quad \ldots .0000$

$0 \quad 0$

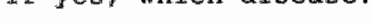

30) Suffer or suffered any of your next of kin (parents, brothers, sisters) from dementia?
o Yes
o No

31) Have you ever been operated?
o Yes
o Mo 
If yes, what for and when?

1.

2 .

3.

32) Have you ever been unconscious?

0 Yes

o No

If yes, cause

duration:

when

33) Do you use medication?

o Yes

o No

If yes, which medication?

NEXT QUESTION DEALS WITH A NUMBER OF SYMPTOMS WHICH YOU MAY OR MAY NOT HAVE EXPERIENCED YOURSELF. YOU CAN CHOOSE FROM FOUR ANSWERS:

- NEVER

- SOMETIMES (ONE A MONTH)

- REGULAR (ONCE A WEEK)

- OFTEN (MORE THAN ONCE A WEEK)

PLEASE CONSIDER YOUR HEALTH CONDITIONS AS EXPERTENCED DURING THE LAST MONTH.

34)

- Do you get up tired in the morning?

- Do you feel excess tiredness after the workday?

- Are you forgetful?

- Do you often forget what you intend to do?

- Do you have to go back and check whether you turned of the gas, locked the door etc.?
Never Sometimes Regular often

0

0

0

0

0

0

0

0

a

o

0

o

0

0

0

0

0

0

0 
- Do you make notes of things you rous t remember?

$$
0
$$

- Do your thoughts stray when you try to concentrate?

$$
\text { o }
$$$$
\text { o }
$$

- Do you fall ableep when watching televis jon?

- Are you lost in your own thoughts?

- Do you notice that you are "daydreaming"?

- Do you have difficulties understanding what you read in newspapers or books?

$$
\text { o }
$$$$
\text { o }
$$$$
0
$$

- Do you have difficulties falling as leep?

- Do you wake up at night?

- Do you have nightmares?

- Does your mood change without reason?

- Are you depressed?

- Are you irritated?

- Are you restless?

- Are you afraid?

- Are you listless?

- Are you drowsy?

- Do yo become tired among other people?

$$
\begin{aligned}
& 0 \\
& 0 \\
& 0 \\
& 0
\end{aligned}
$$$$
0 \quad 0 \quad 0
$$$$
0
$$

0

0

0

0

0

- Do you have difficulties in starting a conversation with others?

- Da you suffer from beadaches?

- Do you sufler from diziness?

- Do you sweat without exerting yourself?

- Do you have palpitations without exerting yourself?

- Do your hands tremble?

- Do you feel as though you have something in your throat?

0

0

0

0

- Do you feel an oppression on your chest?

- Do you suffer from a diminished sexual interest?

- Do your legs feel numb or tingle? 
35) What is your length? ............. cm

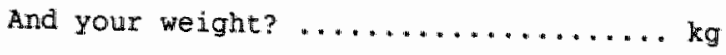

36) Do you drink alcoholics (bear, gin, wine etc.)?

o Yes

o No

If yes, how many drinks a week?

- Less than 10

- 10 to 25

- 25 to 50

o More than 50

37 Do you smoke or have you smoked?

- Yes

o No

If yes, how many cigarettes a day?

o Less than 10

o 10 to 20

o More than 20

How long do or did you smoke?

- Sharter than 1 year

- 1 to 5 years

05 to 10 years

- 10 to 20 years

0 Longer than 20 years

Do you still smoke?

o Yes

o No

38) Did you have serious private problems during the last year?

o Yes

0 No

39) Which hobbies do you have? 
FIMALLT, A NUMBER OF QUESTIONS ARE ASKED ABOUT YOUR LATEST OCCUPATION?

40) Did you carry out your activities under pressure of time (piece work systen)? o Yes

o No

11) Did you get on well with your collaegues?

0 Yes

o No

42) Where there serlous conflicts on your work?

o Yes

o No

43) Did you enjoy'going to your work?

o yes

o No

44) Do you want to inform us of matters that have not been raised in this questionnaire?

o Yes

o No

If yes, what matters?

YOU HAVE COME AT THE END OF THIS QUESTIONNAIRE. PLEASE CHECK WHETHER YOU HAVE ANSWERED COMPLETELY ALL RELEVANT QUESTIONS.

FINALLY, WE WISH TO TRANK YOU AGAIN FOR YOUR PARTICIPATION IN THIS INVESTIGATION! 